\title{
Multivariate Analysis, Mass Balance Techniques, and Statistical Tests as Tools in Igneous Petrology: Application to the Sierra de las Cruces Volcanic Range (Mexican Volcanic Belt)
}

\author{
Fernando Velasco-Tapia \\ Universidad Autónoma de Nuevo León, Facultad de Ciencias de la Tierra, Ex-Hacienda de Guadalupe, \\ Carretera Linares-Cerro Prieto km 8, 67700 Linares, NL, Mexico
}

Correspondence should be addressed to Fernando Velasco-Tapia; velasco@fct.uanl.mx

Received 26 August 2013; Accepted 25 November 2013; Published 5 March 2014

Academic Editors: J. Glodny, N. Hirao, and G.-L. Yuan

Copyright (C) 2014 Fernando Velasco-Tapia. This is an open access article distributed under the Creative Commons Attribution License, which permits unrestricted use, distribution, and reproduction in any medium, provided the original work is properly cited.

\begin{abstract}
Magmatic processes have usually been identified and evaluated using qualitative or semiquantitative geochemical or isotopic tools based on a restricted number of variables. However, a more complete and quantitative view could be reached applying multivariate analysis, mass balance techniques, and statistical tests. As an example, in this work a statistical and quantitative scheme is applied to analyze the geochemical features for the Sierra de las Cruces (SC) volcanic range (Mexican Volcanic Belt). In this locality, the volcanic activity (3.7 to $0.5 \mathrm{Ma}$ ) was dominantly dacitic, but the presence of spheroidal andesitic enclaves and/or diverse disequilibrium features in majority of lavas confirms the operation of magma mixing/mingling. New discriminant-function-based multidimensional diagrams were used to discriminate tectonic setting. Statistical tests of discordancy and significance were applied to evaluate the influence of the subducting Cocos plate, which seems to be rather negligible for the SC magmas in relation to several major and trace elements. A cluster analysis following Ward's linkage rule was carried out to classify the SC volcanic rocks geochemical groups. Finally, two mass-balance schemes were applied for the quantitative evaluation of the proportion of the endmember components (dacitic and andesitic magmas) in the comingled lavas (binary mixtures).
\end{abstract}

\section{Introduction}

Several conventional mineralogical, geochemical, and isotopic tools, using a limited number of variables (e.g., bivariate, trilinear, multielement, and semilogarithmic diagrams), have usually been applied to establish a qualitative or semiquantitative view of igneous petrological mechanisms [1,2]. Particularly, the interaction between, at least, two magmas is one of the most important mechanisms of compositional diversification of igneous rocks [3]. According to genetic relations between the original or resident magma and the later invasive magma, two scenarios could be expected $[4,5]$ : (a) successive pulses of magma derived from a common source intersect in time and space or (b) unrelated chemical distinct magmas, derived from different sources are involved in the interaction episode. Additionally, different styles of the interaction phenomena are related to the variation of physicochemical parameters (e.g., $[3,6,7]$ ): (a) the initial contrast in chemical composition, temperature, and viscosity, (b) the relative mass fractions and the physical state of interacting magmas, and (c) the static versus dynamic environment of interaction. These processes have been broadly divided into (a) magma mingling, a route characterized by a physical juxtaposition and intermingling of contrasting compositions, with little or no chemical homogenization, and (b) magma mixing, where the physical and chemical conditions promote the homogenization of contrasting geochemical and isotopic features, resulting in a single magma of intermediate composition. If a magma mixing/mingling model is proposed, it must include statements specifying (a) the initial compositions of the resident and invasive magmas, 
(b) the modal mineralogy of the magmas prior to mixing, and

(c) the proportions of resident and invasive magmas [4]. A quantitative assessment could be obtained from multivariate statistical techniques [8]. Although these methods have been used with classification purposes in igneous rocks [9], their use to understand magma mixing/mingling processes is still limited [7, 10-13].

On the other hand, magma mixing/mingling processes have been observed in diverse tectonic settings. Consequently, a complete vision of these magmatic localities, commonly dominated by rocks with $\left[\mathrm{SiO}_{2}\right]_{\mathrm{adj}}>52 \%$ (the subscript adj refers to the adjusted silica from the SINCLAS computer program $[14,15]$ ), would be facilitated from the tectonic regime. However, a restricted number of conventional diagrams are available for tectonic discrimination of intermediate $\left(\left[\mathrm{SiO}_{2}\right]_{\mathrm{adj}}=52-63 \% ;[16,17]\right)$ and acid $\left(\left[\mathrm{SiO}_{2}\right]_{\mathrm{adj}}>\right.$ $63 \%$; $[1,18])$ magmas. Additionally, these schemes have been critiqued as a result of a statistically wrong treatment of compositional data, eye-drawn subjective boundaries for different tectonic fields, and lack of representation of the entire statistical population $[19,20]$. S. P. Verma and S. K. Verma [21] and Verma et al. [22], to solve the limitations of the tectonic discrimination conventional schemes, have proposed a set of new discriminant-function-based multidimensional diagrams for intermediate and acid magmas from four tectonic settings (island arc, continental arc, continental rift + ocean island, and collision).

In this context, Velasco-Tapia et al. [23] recently reported, based on mineralogical, geochemical, and $\mathrm{Sr}-\mathrm{Nd}$ isotopic conventional tools, that the formation of the Sierra de las Cruces (SC) volcanic range $(3.7$ to $0.5 \mathrm{Ma}$; central part of the Mexican Volcanic Belt (MVB); Figure 1) was mainly controlled by a magma mixing/mingling process. In this work, as an example, multivariate techniques (linear discriminant, cluster, and principal component analysis), discordancy and significance statistical tests, and mass-balance approaches were applied to establish the tectonic setting and to obtain a quantitative picture of the magmatic evolution of this volcanic range.

\section{Geological Synthesis}

The SC volcanic range is an elongated volcanic range, extending in a NNW-SSE direction for $\sim 65 \mathrm{~km}$, with a width varying between $47 \mathrm{~km}$ to the north and $27 \mathrm{~km}$ to the south (Figure 2; [23-25]). According to K-Ar geochronological data [26], the main mass of SC volcanic range was erupted between 3.7 and 1.8 Ma. After that, in the middle Pleistocene ( $\sim 0.5 \mathrm{Ma})$, another volcanic event produced andesitic domes, being labeled as Ajusco period. It has been considered as the transition to the Sierra de Chichinautzin monogenetic eruptive period (<40 ka; [27-29]).

On the basis of morphostructural and radiometric age criteria, the SC volcanic range has been divided into four sectors bounded by E-W faults [23, 24]: (a) northern sector (SCN; 2.9-3.7 Ma), (b) central sector (SCC; 1.9-2.9 Ma), (c) southern sector (SCS; 0.7-1.9 Ma), and (d) las CrucesChichinautzin transition sector (SCT; $\sim 0.5 \mathrm{Ma}$ ). The northern and central sectors are characterized by morphostructures controlled by N-S and NE-SW fault systems. In contrast, $\mathrm{E}-\mathrm{W}$ faults have ruled the morpholineaments and drainage patterns observed in the southern sector and the transition region.

The SC stratovolcanoes underwent alternated episodes, associated with faulting, of effusive and explosive activity. Porphyritic andesite to dacite lava flows (Lava Dacítica Apilulco; thickness $<4 \mathrm{~m}$ ) with planar fracturing subparallel to the surface constitute the main effusive products. They generally show a mineralogical assemblage of plagioclase + amphibole + orthopyroxene \pm clinopyroxene \pm quartz + Fe-Ti oxides. Spherical to ellipsoidal magmatic enclaves occasionally occur in these lava flows. They are randomly distributed along the volcanic range, although the number and size apparently increase towards the north. Majority of the magmatic enclaves display a few millimeters to 4 centimeters in diameter, although in some northern outcrops they reach $\sim 20 \mathrm{~cm}$ in diameter. The explosive products consist in pyroclastic deposits (Brecha Piroclástica Cantimplora; thickness $=1-4 \mathrm{~m})$, conformed by dacitic blocks $(20-30 \mathrm{~cm})$, pumice clasts $(<15 \mathrm{~cm})$, and ash, that occurred intercalated with the lava flows.

Velasco-Tapia et al. [23] developed an extensive study in the SC volcanic range that includes detailed petrography, mineral chemistry, whole-rock geochemistry, and $\mathrm{Sr}-\mathrm{Nd}$ isotopic data. These authors reported that several disequilibrium features confirm the significant role of the magma mingling/mixing processes between andesitic and dacitic magmas with concomitant fractional crystallization. The SC magmas were probably generated at different levels of the continental crust by partial melting. The magma mixing/mingling evidence includes (a) normal and sieved plagioclases in the same sample, rounded and embayed crystals, and armored rims over the dissolved crystal surfaces; (b) subrounded, vesicular magmatic enclaves, ranging from a few millimeters to $\sim 20$ centimeters in size (mineralogical assemblage: plagioclase + orthopyroxene + amphibole + quartz \pm olivine \pm Fe-Ti-oxides); (c) crystals with reaction rims or heterogeneous plagioclase compositions (inverse and oscillatory zoning or normally and inversely zoned crystals) in the same sample; and (d) elemental geochemical variations and trace element ratio more akin to magma mixing and to some extent diffusion process. Andesitic enclaves have been interpreted as portions of the intermediate magma that did not mix completely (mingling) with the felsic host lavas.

\section{Methods}

In the present work ten samples, collected along the SC volcanic range (Figure 2; SCN: SC46, SC52, and SC52a; SCS: SC51, SC53, and SC58; SCT: SC03, SC16, SC22, and SC60), were studied to obtain new petrographic and geochemical data. Modal compositions were determined by point counting on thin sections using a Prior Scientific petrographic 


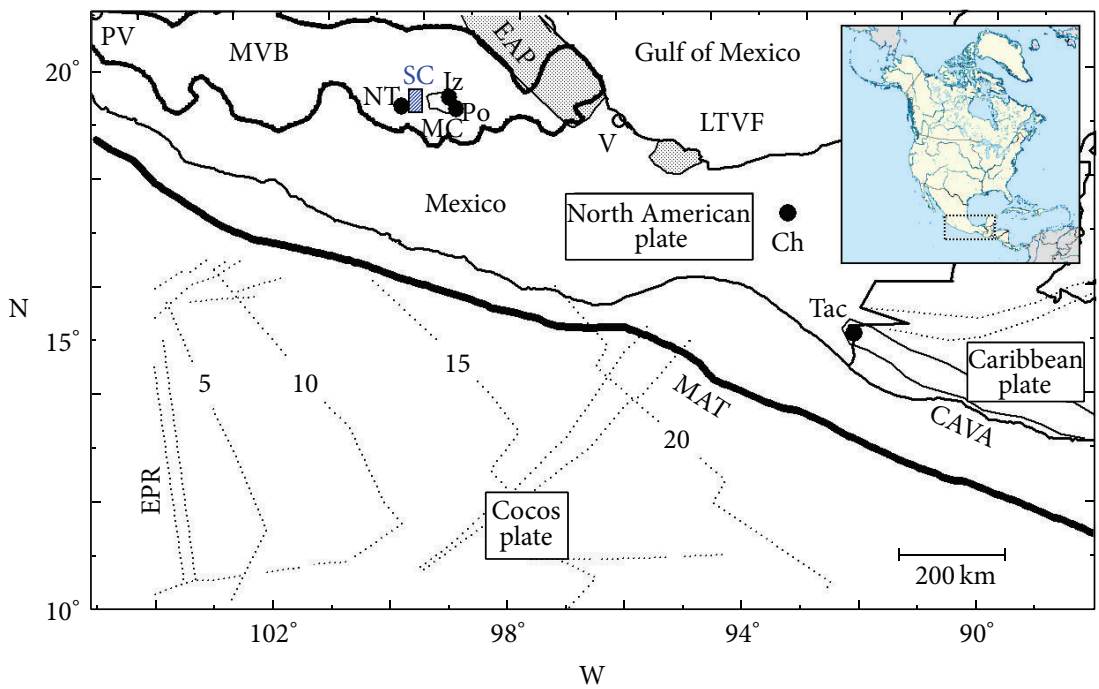

Figure 1: Location of the Sierra de las Cruces (SC) volcanic range (blue shaded box) at the central part of the Mexican Volcanic Belt (MVB) (modified from [30]). For guidance, the black box at the upper right side shows the location of this zone in North America. The figure also includes the approximate location of the Eastern Alkaline Province (EAP), Los Tuxtlas Volcanic Field (LTVF), Central American Volcanic Arc (CAVA), and the Chichón ( $\mathrm{Ch})$ and Tacaná (T) volcanoes. Other tectonic features are the Middle America Trench (MAT, shown by a thick black curve) and the East Pacific Rise (EPR, shown by a pair of dashed-dotted black lines). The traces marked by numbers 5 to 20 on the oceanic Cocos plate give the approximate age of the oceanic plate in Ma. Locations of Iztaccíhuatl (Iz), Popocatépetl (Po), and Nevado de Toluca (NT) are also shown. Cities are PV: Puerto Vallarta, MC: Mexico City, and V: Veracruz.

microscope. Approximately 500 points per sample were counted in order to obtain a representative mode (Table 1).

Major and trace element composition of these SC volcanic rocks (Tables 2 and 3) were determined in ActLabs laboratories (Ancaster, Canada), using the "4LithoRes" methodology (for details consult webpage http://www.actlabsint.com/). Major elements were analyzed by inductively coupled plasma-optical emission spectrometry (ICP-OES) with an analytical precision $<2 \%$ and accuracy typically better than $5 \%$ at $95 \%$ confidence level, based on analysis of diverse geochemical reference materials (GRM). Trace element concentrations were determined by inductively coupled plasmamass spectrometry (ICP-MS) with an analytical precision 3$6 \%$ (occasionally reaching 9-10\%) and an accuracy typically better than $7-12 \%$ for most elements at the $95 \%$ confidence level, based on analysis of diverse GRM.

\section{Sierra de las Cruces Database and Evaluation Scheme}

4.1. Mineralogical and Geochemical Database. A more complete SC database of the mineralogical modes and the wholerock geochemical composition was established from the new as well as the published information reported by VelascoTapia et al. [23]. CIPW norms for samples were calculated on a $100 \%$ anhydrous adjusted basis of major element composition, with $\left[\mathrm{Fe}_{2} \mathrm{O}_{3}\right]_{\text {adj }} /[\mathrm{FeO}]_{\text {adj }}$ ratios adjusted depending on the rock type [34]. Rock classification was based on the total alkali-silica (TAS) scheme $[35,36]$. All computations (anhydrous and iron-oxidation ratio adjustments, norm compositions, and rock classifications) were automatically done using the SINCLAS software $[14,15]$.

4.2. Linear Discrimination Analysis. The tectonic affinity of the SC volcanic rocks was established applying new discriminant-function-based multidimensional diagrams for intermediate $\left(\left[\mathrm{SiO}_{2}\right]_{\mathrm{adj}}=52-63 \%\right)$ and acid $\left(\left[\mathrm{SiO}_{2}\right]_{\mathrm{adj}}>\right.$ $63 \%$ ) rocks using the linear discriminant analysis (LDA) of natural logarithm ratios of major elements, immobile major and trace elements and immobile trace elements. These diagrams $[21,22]$ were proposed to discriminate island arc (IA), continental arc (CA), within-plate (continental rift, $\mathrm{CR}$, and ocean island, OI, together), and collisional (Col) settings. Based on the earlier work of Verma and Agrawal [39] and the modifications outlined by Verma [40], these diagrams also provide probability estimates for individual samples, which were used in the present work.

Firstly, the nature of intermediate or acid magma for each sample was confirmed from the SINCLAS software [14, 15], under the Middlemost [34] option for Fe-oxidation adjustment. After that, a series of natural logarithms of element ratios were estimated for all samples. This transformation provided a Gaussian character to the distribution data, a basic condition of the LDA. After that, the ln-ratio data were used to estimate two discriminant functions (DF1 and DF2), obtained from the LDA (canonical analysis), and the individual probability for each sample to a tectonic regime. This statistical exercise was first performed to discriminate between IA + CA, CR + IO, and Col settings and four times for 


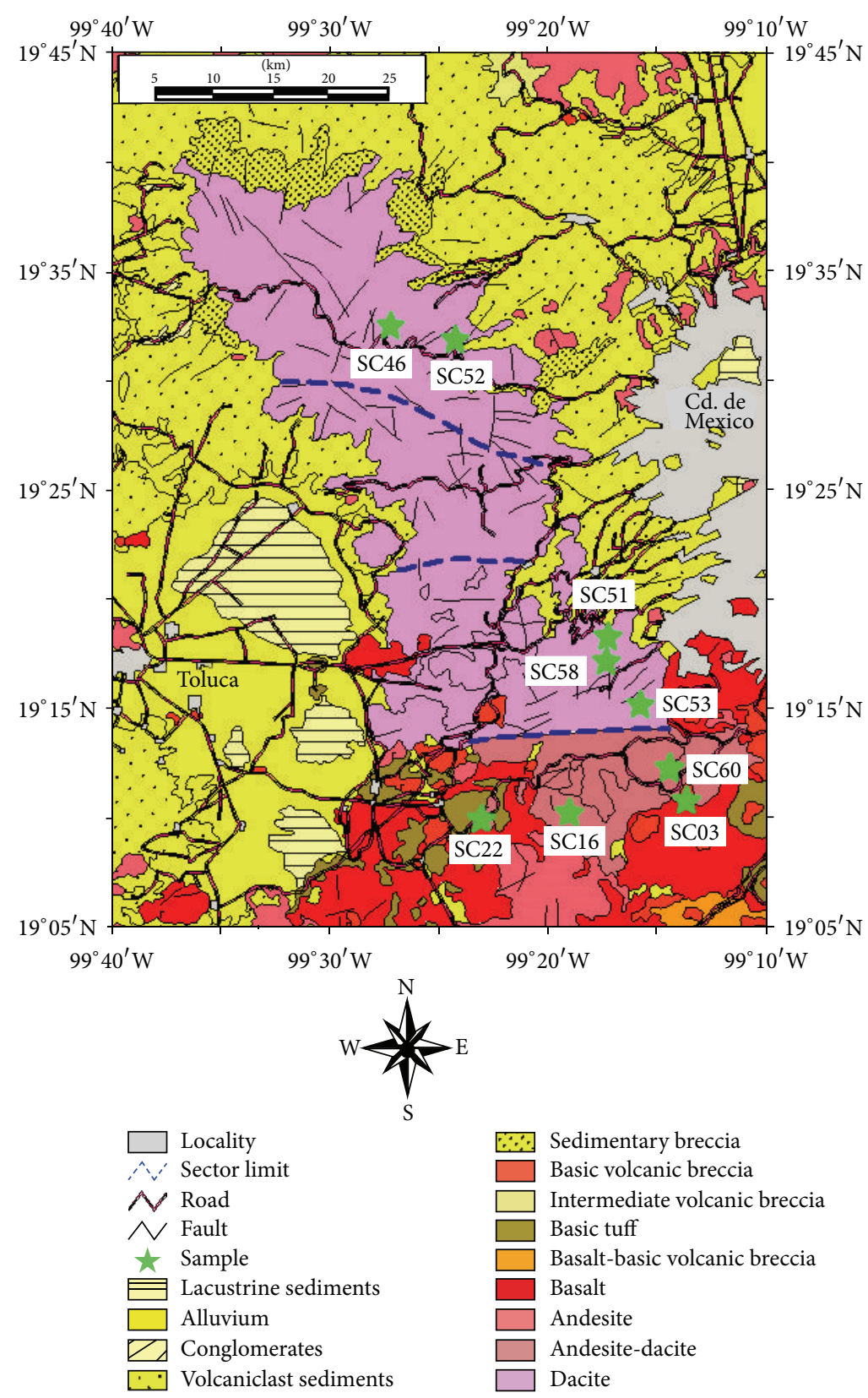

FIGURE 2: Geologic sketch of the Sierra de las Cruces volcanic range, showing lithology, faults, roads, and distribution of the samples (green stars) collected along the volcanic range in this work (modified from [23]). Study area division in four sectors from $\mathrm{N}$ to $\mathrm{S}$ based on K-Ar radiometric data [26]: (a) SCN-northern sector (2.9-3.7 Ma), (b) SCC-central sector (1.9-2.9 Ma), (c) SCS-southern sector (0.7-1.9 Ma), and (d) SCT-transition sector that include the Ajusco volcano $(<0.7 \mathrm{Ma})$.

all possible combinations of three groups at a time out of four groups (IA, CA, CR + OI, and Col). Details of the statistical methodology and LDA equations have been reported in $[21,22]$. It is important to note that the discrimination analysis was carried out considering the four SC sectors. All LDA equations were incorporated in a STATISTICA for Windows (Statsoft, Inc., Tulsa, OK, USA) spreadsheet and discrimination diagrams were constructed from these results.

4.3. Discordancy and Significance Tests. In order to better understand the contribution of the subducted Cocos plate to the SC magmas, the methodology put forth and practiced by Verma [38] was applied. This approach basically consists of comparing the magmas closer to the Middle America Trench (MAT) to those farther from it; that is, the SC sectors were statistically compared as two groups. The null hypothesis $\left(\mathrm{H}_{0}\right.$ : the two groups did not differ significantly at strict $99 \%$ confidence level) and the alternate hypothesis $\left(\mathrm{H}_{\mathrm{A}}\right.$ : the two groups differ significantly at $99 \%$ confidence level) were tested by Fisher $F$ and Student's $t$-tests (UDASYS software, [37]). Because the significance tests require that the data be normally distributed, single-outlier type discordancy 


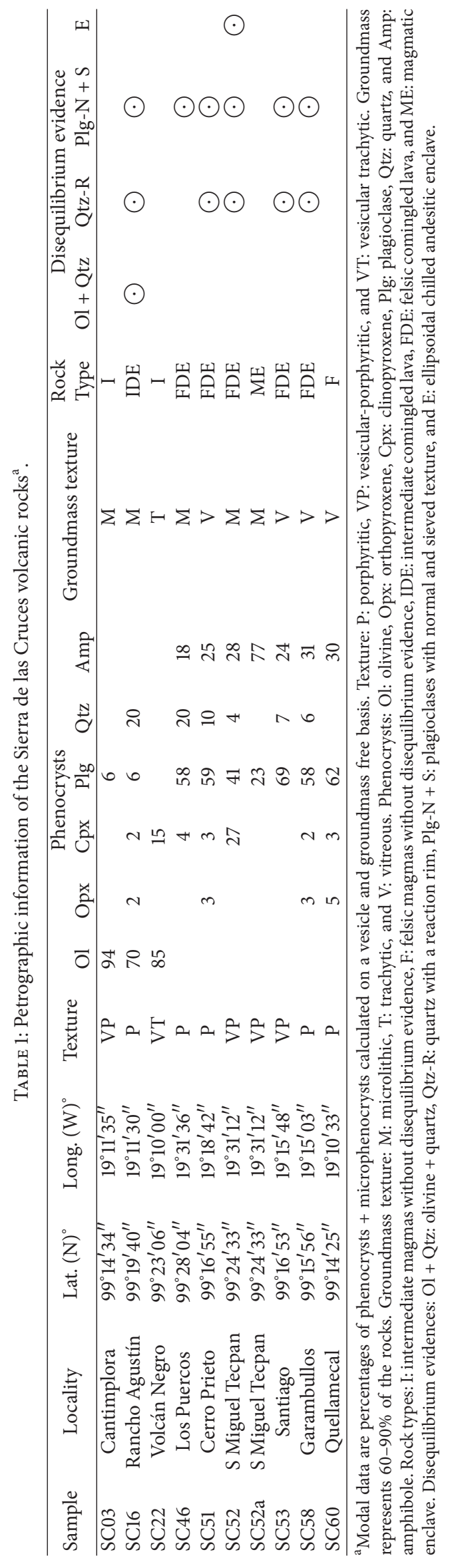


tests were applied at strict 99\% confidence level, for which DODESSYS software of Verma and Díaz-González [41] was used.

4.4. Cluster Analysis. The principal aim of this statistical tool is to partition observations into a number of groups. It is expected that the observations within a cluster are as similar as possible, whereas the differences between the clusters are as large as possible. In magma mingling scenario, this technique would be helpful for the SC sample distribution in resident, invasive, and comingled magmas.

In this work, cluster analysis was performed using the natural logarithm of major elements $\left(\left[\mathrm{SiO}_{2}\right]_{\mathrm{adj}}-\left[\mathrm{P}_{2} \mathrm{O}_{5}\right]_{\mathrm{adj}}\right)$ and representative trace (transition: $\mathrm{Co}, \mathrm{V}$; rare earth: La, $\mathrm{Eu}, \mathrm{Yb}$; lithophile: $\mathrm{Ba}, \mathrm{Sr}, \mathrm{U}$; high-field strength: Hf, Y, Zr) elements to $\left[\mathrm{Al}_{2} \mathrm{O}_{3}\right]_{\text {adj }}$ ratios by using a hierarchical cluster method (HCM; [42]). Geochemical ratios were previously standardized (z-scores) by means of

$$
K_{i j}=\frac{X_{i j}-X}{S_{i c}}
$$

where $K_{i j}$ is the standardized value of $X_{i j}$, the $i$ th variable for the $j$ th sample, $X$ is the mean value of the $i$ th variable, and $S_{i c}$ is its standard deviation. Additionally, the normality of each standardized variable was confirmed by the Shapiro-Wilks test. Cluster analysis applied a Ward's linkage rule, which linked iteratively nearby points through a similarity matrix and performed an ANOVA test to evaluate the distance between clusters [43]. The adopted procedure gives equal weight to each geochemical ratio. The measure of similarity was simply the distance as defined in Euclidean space. The distance between two samples $(j, k)$ is given by

$$
d_{j k}=\left[\sum_{i=1}^{N}\left(K_{i j}-K_{i k}\right)^{2}\right]^{1 / 2}
$$

where $K_{i j}$ denotes the $K$ th variable measured on object $i$ in sample $j$ and $K_{j k}$ is the $K$ th variable measured on object $i$ in sample $k$. The results of the cluster analysis were graphically displayed in three dendrograms with units in Euclidean values, corresponding to northern, central, and southerntransition SC sectors.

The weight of geochemical log-ratios in the cluster approach was determined from the results obtained in a principal component analysis (PCA). It has been defined as an orthogonal linear transformation for reducing the dimensionality of a dataset by expressing it as the combination of a small number of linearly independent factors or "principal components." Each factor will be a function of the individual contributions of the original variables [44]. The greatest variance for the transformed data was linked to the first principal component, whereas the second variance magnitude was related to the second principal component, and so on. The PCA considers a data matrix, $\mathbb{X}$ ( $n$ rows $\times p$ columns; rows represent different samples, and columns give a particular chemical component; each component which has been standardized yielded a zero empirical mean).
The transformation is stated by a set of $p$-dimensional vectors $\mathbb{W}_{(k)}=\left(w_{1}, \ldots, w_{p}\right)_{(k)}$ that map each row vector $\mathbb{X}_{(i)}$ of $\mathbb{X}$ to a new vector of principal component factors $\mathbb{t}_{(i)}=\left(t_{1}, \ldots, t_{p}\right)_{(i)}$ given by

$$
\mathbb{t}_{k(i)}=\mathbb{x}_{(i)} \cdot \mathbb{W}_{(k)} .
$$

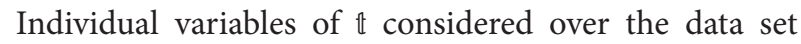
successively inherit the maximum possible variance from $\mathbb{x}$, with each loading w constrained to be a unit vector. The first principal component $\mathbb{W}_{(1)}$ satisfied

$$
\mathbb{W}_{(1)}=\arg \max \left\{\sum_{i}\left(t_{1}\right)_{(i)}^{2}\right\}=\arg \max \sum_{i}\left(\mathbb{x}_{(i)} \cdot \mathbb{W}\right)^{2},
$$

where the quantity to be maximized is known as Rayleigh quotient. The $k$ th component was determined by subtracting the $k-1$ principal components from $\mathbb{X}$ :

$$
\widehat{\mathbb{X}}_{k-1}=\mathbb{X}-\sum_{s=1}^{k-1} \mathbb{X} \mathbb{W}_{(s)} \mathbb{W}_{(s)}^{\mathbb{T}} .
$$

The vector associated with this component and showing the maximum variance from this new matrix would be defined as

$$
\mathbb{W}_{(k)}=\arg \max \left\{\left\|\widehat{\mathbb{X}}_{k-1} \mathbb{W}\right\|^{2}\right\} .
$$

All calculations related to cluster analysis were carried out using the STATISTICA for Windows software.

4.5. Mass-Balance Evaluations. Nixon [31] applied a simple mass-balance scheme for the quantitative characterization of binary mixtures and end-member compositions in the Iztaccíhuatl volcano (central MVB). The author suggested that, despite the compositional heterogeneity, if a chemical component can be found whose concentration is invariant in time and known in the mix and in each of the endmembers, it is possible to treat quantitatively the magma mixing process.

Mixing proportions may be calculated considering the lever principle and the composition of the comingled magma subsequently described for all chemical components. The amount of a component in the mixed lava could be represented by

$$
Q_{A}^{i}=\frac{\left|C_{M}^{i}-C_{B}^{i}\right|}{\left|C_{A}^{i}-C_{B}^{i}\right|}
$$

where $Q_{A}^{i}+Q_{B}^{i}=1$, and $Q^{i}$ and $C^{i}$ represent the weight fraction and concentration, respectively, of element $i$ in subscripted end-members $A$ and $B$ and mixture $M$. The composition of an end-member could be estimated by

$$
C_{A}^{j}=\frac{\left|C_{M}^{j}-Q_{B}^{i} C_{B}^{j}\right|}{Q_{A}^{i}},
$$

where constituent $i \neq j$. In this work, this mass-balance approach (model A) was applied to SC lavas, being restricted 
to those sectors where the end-member compositions were available and to those components that exhibit a statistically significant linear coherence in $\left[\mathrm{SiO}_{2}\right]_{\mathrm{adj}}$-Harker diagrams. This test involved the evaluation, at $99 \%$ confidence level, of Pearson product-moment correlation coefficient $(r)$ and the sample size $(n)$. Details and required caution in the use of $r$ have been reported in Bevington and Robinson [45].

On the other hand, Zou [33] reported a mass-balance approach to explain the $y_{m}=(u / a)_{m}$ and $x_{m}=(v / b)_{m}$ geochemical ratios (where $a, b, u$, and $v$ represent major or trace elements) in SC comingled lavas as a product of a mixture of two components 1 and 2. The variation in the $y_{m}$ and $x_{m}$ geochemical ratios could be modeled by the hyperbolic equation (condition $a_{1} / a_{2} \neq b_{1} / b_{2}$ ):

$$
A x_{m}+B x_{m} y_{m}+C y_{m}+D=0 \text {. }
$$

In this model, the $A$ to $D$ coefficients have been defined as

$$
\begin{gathered}
A=a_{2} b_{1} y_{2}-a_{1} b_{2} y_{1}, \\
B=a_{1} b_{2}-a_{2} b_{1}, \\
C=a_{2} b_{1} x_{1}-a_{1} b_{2} x_{2}, \\
D=a_{1} b_{2} x_{2} y_{1}-a_{2} b_{1} x_{1} y_{2},
\end{gathered}
$$

where the geochemical ratios in the components 1 and 2 are

$$
\begin{aligned}
& x_{1}=\frac{v_{1}}{b_{1}}, \\
& x_{2}=\frac{v_{2}}{b_{2}}, \\
& y_{1}=\frac{u_{1}}{a_{1}}, \\
& y_{2}=\frac{u_{2}}{a_{2}} .
\end{aligned}
$$
by

The proportion of the first component could be estimated

$$
f_{1}=\frac{-a_{2} y_{m}+a_{2} y_{2}}{\left(a_{1}-a_{2}\right) y_{m}-a_{1} y_{1}+a_{2} y_{2}} \text {. }
$$

In this work, the scheme described by Zou ([33], model B) was applied to evaluate the mixing/mingling process in the SC northern sector. All calculations of mixing models were carried out using the STATISTICA for Windows software.

\section{Results}

Ten samples of SC database proved to be intermediate magmas. The set of major element based diagrams $(n=$ 10; Table 4 and Figure 3) showed a collisional setting with total percent probability value (\% prob) of about $45.8 \%$. However, immobile major and trace element based diagrams
( $n=9$; Table 4 and Figure 4$)$ indicated a within-plate regime, although with a relatively low $\%$ prob of only about 38.1 . Unlike other sets of diagrams, a continental arc setting can be inferred from those based on immobile trace elements $(n=$ $10 ; \%$ prob $=39.7$; Table 4 and Figure 5). It is important to note that intermediate samples from southern and transition sectors (1.9 to $0.5 \mathrm{Ma}$ ) represent the main contribution to the collisional and within-plate settings.

A relatively large number of samples $(n=46)$ from SC database proved to be of acid magma. In contrast to intermediate magmas, all diagrams indicated a subductionrelated setting for the SC acid magmas, with total percent probability values for this tectonic regime of about $74.1 \%$, $63.0 \%$, and $68.7 \%$, respectively, for the major, major and trace, and trace element based diagrams (Table 5 and Figures 6, 7, and 8). The results of the tectonic setting are further evaluated from discordancy and significance tests in the Discussion section below.

On the other hand, the hierarchical agglomeration process was carried out for each SC sector (SCN: 22 samples; SCC: 12 samples; and SCS and SCT: 22 samples) and their results were summarized in three dendrograms with units in Euclidean values (Figures 9(a)-9(c)). The statistical parameters (mean, minimum, maximum, and standard deviation) associated with the centroid of each cluster are reported in Table 6.

The studied rocks from northern SC sector (Table 6; Figure 9(a)) were distributed in three general clusters (N1 [13.6\%], N2 [54.5\%], and N3 [31.9\%]). The PCA calculation indicated that the $\sim 94.2 \%$ of geochemical variability of samples from northern SC sector could be explained by three factors. The factor F1 contributed with $57.4 \%$, being associated with major (excepting $\mathrm{Na}$ and $\mathrm{P}$ ) and transition elements; rare earth elements and yttrium ruled a contribution of $18.6 \%$ by means of the factor F2 (Figure 10(a)). The principal component F3 (a function of $\mathrm{Na}, \mathrm{P}$, and $\mathrm{Sr}$ ) explained the $8.2 \%$ of the chemical variability.

The samples from central SC conformed four groups (C1 [8.3\%], C2 [25.0\%], C3 [8.3\%], and C4 [58.3\%]; Table 6 and Figure $9(\mathrm{~b}))$. A $\sim 94.1 \%$ of the chemical variability can be explained by means of five factors. The factor F1 (45.0\%) is controlled by $\mathrm{Si}$ and alkali composition. A $32.0 \%$ of the compositional heterogeneity has been associated with the incompatible elements using the principal component F2 (Figure 10(b)). The factor F3 (ruled by Mg, Ca, and HFSE) contributed with a $10.6 \%$.

The samples of SCS and SCT were agglomerated in three geochemical groups (ST1 [36.4\%], ST2 [40.9\%], and ST3 [22.7\%]; Table 6 and Figure 9(c)). PCA calculations have revealed that a $\sim 90 \%$ of the geochemical composition could be explained as a function of five principal components. The factor F1, associated with major elements (excepting $\mathrm{Na}$ and $\mathrm{K}$ ), Co, and $\mathrm{Eu}$, contributed with $42.8 \%$. F2 factor, which represents a $24.7 \%$, is controlled by $\mathrm{Ba}, \mathrm{K}$, and $\mathrm{U}$ (Figure $10(\mathrm{c})$ ). An $11.9 \%$ of the chemical heterogeneity is explained by the factor $\mathrm{F} 3$, a variable ruled by $\mathrm{Na}, \mathrm{K}$, and $\mathrm{V}$ composition. 


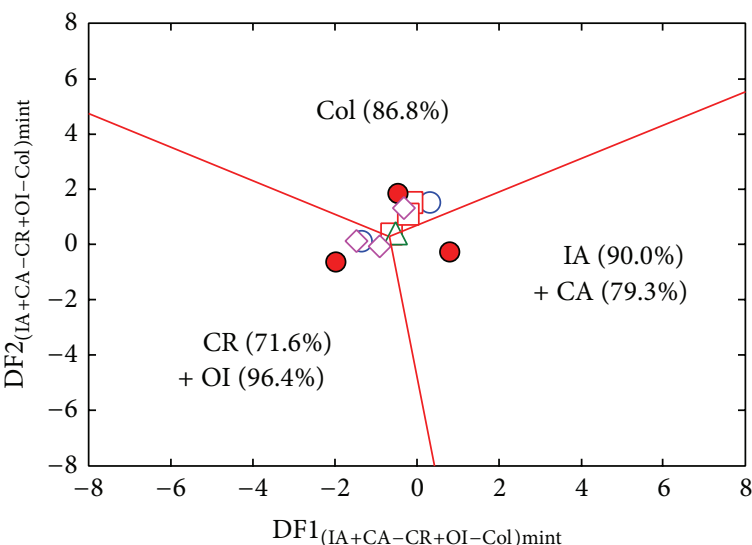

(a)

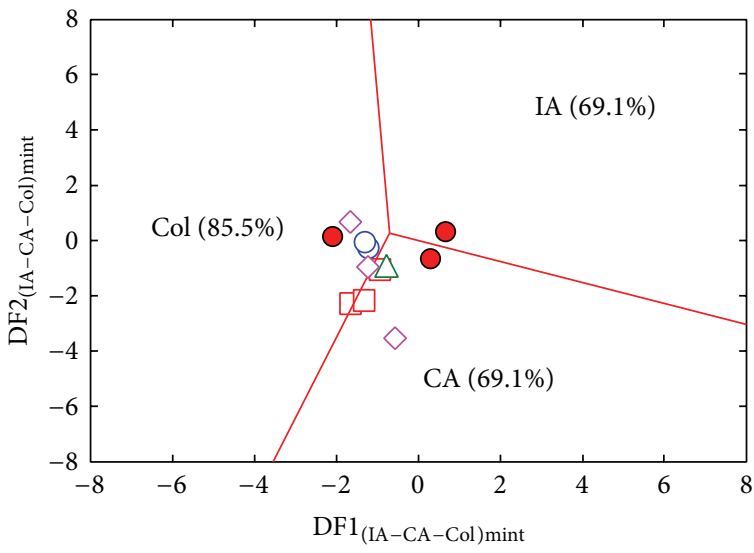

(c)

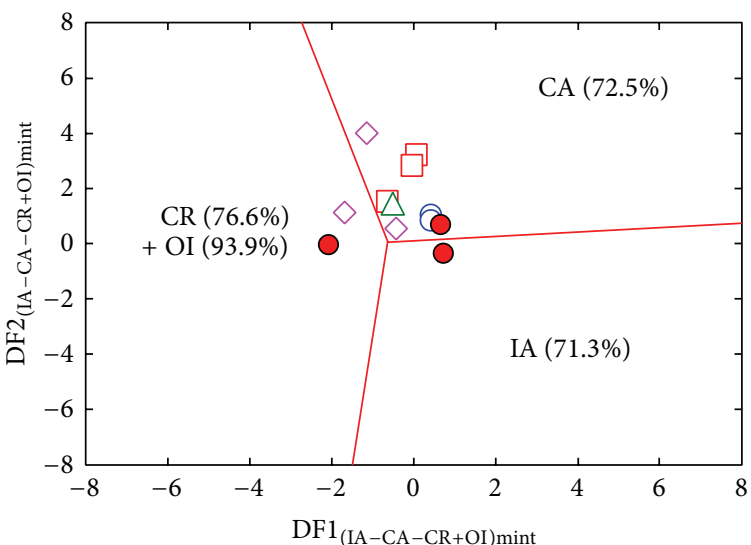

(b)

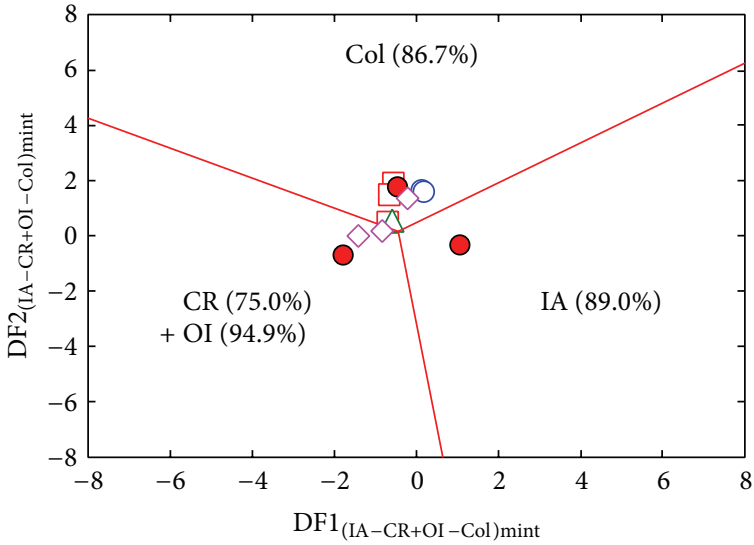

(d)

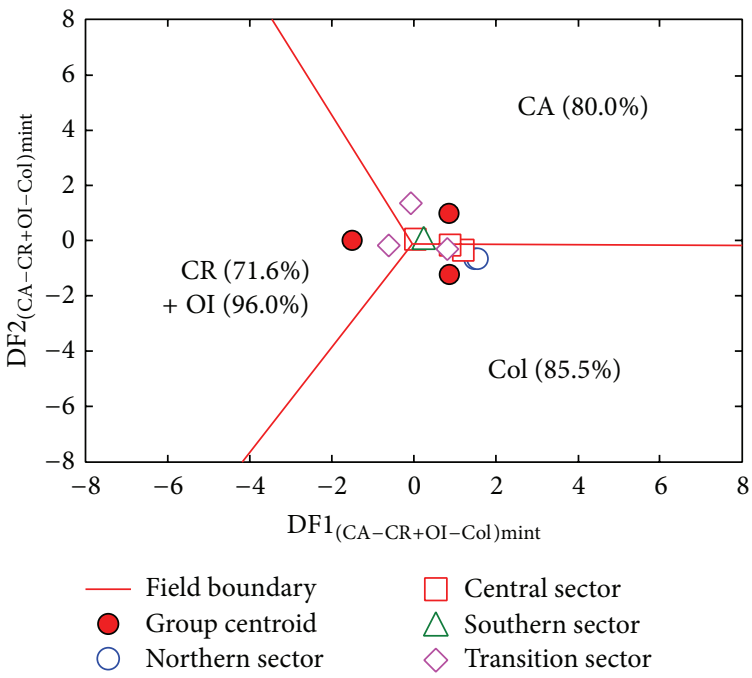

(e)

FIGURE 3: Discriminant-function multidimensional diagrams [21], based on ln-transformed ratios of major elements, for the tectonic discrimination of intermediate Sierra de las Cruces rocks. Tectonic settings: IA: island arc, CA: continental arc, CR: continental rift, OI: ocean island, and Col: collision. The symbols are explained as inset in (a). In (a), five groups are represented as three groups by combining IA and CA as IA + CA and CR and OI as CR + OI. The other four diagrams ((b)-(e)) are for three groups at a time. The subscript mint refers to the set of multidimensional diagrams based on $\ln$-transformed major element $(\mathrm{m})$ ratios for intermediate (int) magmas. Filled circles display the compositional centroid for each tectonic setting. The percentages in each field are the discrimination effectivity. The thick lines represent equal probability discrimination boundaries in all diagrams. The coordinates of the field boundaries and additional information are reported in [21]. 


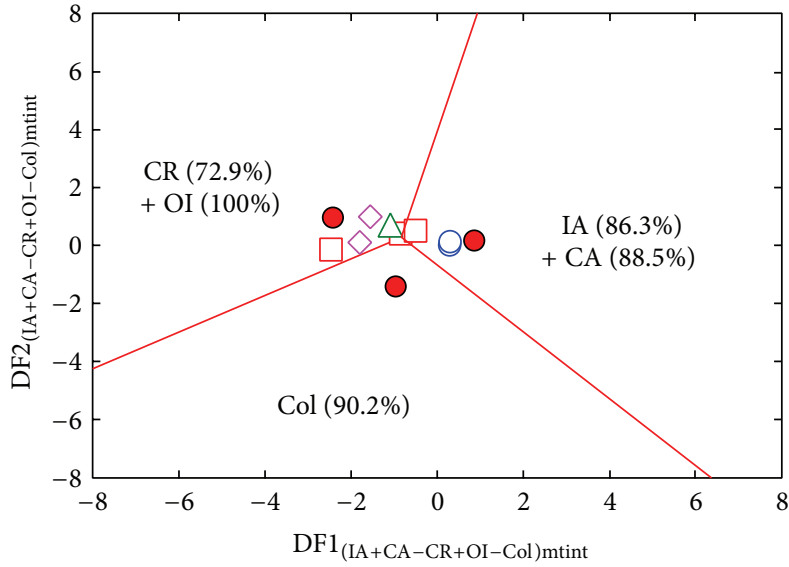

(a)

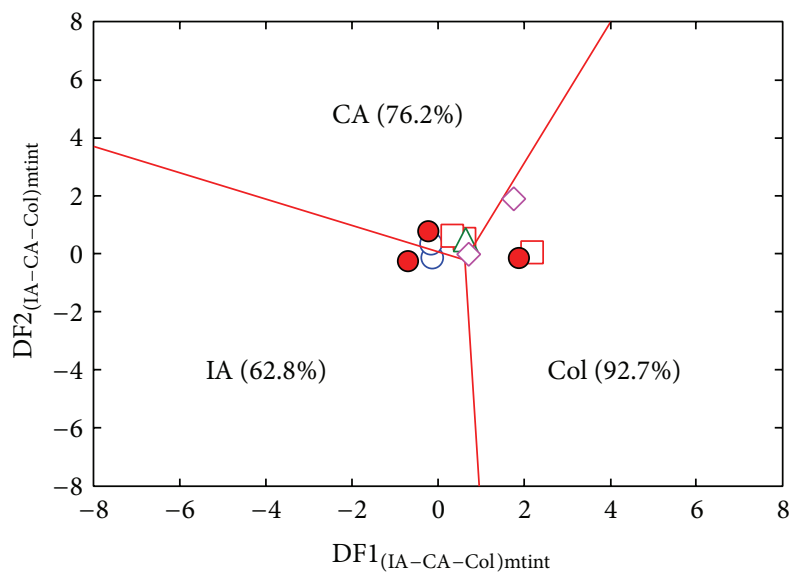

(c)

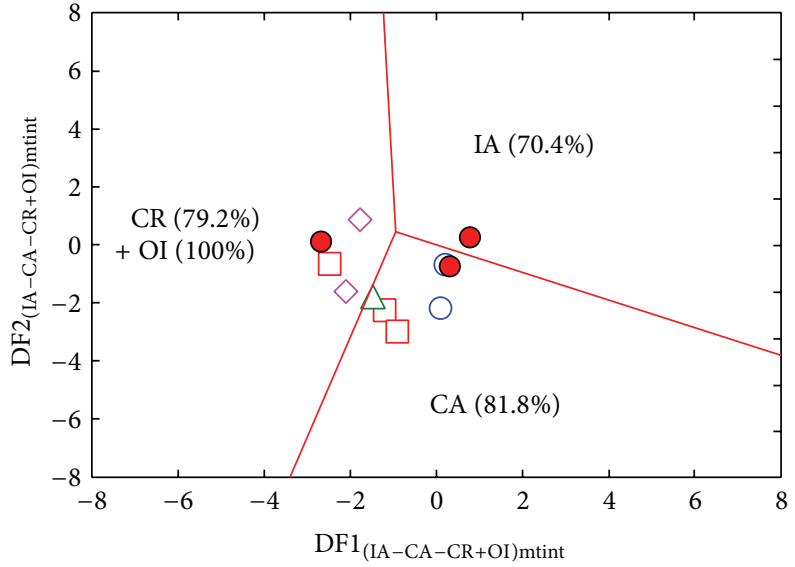

(b)

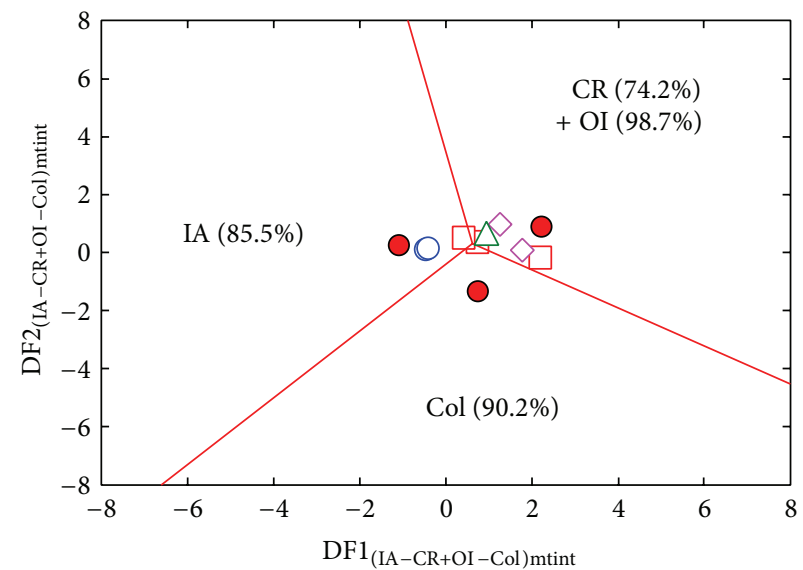

(d)

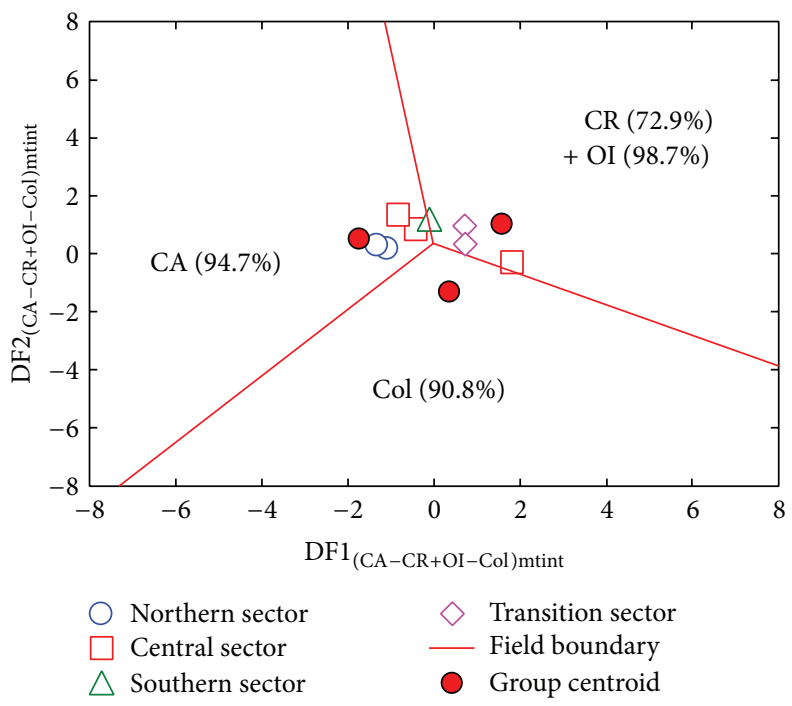

(e)

FIGURE 4: Discriminant-function multidimensional diagrams based on ln-transformed ratios of immobile major and trace elements for tectonic discrimination of intermediate Sierra de las Cruces magmas. The symbols are explained as inset in (a); more details are in Figure 3. The subscript "mtint" in axis names refers to major $(\mathrm{m})$ and trace $(\mathrm{t})$ element ratios for intermediate (int) magmas. 


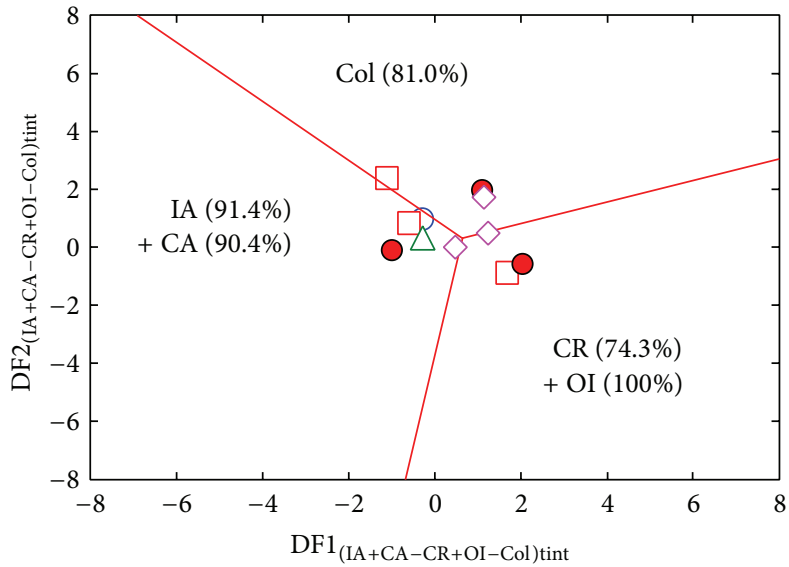

(a)

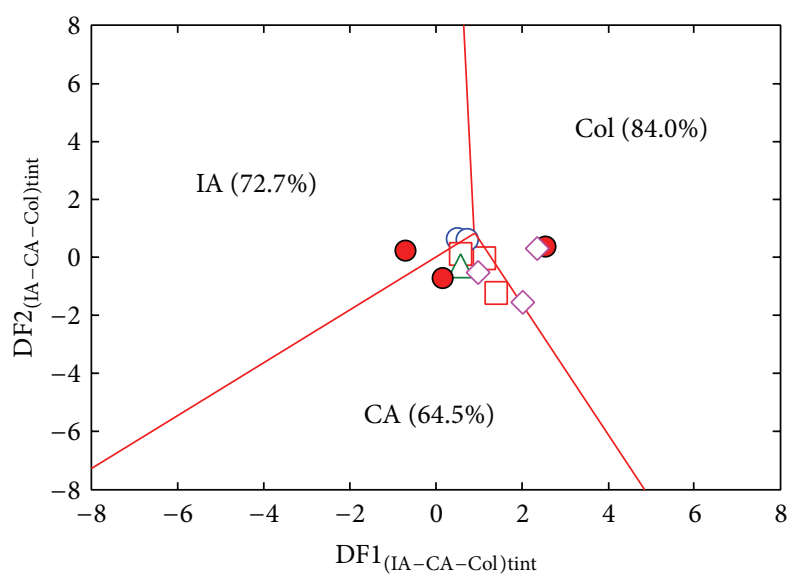

(c)

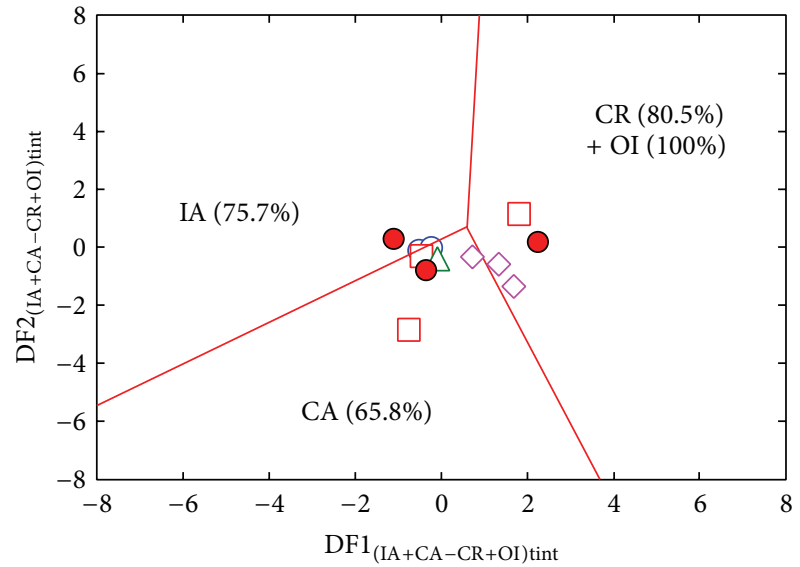

(b)

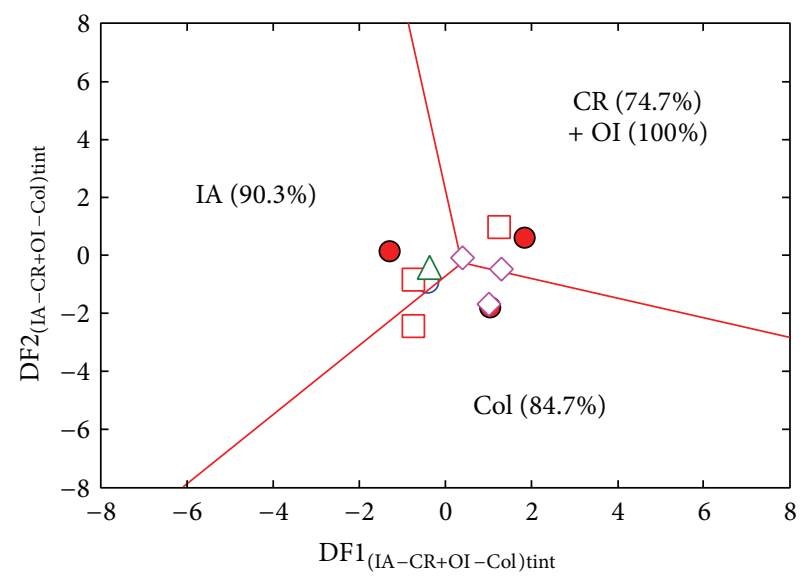

(d)

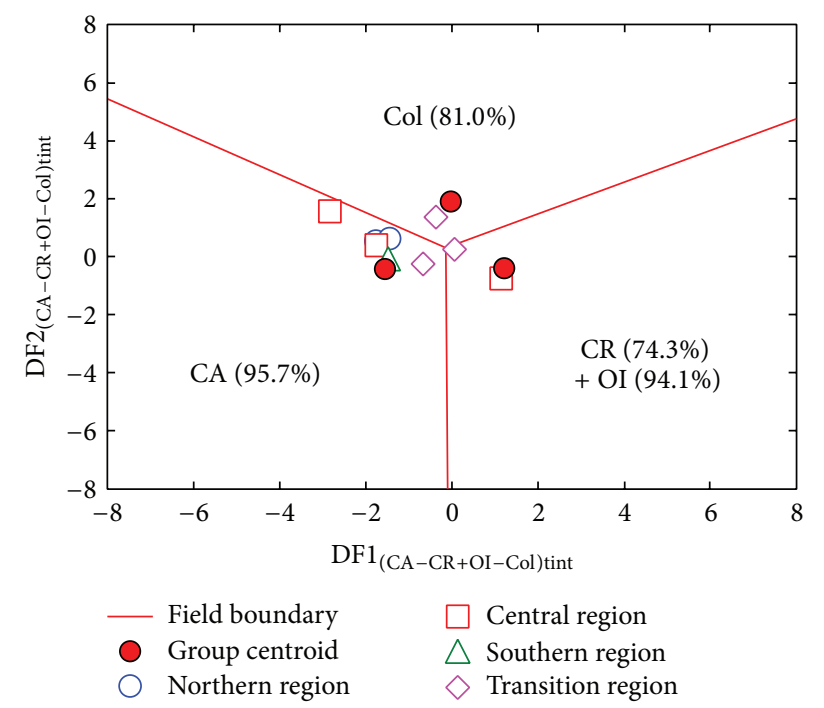

(e)

FIGURE 5: Discriminant-function multidimensional diagrams based on ln-transformed ratios of immobile trace elements for tectonic discrimination of intermediate Sierra de las Cruces magmas. The symbols are explained as inset in (a); more details are in Figure 3. The subscript "tint" in axis names refers to trace ( $\mathrm{t}$ ) element ratios for intermediate (int) magmas. 


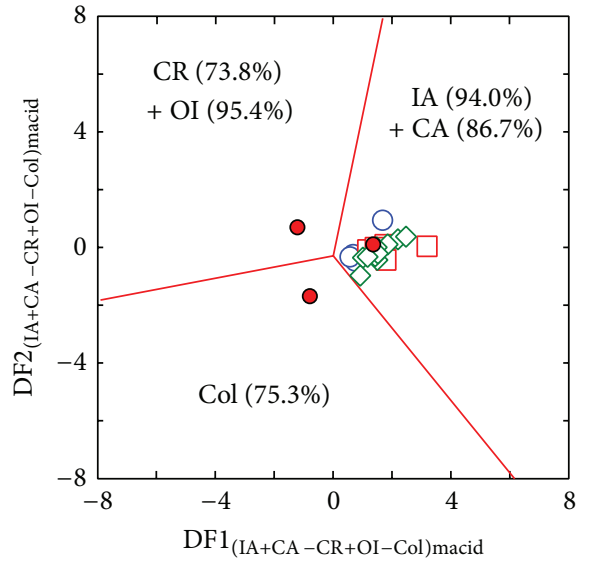

(a)

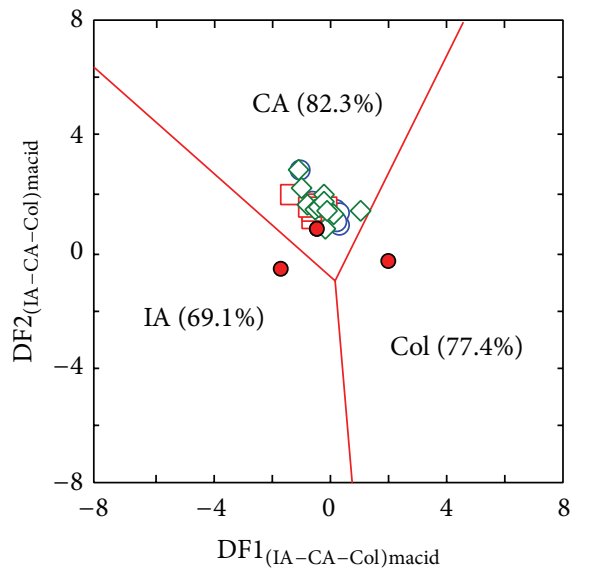

(c)

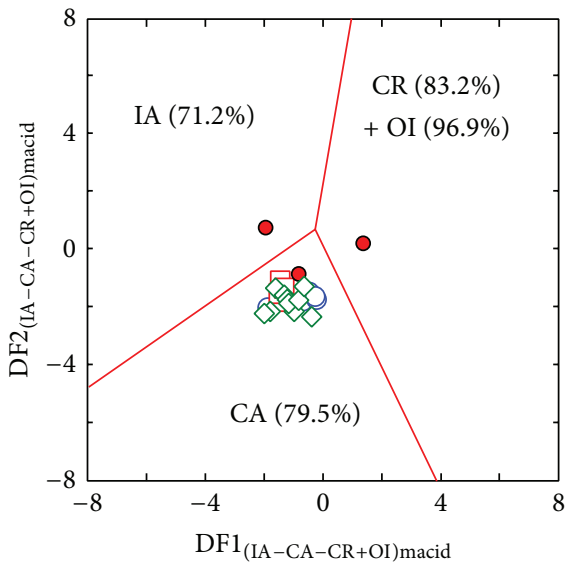

(b)

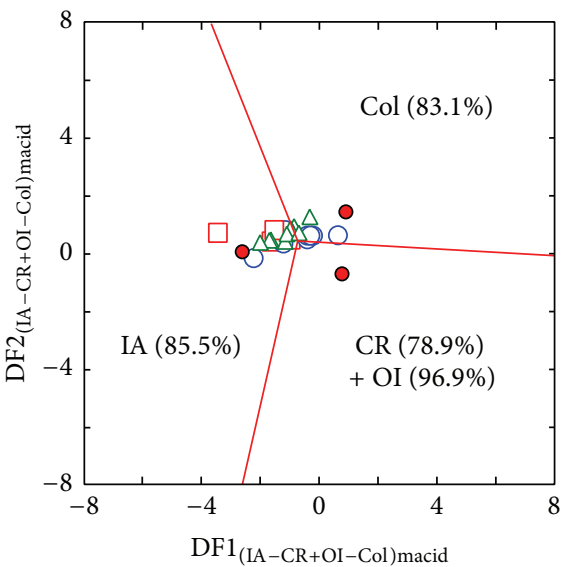

(d)

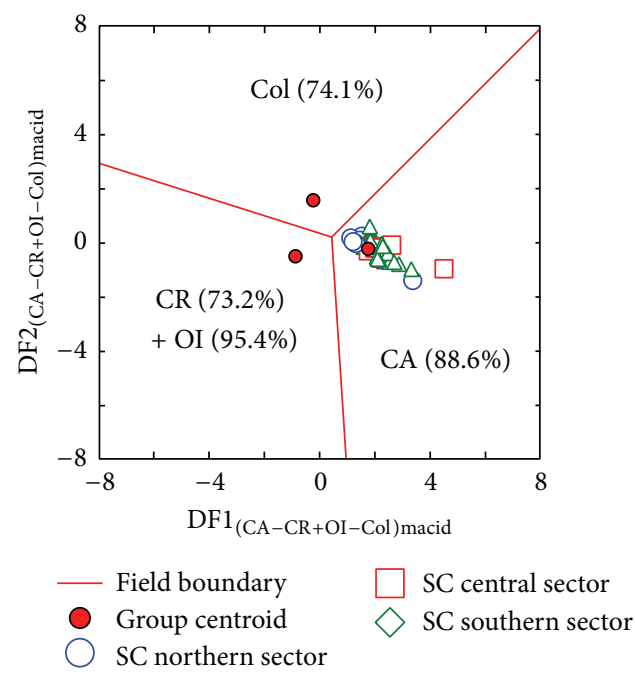

(e)

FiguRE 6: Discriminant-function multidimensional diagrams [22], based on ln-transformed ratios of major elements, for the tectonic discrimination of acid Sierra de las Cruces rocks. Tectonic settings: IA: island arc, CA: continental arc, CR: continental rift, OI: ocean island, and Col: collision. The symbols are explained as inset in (a). In (a), five groups are represented as three groups by combining IA and CA as IA + CA and CR and OI as CR+OI. The other four diagrams ((b)-(e)) are for three groups at a time. The subscript "macid" refers to the set of multidimensional diagrams based on ln-transformed major element (m) ratios for acid (acid) magmas. Filled circles display the compositional centroid for each tectonic setting. The percentages in each field are the discrimination effectivity. The thick lines represent equal probability discrimination boundaries in all diagrams. The coordinates of the field boundaries and additional information are reported in $[22]$. 


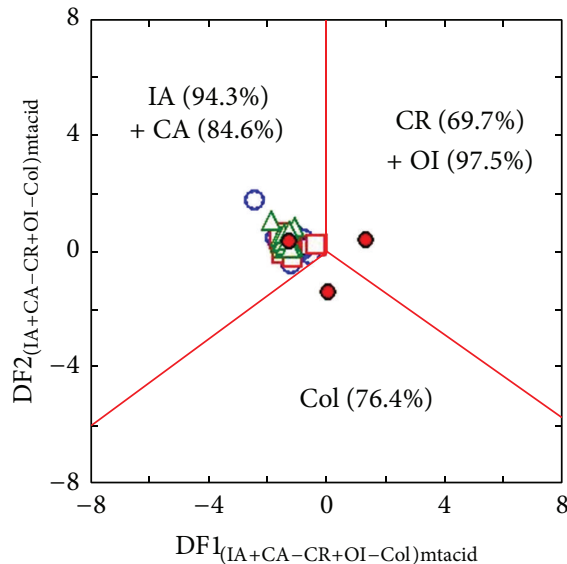

(a)

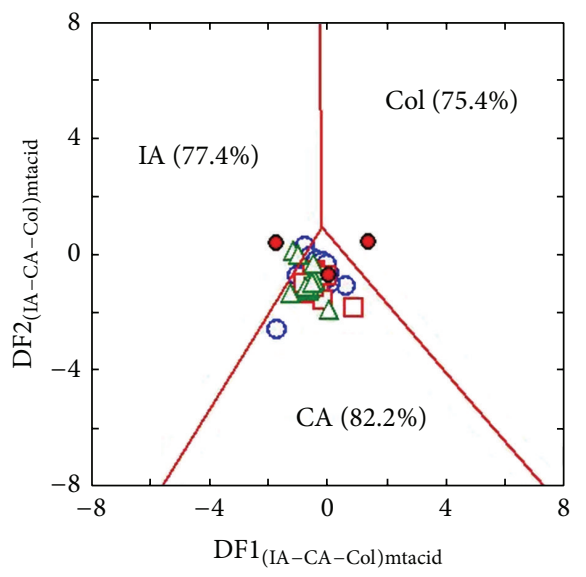

(c)

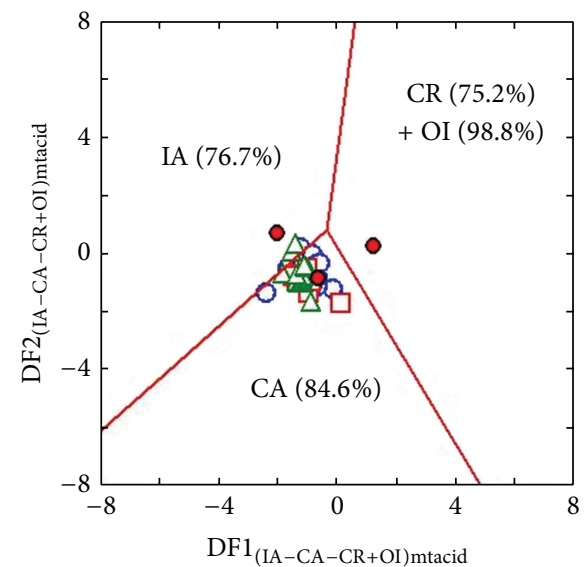

(b)

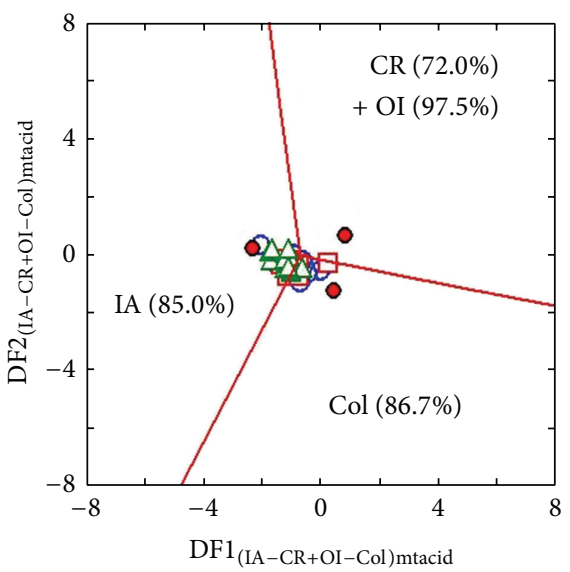

(d)

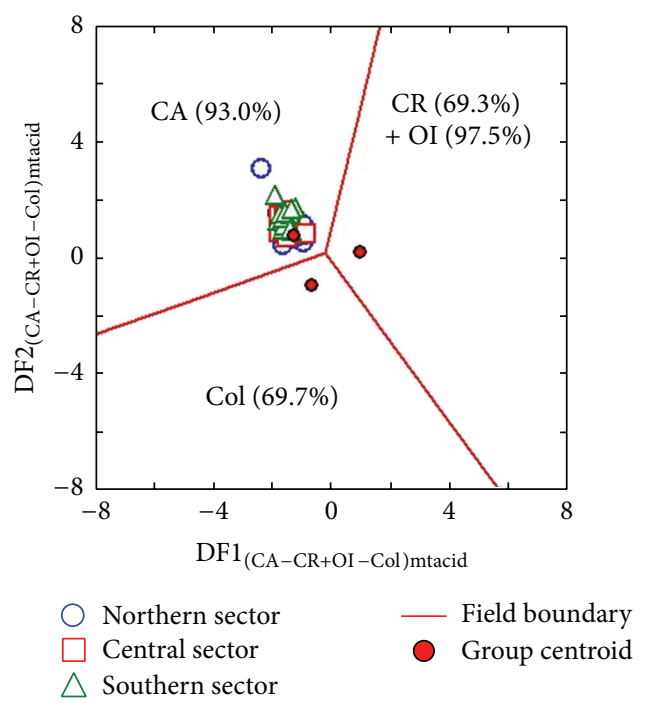

(e)

FiguRE 7: Discriminant-function multidimensional diagrams based on ln-transformed ratios of immobile major and trace elements for tectonic discrimination of acid Sierra de las Cruces magmas. The symbols are explained as inset in (a); more details are in Figure 6. The subscript "mtacid" in axis names refers to major $(\mathrm{m})$ and trace $(\mathrm{t})$ element ratios for acid (acid) magmas. 


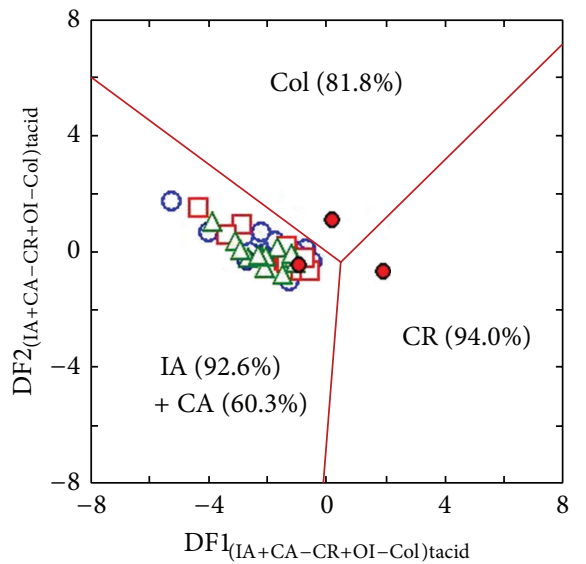

(a)

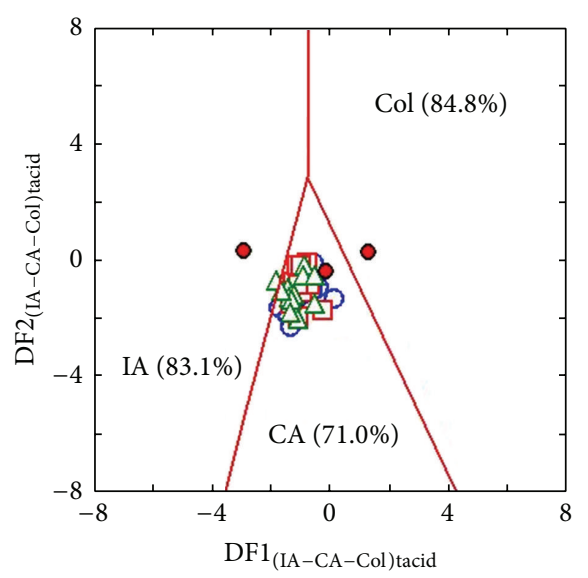

(c)

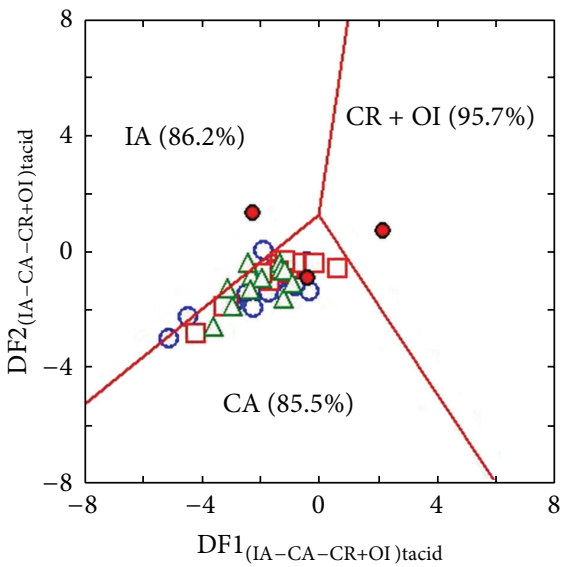

(b)

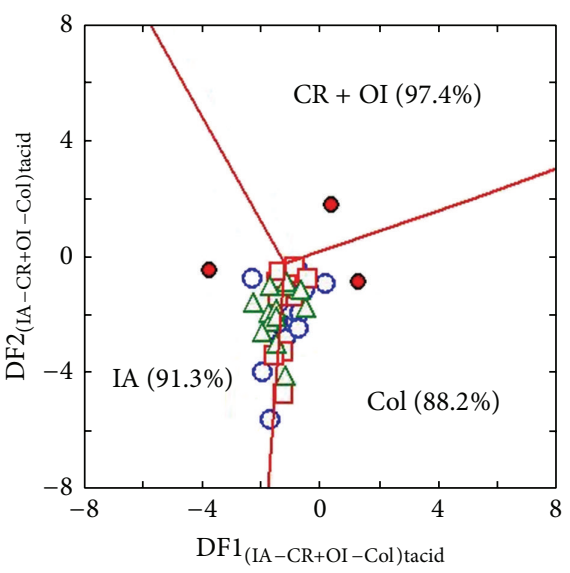

(d)

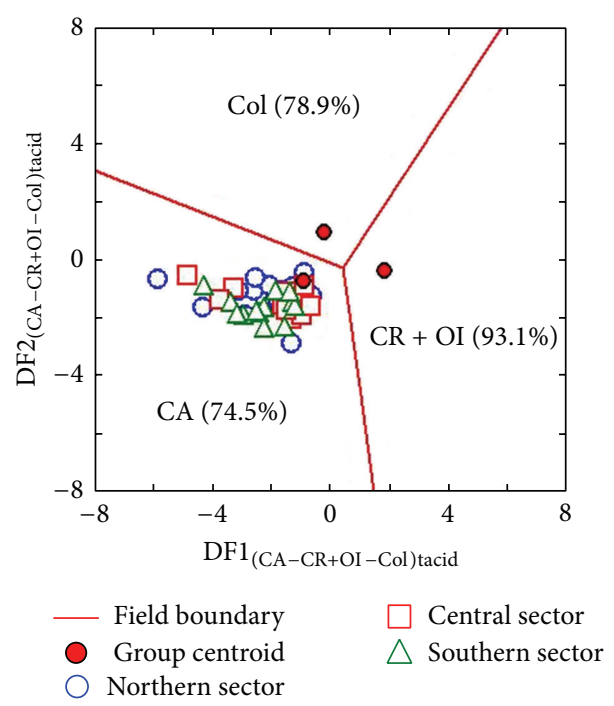

(e)

Figure 8: Discriminant-function multidimensional diagrams based on ln-transformed ratios of immobile trace elements for tectonic discrimination of acid Sierra de las Cruces magmas. The symbols are explained as inset in (a); more details are in Figure 6. The subscript "tacid" in axis names refers to trace ( $\mathrm{t}$ ) element ratios for acid (acid) magmas. 
TABLE 2: Major element composition $(\% \mathrm{~m} / \mathrm{m})$ and CIPW norm for the volcanic rocks from the Sierra de las Cruces range ${ }^{\mathrm{a}}$.

\begin{tabular}{|c|c|c|c|c|c|c|c|c|c|c|}
\hline Sample & SC03 & SC16 & SC22 & SC46 & SC51 & SC52 & SC52a & SC53 & SC58 & SC60 \\
\hline Sector & SCT & SCT & SCT & SCN & SCN & SCN & SCN & SCS & SCS & SCS \\
\hline TAS & $\mathrm{D}$ & A & BTA & $\mathrm{D}$ & $\mathrm{D}$ & $\mathrm{D}$ & $\mathrm{BA}$ & A & $\mathrm{D}$ & $\mathrm{D}$ \\
\hline \multicolumn{11}{|c|}{ Major-element measured composition $(\% \mathrm{~m} / \mathrm{m})$} \\
\hline $\mathrm{SiO}_{2}$ & 60.88 & 54.64 & 53.44 & 64.29 & 65.91 & 60.73 & 48.34 & 54.81 & 63.21 & 66.71 \\
\hline $\mathrm{TiO}_{2}$ & 0.981 & 0.912 & 1.542 & 0.661 & 0.583 & 0.785 & 1.636 & 1.128 & 0.695 & 0.582 \\
\hline $\mathrm{Al}_{2} \mathrm{O}_{3}$ & 16.72 & 19.80 & 15.51 & 15.98 & 15.24 & 16.10 & 16.91 & 18.99 & 16.89 & 15.85 \\
\hline $\mathrm{Fe}_{2} \mathrm{O}_{3}{ }^{\mathrm{t}}$ & 4.57 & 5.43 & 8.66 & 4.28 & 4.00 & 5.43 & 9.35 & 6.67 & 5.00 & 3.90 \\
\hline $\mathrm{MnO}$ & 0.099 & 0.092 & 0.136 & 0.065 & 0.061 & 0.062 & 0.105 & 0.103 & 0.073 & 0.062 \\
\hline $\mathrm{MgO}$ & 6.12 & 2.23 & 6.71 & 1.52 & 2.02 & 2.43 & 6.59 & 2.34 & 1.37 & 1.68 \\
\hline $\mathrm{CaO}$ & 5.57 & 2.66 & 7.43 & 3.69 & 3.87 & 4.44 & 5.56 & 4.59 & 4.30 & 3.90 \\
\hline $\mathrm{Na}_{2} \mathrm{O}$ & 2.97 & 3.47 & 3.98 & 4.07 & 4.01 & 4.01 & 2.36 & 3.68 & 4.40 & 4.56 \\
\hline $\mathrm{K}_{2} \mathrm{O}$ & 0.80 & 0.80 & 1.53 & 2.50 & 2.52 & 1.89 & 1.30 & 0.84 & 1.68 & 2.23 \\
\hline $\mathrm{P}_{2} \mathrm{O}_{5}$ & 0.14 & 0.22 & 0.63 & 0.18 & 0.18 & 0.21 & 0.19 & 0.26 & 0.13 & 0.17 \\
\hline LOI & 0.60 & 8.95 & 0.11 & 2.70 & 2.30 & 3.01 & 7.59 & 7.01 & 3.06 & 0.24 \\
\hline Total & 99.430 & 99.204 & 99.678 & 99.906 & 100.704 & 99.097 & 99.931 & 100.421 & 100.808 & 99.884 \\
\hline \multicolumn{11}{|c|}{ CIPW norm } \\
\hline Q & 18.730 & 23.358 & - & 20.600 & 21.530 & 16.476 & 5.223 & 16.302 & 18.988 & 20.458 \\
\hline Or & 4.621 & 5.260 & 9.142 & 15.123 & 15.182 & 11.672 & 8.386 & 5.342 & 10.194 & 13.261 \\
\hline $\mathrm{Ab}$ & 25.520 & 32.678 & 34.050 & 35.539 & 34.591 & 35.463 & 21.797 & 33.517 & 38.230 & 38.839 \\
\hline An & 27.132 & 13.089 & 20.155 & 17.677 & 16.451 & 21.265 & 28.762 & 22.684 & 21.039 & 16.298 \\
\hline $\mathrm{C}$ & 1.230 & 9.925 & - & 0.330 & - & - & 2.145 & 4.633 & 0.333 & - \\
\hline $\mathrm{Di}$ & - & - & 10.431 & - & 1.568 & 0.264 & - & - & - & 1.685 \\
\hline Hy & 18.933 & 11.093 & 18.543 & 7.305 & 7.560 & 10.617 & 26.668 & 12.075 & 7.579 & 6.444 \\
\hline $\mathrm{Ol}$ & - & - & 0.202 & - & - & - & - & - & - & - \\
\hline Mt & 1.612 & 2.099 & 3.040 & 1.695 & 1.564 & 2.178 & 3.146 & 2.494 & 1.970 & 1.506 \\
\hline Il & 1.892 & 1.928 & 2.961 & 1.295 & 1.128 & 1.557 & 3.392 & 2.306 & 1.356 & 1.113 \\
\hline Ap & 0.329 & 0.568 & 1.476 & 0.431 & 0.424 & 0.507 & 0.480 & 0.649 & 0.308 & 0.396 \\
\hline Mg-v & 77.719 & 51.684 & 66.871 & 48.905 & 57.634 & 54.66 & 63.940 & 47.752 & 42.473 & 53.718 \\
\hline $\mathrm{FeO}^{\mathrm{t}} / \mathrm{MgO}$ & 0.672 & 2.191 & 1.161 & 2.533 & 1.782 & 2.01 & 1.277 & 2.565 & 3.283 & 2.089 \\
\hline
\end{tabular}

${ }^{a}$ TAS: rock classification following the Le Bas et al [36] scheme. A: andesite, BA: basaltic andesite, BTA: basaltic trachyandesite, and D: dacite. Adjusted composition $(\% \mathrm{~m} / \mathrm{m})$ and CIPW norm calculated applying SINCLAS program $[14,15] . \mathrm{Mg}-\mathrm{v}=100 * \mathrm{Mg}^{+2} /\left(\mathrm{Mg}^{+2}+0.9 *\left[\mathrm{Fe}^{+2}+\mathrm{Fe}^{+3}\right]\right)$, atomic; $\mathrm{Fe}^{+2}$ and $\mathrm{Fe}^{+3}$ calculated from adjusted $\mathrm{FeO}$ and $\mathrm{Fe}_{2} \mathrm{O}_{3}$ following Middlemost [34].

The mass-balance approach for magma mixing (model A) used by Nixon [31] was applied to the geochemical data from $\mathrm{SC}$ resulting in $\mathrm{N} 2$ comingled lavas). The mixing analysis was essentially limited to $\left[\mathrm{SiO}_{2}\right]_{\mathrm{adj}},\left[\mathrm{Fe}_{2} \mathrm{O}_{3}\right]_{\mathrm{adj}},[\mathrm{FeO}]_{\mathrm{adj}}$, $[\mathrm{MnO}]_{\mathrm{adj}},[\mathrm{MgO}]_{\mathrm{adj}},[\mathrm{CaO}]_{\mathrm{adj}},\left[\mathrm{K}_{2} \mathrm{O}\right]_{\mathrm{adj}}, \mathrm{Co}, \mathrm{Cr}, \mathrm{Ni}$, and $\mathrm{V}$, since all these constituents exhibit a statistically significant linear coherence in Harker diagrams $(r=0.89-0.98 ; n=22$; statistically significant at $99 \%$ confidence level; Figures 11 and 12) and have relatively small concentration ranges in felsic N3 end-member (Table 6).

The proportion of the intermediate $\mathrm{N} 1$ end-member in each N2 mixed lava was calculated using (7) and the average composition of the intermediate $\left(I_{\mathrm{SC}}\right)$ and felsic $\left(F_{\mathrm{SC}}\right)$ end-members. Calculated proportions exhibit internal consistency for majority of the chemical components (Figure 13). For each sample, the estimated proportions display a Gaussian distribution (their normality behavior was proved by a Schapiro-Wilks test), covering between $\sim 15$ and $47 \%$ in average proportion of the andesitic $\mathrm{N} 1$ end-member (Figure 14).

On the other hand, the mixing model B [33] was applied to lavas of the northern SC sector. The coefficients $A$ to $D((10 \mathrm{a})-(10 \mathrm{~d}))$ of the hyperbolic mixing equation (9) were established for twelve geochemical ratio-ratio $u / a-v / b$ systems (Table 7): (1) $u / a:\left[\mathrm{Fe}_{2} \mathrm{O}_{3}\right]_{\mathrm{adj}} /\left[\mathrm{K}_{2} \mathrm{O}\right]_{\mathrm{adj}}$, $\left[\mathrm{Fe}_{2} \mathrm{O}_{3}\right]_{\mathrm{adj}} /\left[\mathrm{Al}_{2} \mathrm{O}_{3}\right]_{\mathrm{adj}}, \mathrm{V} / \mathrm{Ba}, \mathrm{V} / \mathrm{U}, \mathrm{Cr} / \mathrm{Th}$, and $\mathrm{Cr} / \mathrm{Yb}-v / b$ : $\left[\mathrm{SiO}_{2}\right]_{\mathrm{adj}} /[\mathrm{FeO}]_{\mathrm{adj}} ;$ (2) $u / a:[\mathrm{MgO}]_{\mathrm{adj}} / \mathrm{Eu},[\mathrm{MgO}]_{\mathrm{adj}} / \mathrm{Hf}$, $[\mathrm{CaO}]_{\mathrm{adj}} / \mathrm{Ta}, \quad[\mathrm{CaO}]_{\mathrm{adj}} / \mathrm{Zr}, \quad \mathrm{Ga} / \mathrm{Ni}$, and $\mathrm{Ga} / \mathrm{Rb}-v / b$ : $\left.\left[\mathrm{SiO}_{2}\right]_{\mathrm{adj}} / \mathrm{V}\right)$. Figures 15 and 16 show some examples of the ratio-ratio diagrams for the SCN lavas, including the average composition of the intermediate $\left(I_{\mathrm{SC}}\right)$ and felsic $\left(F_{\mathrm{SC}}\right)$ end-members (black filled square and circle) and their hyperbolic mixing models (black solid line). The application of model B revealed that the percentages $\left(100 * f_{1}\right)$ of the component $\mathrm{N} 1$ in each of the comingled lavas $\mathrm{N} 2$ range 
TABle 3: Trace element composition ( $\mathrm{ppm}$ ) for the volcanic rocks from the Sierra de las Cruces range.

\begin{tabular}{|c|c|c|c|c|c|c|c|c|c|c|}
\hline Sample & SC03 & SC16 & SC22 & SC46 & SC51 & SC52 & SC52a & SC53 & SC58 & SC60 \\
\hline Sector & SCT & SCT & SCT & SCN & SCN & SCN & SCN & SCS & SCS & SCS \\
\hline TAS & $\mathrm{D}$ & $\mathrm{A}$ & BTA & $\mathrm{D}$ & $\mathrm{D}$ & $\mathrm{D}$ & $\mathrm{BA}$ & $\mathrm{A}$ & $\mathrm{D}$ & $\mathrm{D}$ \\
\hline $\mathrm{La}$ & 14.1 & 20.0 & 34.8 & 23.4 & 25.2 & 24.1 & 16.2 & 18.8 & 11.1 & 17.1 \\
\hline $\mathrm{Ce}$ & 31.2 & 47.9 & 77.8 & 41.2 & 40.6 & 38.2 & 40.9 & 41.2 & 21.8 & 34.1 \\
\hline $\operatorname{Pr}$ & 4.03 & 7.28 & 10.10 & 6.54 & 6.12 & 6.71 & 5.19 & 5.14 & 2.99 & 4.35 \\
\hline $\mathrm{Nd}$ & 17.1 & 29.7 & 42.9 & 26.5 & 24.7 & 28.4 & 24.3 & 21.6 & 12.6 & 17.4 \\
\hline $\mathrm{Sm}$ & 3.9 & 6.1 & 9.0 & 5.4 & 4.8 & 5.6 & 5.5 & 4.6 & 2.9 & 3.6 \\
\hline $\mathrm{Eu}$ & 1.24 & 1.77 & 2.67 & 1.52 & 1.37 & 1.66 & 1.65 & 1.57 & 1.08 & 1.10 \\
\hline Gd & 3.9 & 6.2 & 8.0 & 4.4 & 4.3 & 5.0 & 5.3 & 4.6 & 2.9 & 3.3 \\
\hline $\mathrm{Tb}$ & 0.6 & 0.9 & 1.1 & 0.7 & 0.7 & 0.7 & 0.8 & 0.7 & 0.5 & 0.5 \\
\hline Dy & 3.3 & 5.2 & 5.7 & 3.8 & 3.7 & 4.0 & 4.6 & 3.9 & 2.6 & 2.7 \\
\hline Ho & 0.7 & 1.0 & 1.0 & 0.7 & 0.7 & 0.8 & 0.9 & 0.8 & 0.5 & 0.5 \\
\hline $\mathrm{Er}$ & 1.9 & 2.7 & 2.9 & 2.0 & 2.1 & 2.2 & 2.5 & 2.2 & 1.5 & 1.6 \\
\hline $\mathrm{Tm}$ & 0.28 & 0.37 & 0.42 & 0.30 & 0.30 & 0.30 & 0.36 & 0.32 & 0.22 & 0.22 \\
\hline $\mathrm{Yb}$ & 1.7 & 1.8 & 2.5 & 2.0 & 1.9 & 1.9 & 2.2 & 1.9 & 1.4 & 1.4 \\
\hline $\mathrm{Lu}$ & 0.24 & 0.32 & 0.40 & 0.30 & 0.30 & 0.29 & 0.33 & 0.29 & 0.23 & 0.21 \\
\hline $\mathrm{Sc}$ & 15 & & 19 & 11 & 9 & 15 & 37 & 18 & 13 & 8 \\
\hline $\mathrm{V}$ & 102 & 39 & 150 & 88 & 75 & 109 & 216 & 119 & 59 & 51 \\
\hline $\mathrm{Cr}$ & 246 & 28 & 260 & 60 & 60 & 150 & 360 & 150 & 170 & 40 \\
\hline Co & 18 & 10 & 29 & 10 & 9 & 15 & 40 & 21 & 15 & 9 \\
\hline $\mathrm{Ni}$ & 88 & & 110 & 30 & 30 & 50 & 110 & 80 & 50 & 20 \\
\hline $\mathrm{Cu}$ & 21 & 94 & 30 & 10 & 20 & 20 & 60 & & 20 & 20 \\
\hline $\mathrm{Ga}$ & 13 & 22 & 20 & 18 & 20 & 21 & 22 & 24 & 21 & 21 \\
\hline $\mathrm{Rb}$ & 13 & 3 & 28 & 59 & 61 & 40 & 22 & 6 & 38 & 58 \\
\hline $\mathrm{Sr}$ & 380 & 303 & 763 & 521 & 502 & 582 & 445 & 569 & 454 & 368 \\
\hline $\mathrm{Y}$ & 20 & 32 & 28 & 20 & 21 & 19 & 22 & 21 & 15 & 18 \\
\hline $\mathrm{Zr}$ & 136 & 156 & 237 & 156 & 160 & 158 & 162 & 194 & 143 & 149 \\
\hline $\mathrm{Nb}$ & 6.0 & 5.4 & 17.0 & 4.0 & 4.0 & 3.0 & 3.0 & 8.0 & 13.0 & 4.0 \\
\hline Cs & & & 2.1 & 2.8 & 2.7 & 1.1 & & & 1.2 & 2.1 \\
\hline $\mathrm{Ba}$ & 276 & 412 & 648 & 542 & 571 & 481 & 344 & 660 & 388 & 481 \\
\hline $\mathrm{Hf}$ & 3.4 & 4.4 & 5.4 & 4.2 & 4.2 & 4.4 & 4.7 & 4.8 & 3.8 & 4.2 \\
\hline $\mathrm{Ta}$ & 0.40 & 0.33 & 1.10 & 0.5 & 0.5 & 0.30 & 0.20 & 0.7 & 0.3 & 0.6 \\
\hline $\mathrm{Pb}$ & 72 & & 11 & 11 & 14 & 11 & 23 & 10 & 9 & 11 \\
\hline Th & 1.8 & 3.0 & 4.1 & 6.7 & 6.7 & 4.0 & 3.0 & 5.0 & 3.4 & 8.2 \\
\hline $\mathrm{U}$ & 0.6 & 1.3 & 1.2 & 2.6 & 2.5 & 1.6 & 1.1 & 1.1 & 1.4 & 3.1 \\
\hline
\end{tabular}

from 11 to $58 \%$ (Figure 14). Each mean and its uncertainty were estimated from a statistic sample of twelve ratio-ratio systems displaying a Gaussian behavior (normality proved by a Schapiro-Wilks test).

\section{Discussion}

6.1. Tectonic Setting. The MVB (Figure 1) has been considered as a very tectonically complex zone. In the framework of the theory of plate tectonics, the origin of this volcanic province has been explained by means of the subduction of Cocos and Rivera plates under the North American plate. However, several geological, geophysical, and geochemical characteristics observed in central MVB and the entire province do not support this simple model. Particularly, a strong controversy regarding the tectonic regime has been widely documented in the literature (e.g., [29, 30, 38, 46-53]).

How to interpret the seemingly contradictory results obtained in the tectonic discrimination analysis for the SC magmas (Tables 4 and 5)? A transitional continental arc to within-plate setting can be tentatively considered as a consistent model for the central MVB. Felsic magmas display geochemical features consistent with an origin from the upper continental crust. The genesis of the majority of the Mexican crustal source rocks has been associated with continental arc regime. Afterwards, a change in the tectonic setting could be related to a relatively fast variation in the Cocos plate subduction angle. 


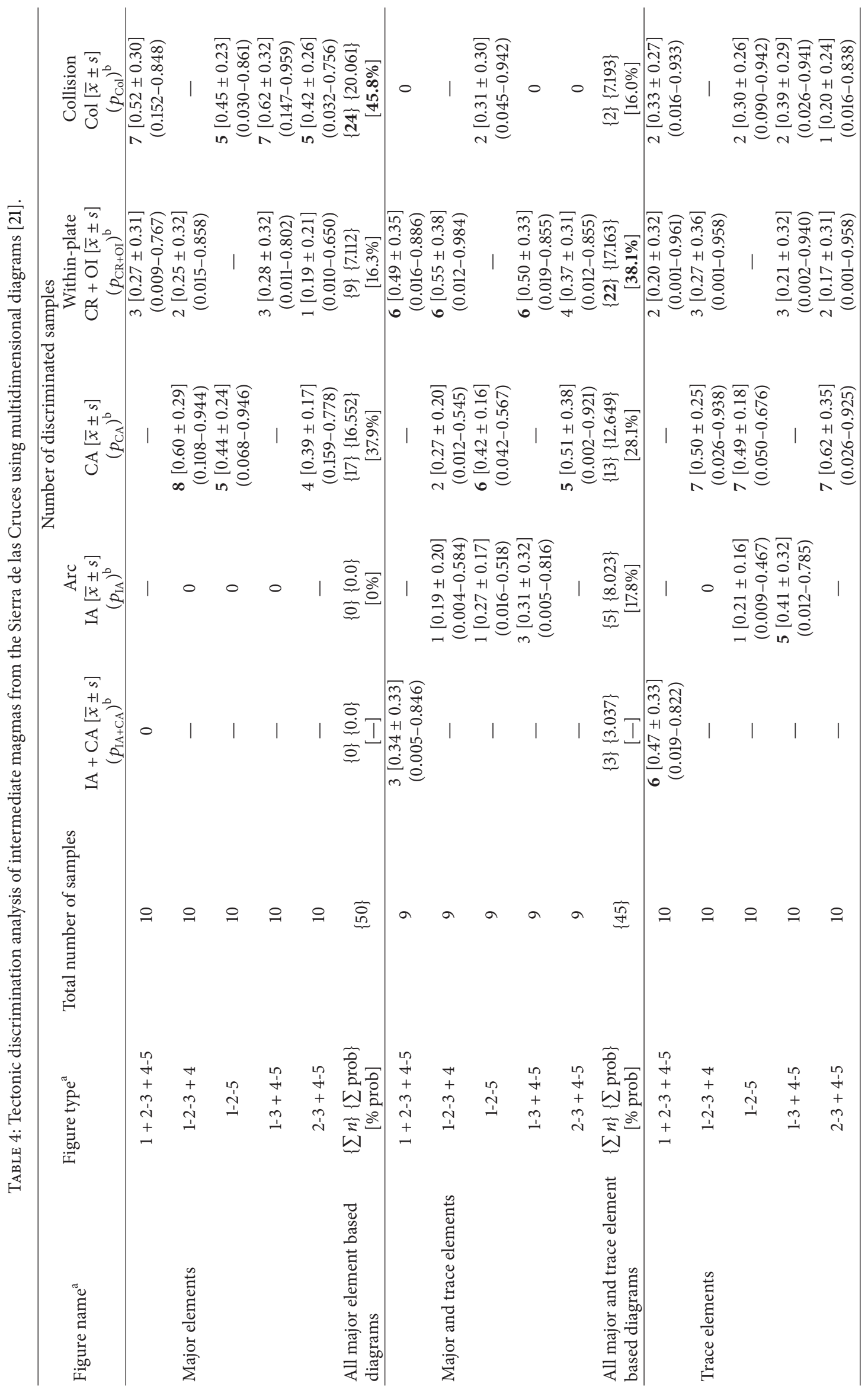




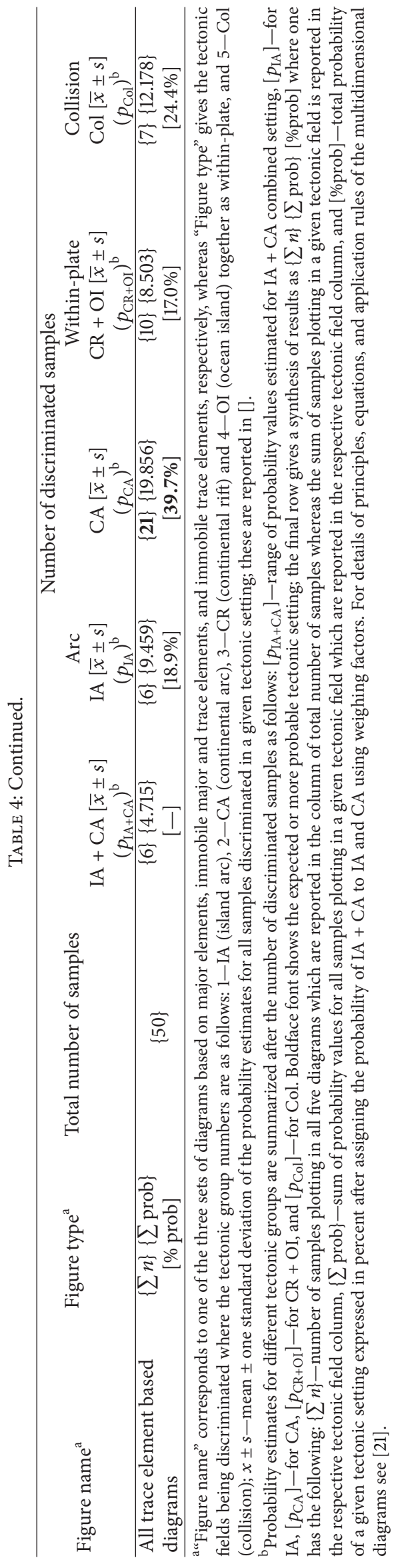




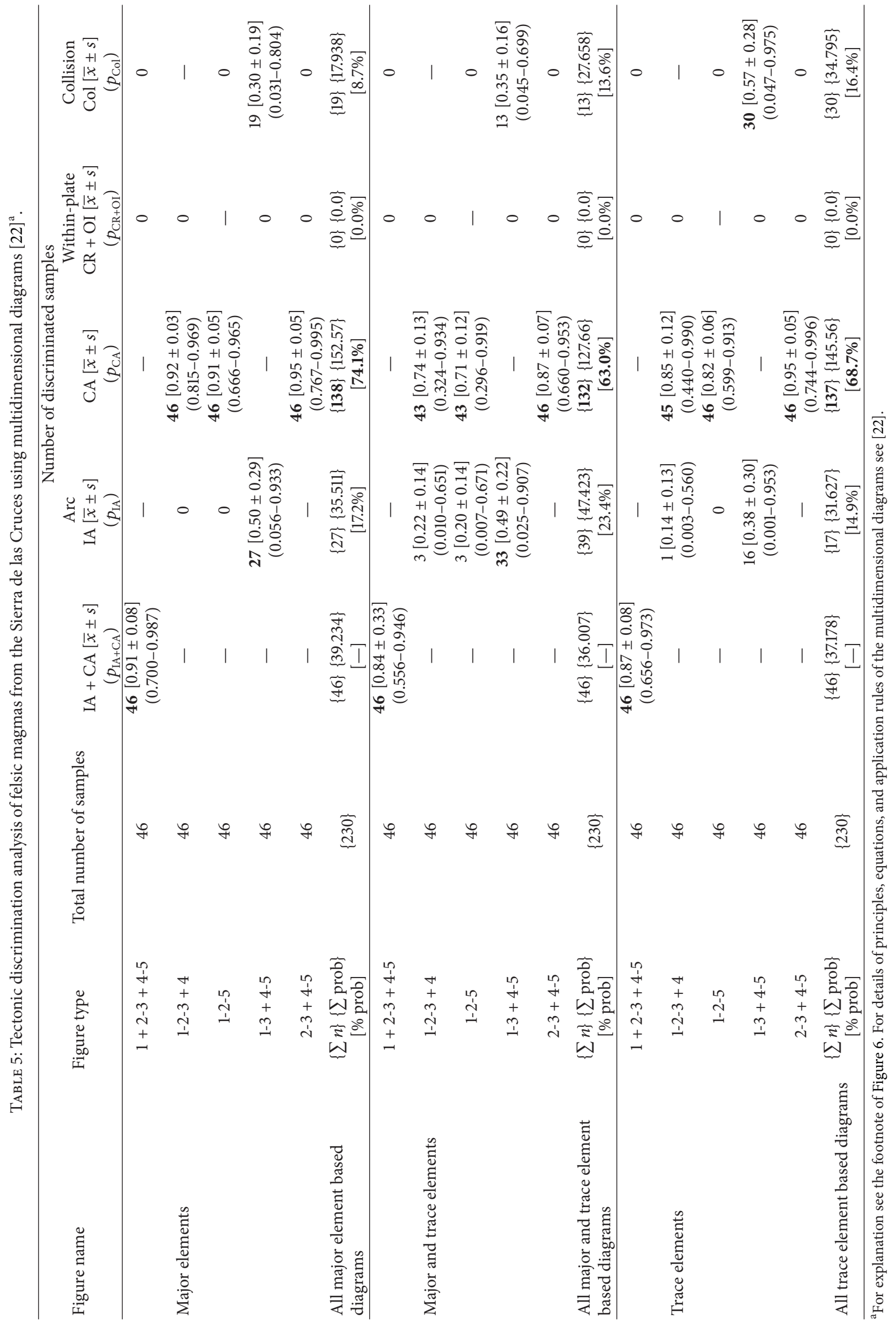




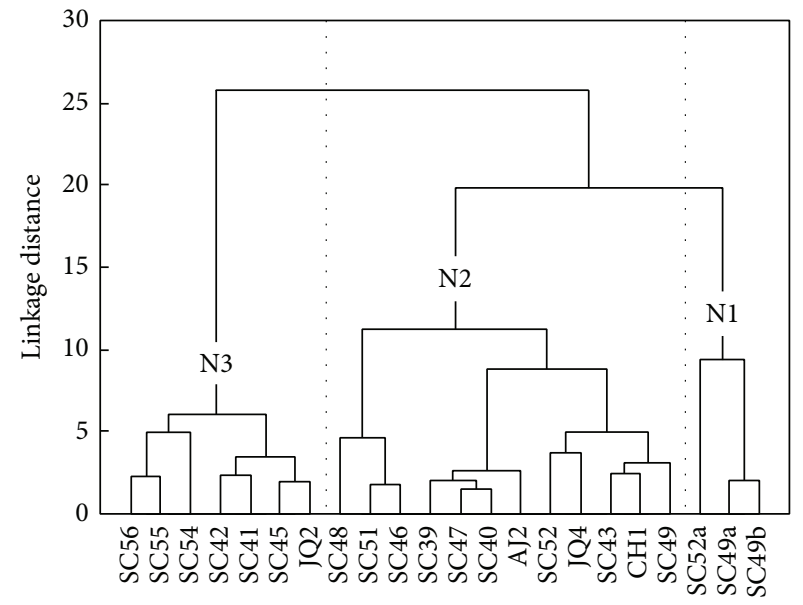

(a)

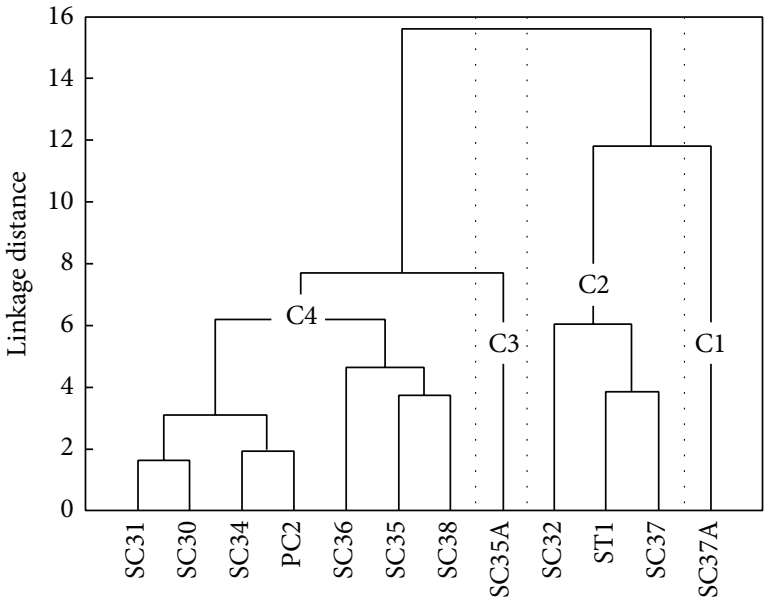

(b)

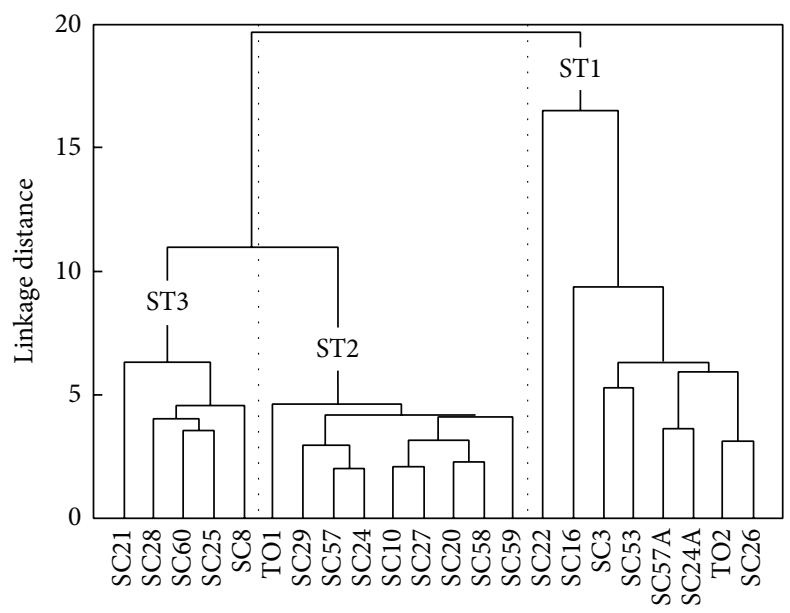

(c)

Figure 9: Dendrograms showing the results of the cluster analysis (considering Euclidean linkage distances) for the volcanic rocks from the (a) northern, (b) central, and (c) south + transition Sierra de las Cruces sectors.

However, the Cocos plate tectonic evolution is an issue that has not been solved. Pérez-Campos et al. [54] pointed out that the history of volcanism has been used to infer the evolving geometry of subduction. According to this model, during earlier Eocene the volcanic arc in central Mexico was nearer to the coast and parallel to the trench consistent with steep subduction. In late Eocene $(30 \mathrm{Ma})$ there was a hiatus, thought to be associated with a flattening process. At $20 \mathrm{Ma}$, after a $10 \mathrm{Ma}$ lull, volcanic activity resumed. At $\sim 10 \mathrm{Ma}$, the western part of the Cocos plate separated to form Rivera plate. At about this time, the development and propagation of a tear in the subduction plate have been suggested, culminating with the lower portion of the Cocos plate breaking off. The west-east propagating volcanism along the MVB reached the longitude of Mexico City at about 7 Ma. Additionally, Peláez Gaviria et al. [55] have reported changes during the last 3.5 $\mathrm{Ma}$ in the plate configuration at the north of the Middle America Trench (MAT) as a result of (a) the propagation of the Pacific-Cocos Segment of the East Pacific Rise (EPRPCS), (b) the collision of the EPR-PCS with the MAT at 1.7 Ma, and (c) the formation of the Rivera Transform.
Actually, subhorizontal subduction of Cocos plate has been inferred by Pérez-Campos et al. [54], Husker and Davis [56], and Pacheco and Singh [57] from seismic data obtained from a dense network. Particularly, the dip angle of Cocos slab decreases gradually from $\sim 50^{\circ}$ to $0^{\circ}$ along the labeled Michoacan segment of the Mexican subduction zone [57]. However, this quasihorizontal subduction and a very shallow subducted slab (at most at about $40 \mathrm{~km}$ in depth) are not thermodynamically favorable conditions for arc-related magma generation [58].

The diminution or even cessation of arc-related volcanism observed in the south-central Andes has been related to subhorizontal subduction of the Nazca plate [59]. The SC intermediate rocks could be a volcanism generated under this complex condition of the tectonic transition to an extensional regime. Additionally, Velasco-Tapia and Verma [29] have inferred, from inverse and direct immobile trace element modeling, combined ${ }^{87} \mathrm{Sr} /{ }^{86} \mathrm{Sr}$ and ${ }^{143} \mathrm{Nd} /{ }^{144} \mathrm{Nd}$ isotopic ratios, and the use of multidimensional log-ratio discriminant-function-based diagrams, that mafic magmas from the Sierra de Chichinautzin (the post-SC volcanic event 


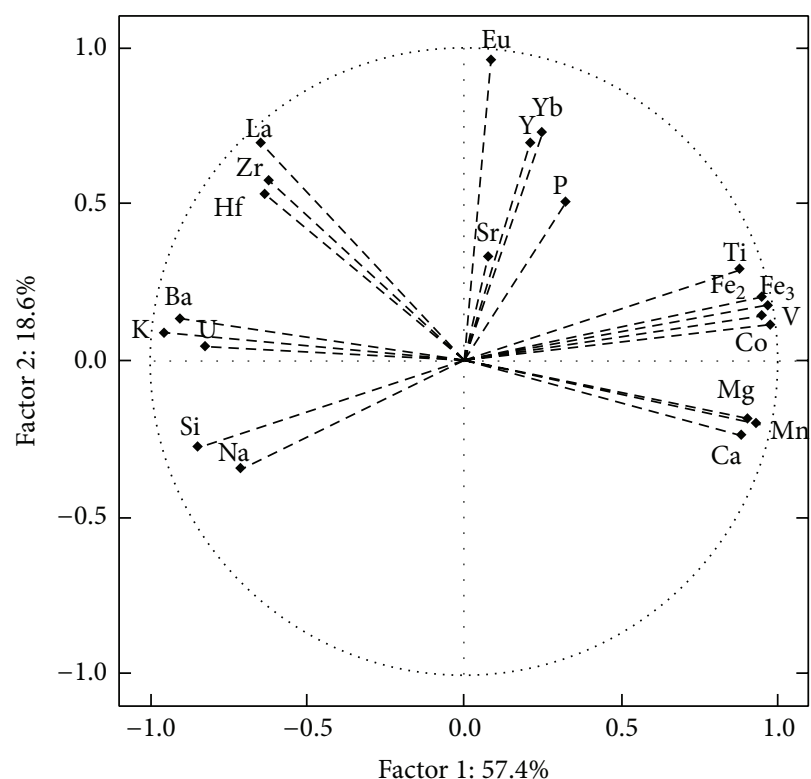

(a)

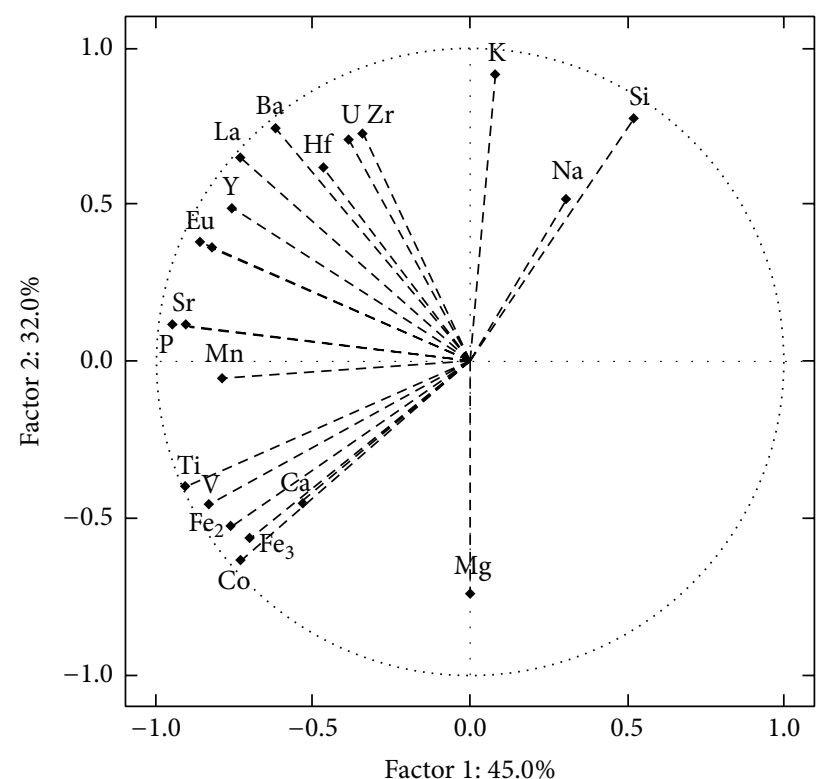

(b)

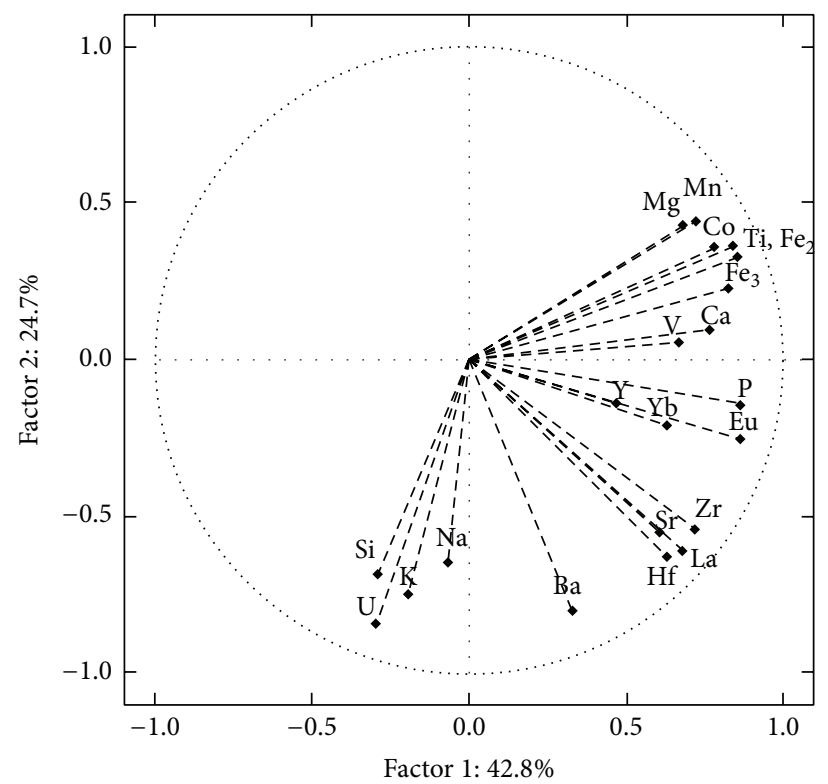

(c)

FIGURE 10: Projection of the variables on the factor-plane F2-F1 generated by principal component analysis (PCA) for the Sierra de las Cruces sectors: (a) northern, (b) central, and (c) southern + transition.

of $<40 \mathrm{ka}$ ) were undoubtedly generated by partial melting of continental lithospheric mantle in a within-plate setting.

Although the previous studies and this work represent significant contributions to the understanding of the origin of the volcanism in the central MVB, more geologicalgeophysical-geochemical collaborative research is needed to clearly understand the evolution of the tectonic regime in this area and the entire MVB.

6.2. Application of Discordancy and Significance Tests. The acid rock data of SC were placed in two groups: Grl close to the MAT (consisting of the data from the southern and transition sectors) and Gr2 farther away from the MAT (data from the northern and central sectors). A statistical comparison of these groups was carried out using Fisher $F$ test and Student's $t$-test. The results are summarized in Table 8. No statistically significant difference was observed between the two groups for any of the elements listed in Table 8 (see true for all elements in both one-sided and twosided columns of Table 8). The same is true for the $\mathrm{Nb}$ anomaly as well as for ratios of large-ion lithophile elements 


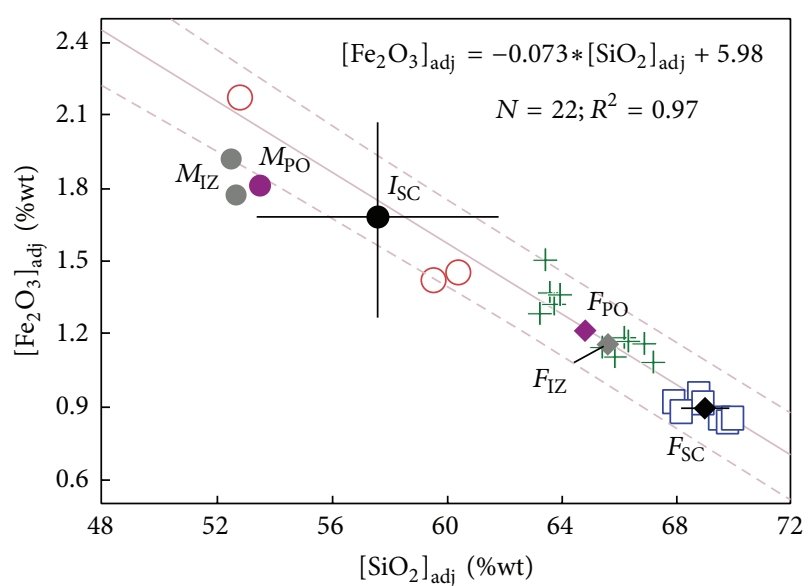

(a)

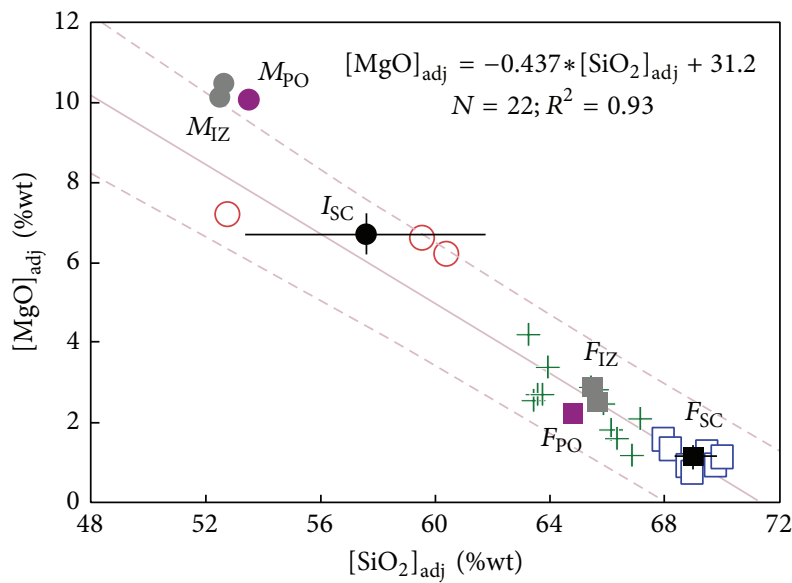

(c)

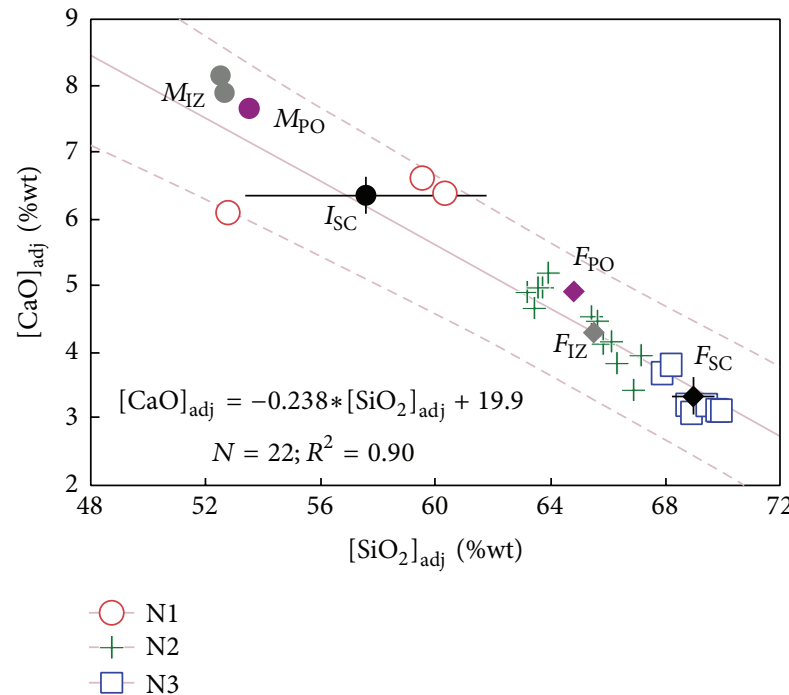

(e)

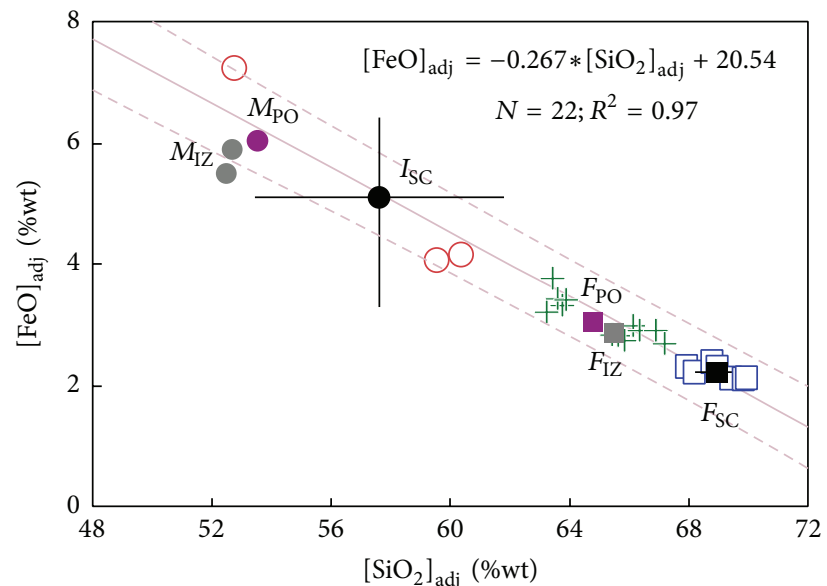

(b)

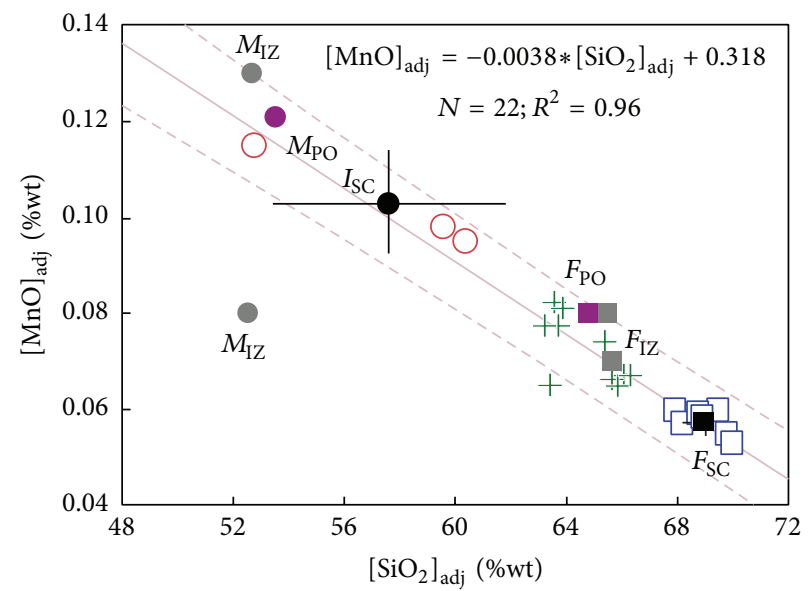

(d)

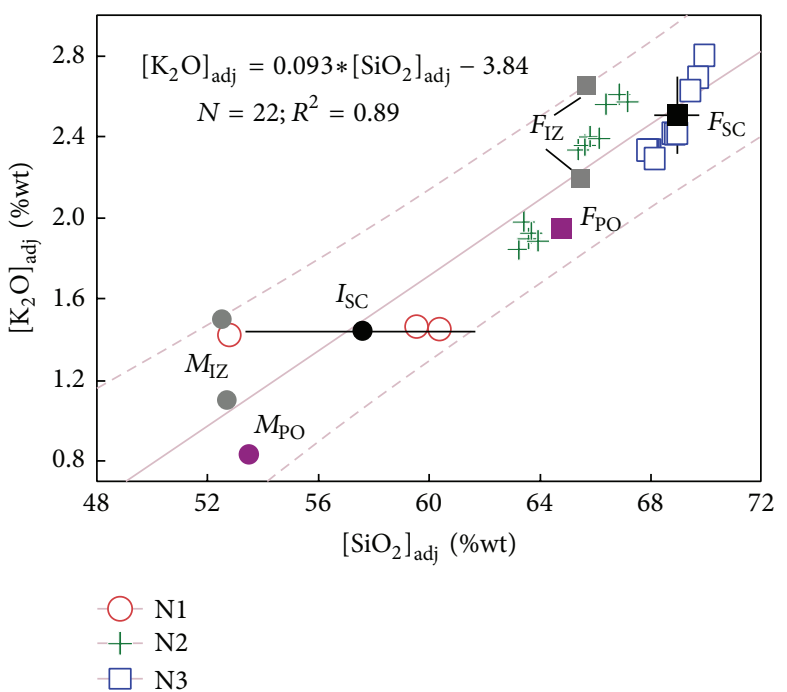

(f)

FIGURE 11: Major element Harker-type diagrams for volcanic rocks from the Sierra de las Cruces northern sector. An ordinary least-squares (OLS) regression model is included in each diagram (OLS equation; $N$ is number of samples; $R^{2}$ is Pearson regression coefficient; solid line is OLS model; discontinuous lines are $95 \%$ confidence regression bands). Abbreviations for end-members in mixing/mingling models: (a) Sierra de las Cruces: $I_{\mathrm{SC}}$ : intermediate and $F_{\mathrm{SC}}$ : felsic; (b) Iztaccíhuatl volcano [31]: $M_{\mathrm{IZ}}$ : mafic and $F_{\mathrm{IZ}}$ : felsic; (c) Popocatépetl volcano [32]: $M_{\mathrm{PO}}$ : mafic and $F_{\mathrm{PO}}$ : felsic. 

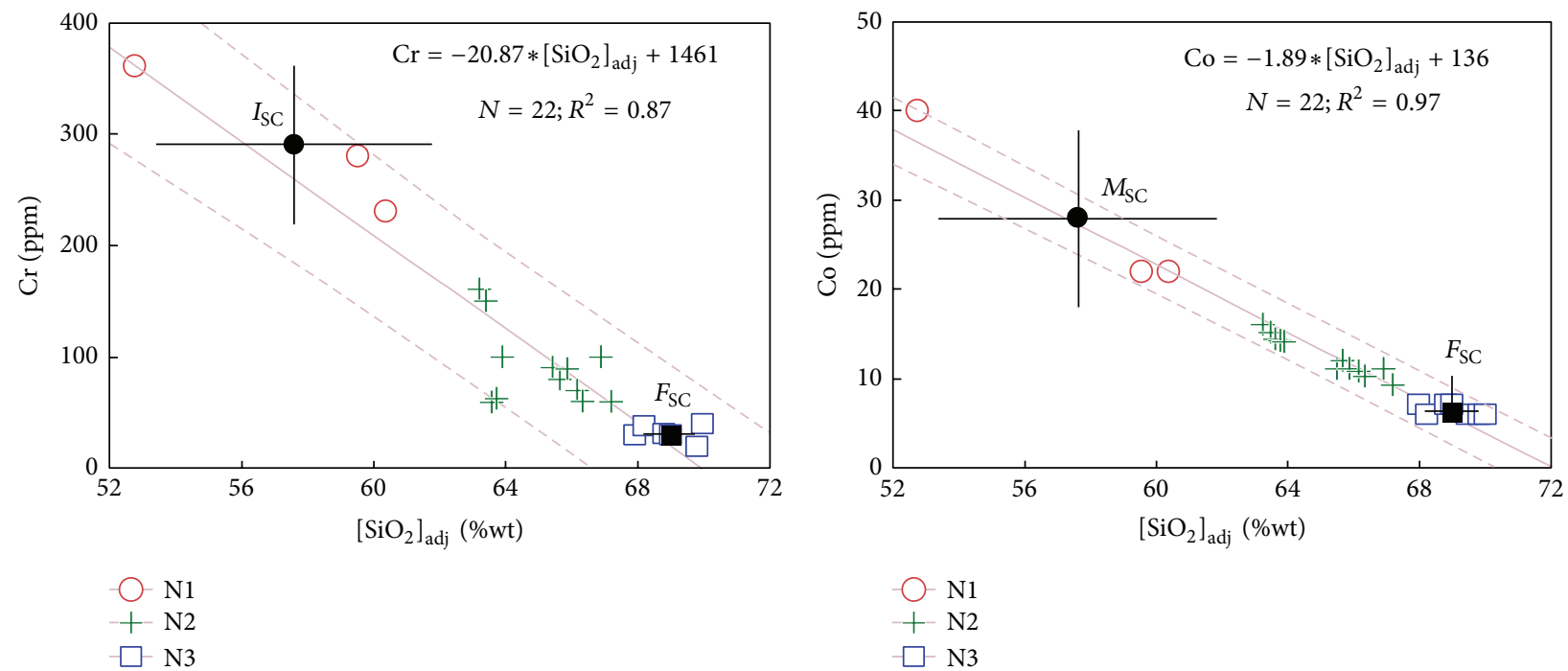

(a)

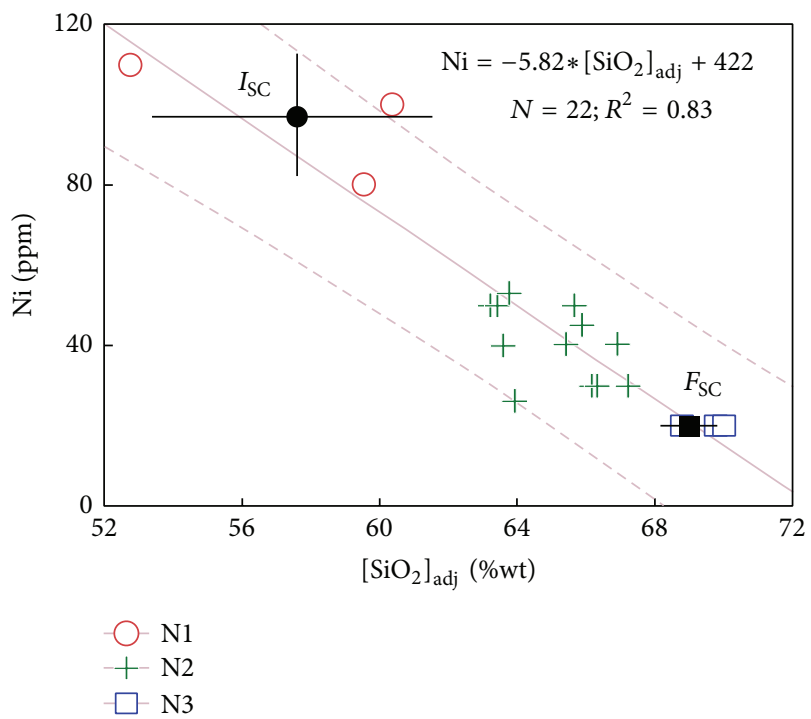

(c)

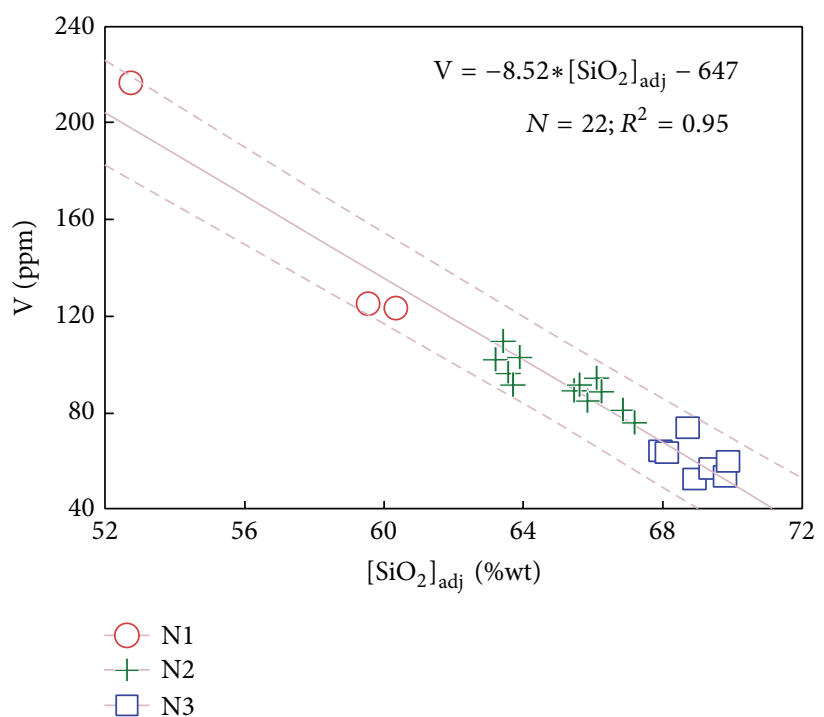

(d)

Figure 12: Trace element Harker-type diagrams for volcanic rocks from the Sierra de las Cruces northern sector. OLS regression models as those presented in Figure 11.

(LILE) to light rare earth elements (LREE) and LILE to highfield strength elements (HFSE) (see [38] for the importance of these ratios for subduction processes). Therefore, the negligible contribution from the subducted slab to the SC magmas can be safely inferred. The intermediate rock data were not so numerous and, therefore, are not reported here, although they confirmed the results for acid rocks.

6.3. Magmatic Clusters. The statistical analysis of samples from northern SC sector (Figure 9(a) and Table 6) revealed that group $\mathrm{N} 1$ corresponds to the intermediate magmatic enclaves (SC49A, SC49B, and SC52A). Dacitic lavas without disequilibrium features dominate the N3 group, being accompanied by some mixed lavas with similar chemical composition. These groups are widely spaced, as observed in the dendrogram, with a Euclidian linkage distance of 25. In comparison with $\mathrm{N} 3$ felsic magmas, the intermediate samples of $\mathrm{N} 1$ group have higher contents of $\left[\mathrm{TiO}_{2}\right]_{\mathrm{adj}},\left[\mathrm{Fe}_{2} \mathrm{O}_{3}\right]_{\mathrm{adj}}$, $[\mathrm{FeO}]_{\mathrm{adj}},[\mathrm{MnO}]_{\mathrm{adj}},[\mathrm{MgO}]_{\mathrm{adj}},[\mathrm{CaO}]_{\mathrm{adj}}$, and transition elements (e.g., Co and V). Cluster N2 seems to be representing the group including the majority of comingled lavas observed in this sector. It is important to note that the northern SC sector displays a relatively high density of magmatic enclaves included in felsic magmas, also showing the specimens with the higher size (reaching $\sim 20 \mathrm{~cm}$ ) in the entire volcanic range. This fact could be related to an increase in fault and fracture density in this direction [24], a favorable condition for magma mingling/mixing processes. 


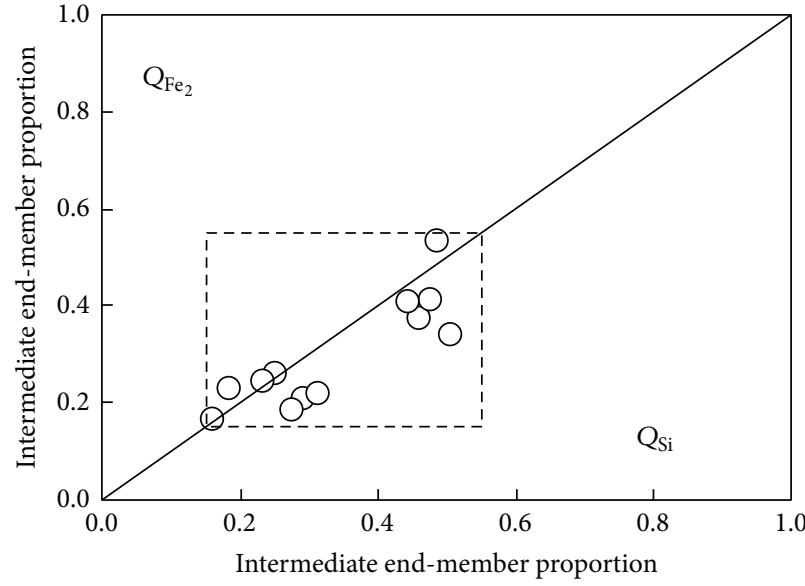

(a)

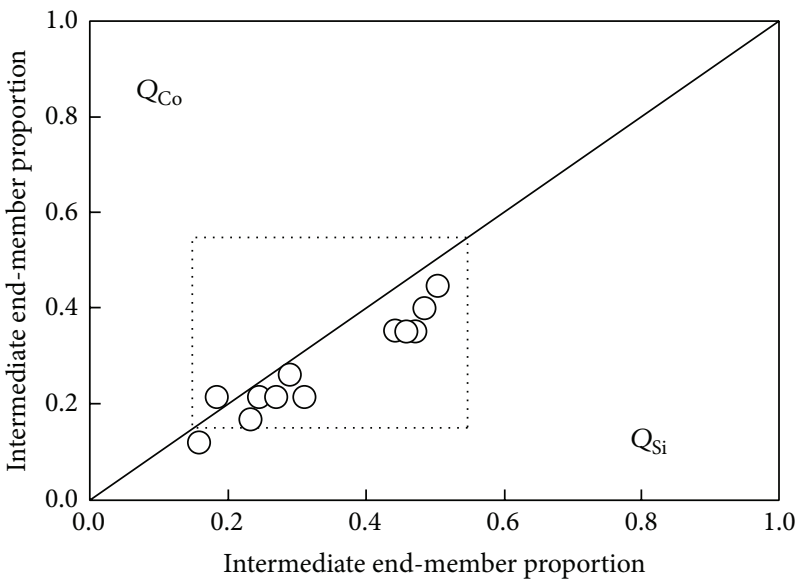

(c)

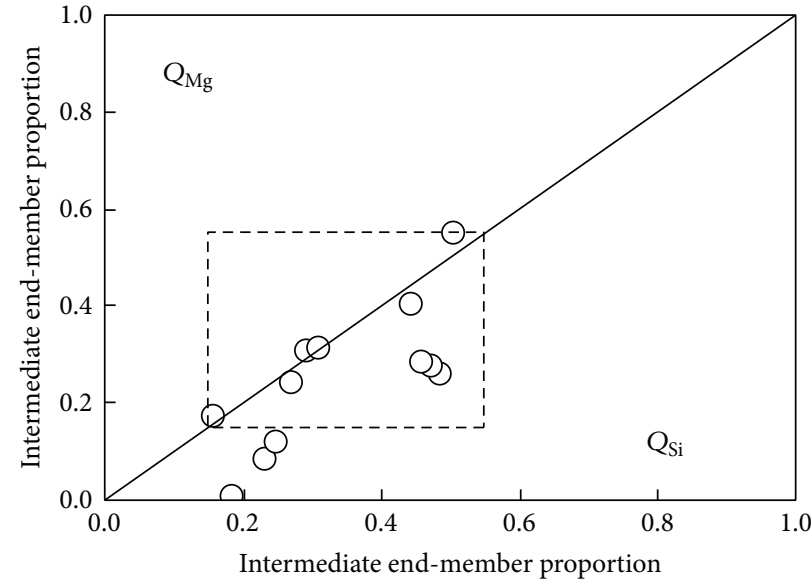

(b)

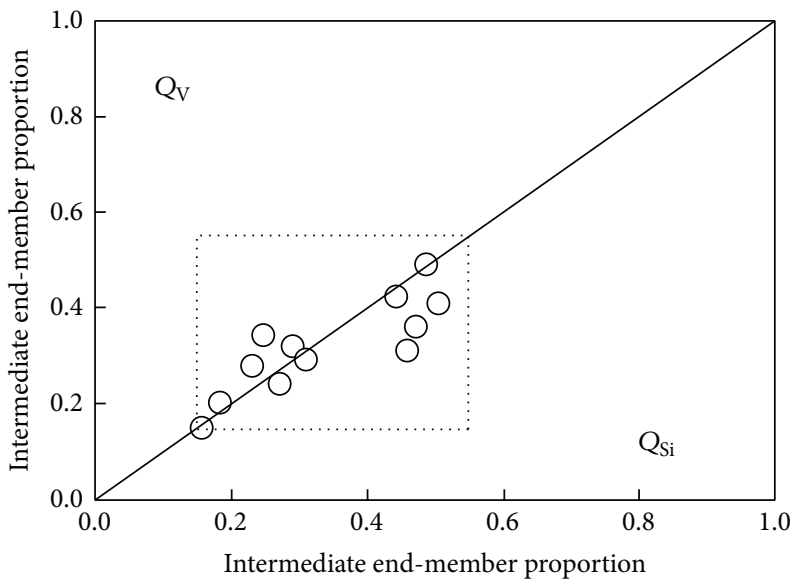

(d)

Figure 13: Mean proportions of mafic end-members in the comingled lavas from the Sierra de las Cruces, calculated using the mass-balance equation $Q_{A}^{i}=\left|C_{M}^{i}-C_{B}^{i}\right| /\left|C_{A}^{i}-C_{B}^{i}\right|[31]$ for $\left[\mathrm{SiO}_{2}\right]_{\mathrm{adj}},[\mathrm{FeO}]_{\mathrm{adj}},[\mathrm{MgO}]_{\mathrm{adj}}$, Co, and V. Proportions determined using $\left[\mathrm{SiO}_{2}\right]_{\mathrm{adj}}$ are plotted against those obtained using the other constituents. The diagonal line indicates perfect agreement between results.

The central SC sector did not include dacitic rocks without disequilibrium features. The $\mathrm{C} 1$ and $\mathrm{C} 3$ clusters (Figure 9(b) and Table 6) represent intermediate magmatic enclaves (SC35A and SC37A). The mixed lavas were more loosely grouped in two different clusters (C2 and C4), each of them with relatively lower levels of similarity in relation to a magmatic enclave. In comparison with the northern sector, the Euclidian linkage distances are relatively tiny: $\mathrm{Cl}$ $+\mathrm{C} 2$ clusters show a separation of $\sim 16$ units in relation to $\mathrm{C} 3+\mathrm{C} 4$ subgroups. The samples from southern and transition SC sectors separated into three sets (Figure 9(c) and Table 6) relating primarily to differences in $\left[\mathrm{SiO}_{2}\right]_{\mathrm{adj}}$, $\left[\mathrm{TiO}_{2}\right]_{\mathrm{adj}},\left[\mathrm{Fe}_{2} \mathrm{O}_{3}\right]_{\mathrm{adj}}$, and $[\mathrm{FeO}]_{\text {adj }}$ contents. The cluster ST1 includes magmatic enclaves (with a relatively small size of $\sim 2-4 \mathrm{~cm}$ ) and lavas with an intermediate composition $\left(\left[\mathrm{SiO}_{2}\right]_{\mathrm{adj}}=54-61 \%\right)$. This group shows a strong contrast in relation to the other clusters, as reflected by a Euclidean linkage distance of $\sim 20$. The majority of the dacitic mixed lavas were within the cluster ST2 $\left(\left[\mathrm{SiO}_{2}\right]_{\mathrm{adj}}=63-66 \%\right)$, whereas dacitic lavas without disequilibrium features conformed the cluster ST3 $\left(\left[\mathrm{SiO}_{2}\right]_{\mathrm{adj}}=65-69 \%\right)$.

6.4. Magma Mixing Process. Along the entire MVB, magma mixing/mingling has also been inferred as a significant mechanism in the petrologic evolution of stratovolcanoes (Tequila [60, 61]; Tancitaro [62]; Iztaccíhuatl [31]; Popocatépetl [32, 63, 64]; Telapón [65]), cinder cones and monogenetic fields (Sanganguey [66]; Chichinautzin [29]), or calderas (Amealco [67]; La Primavera [68]).

Particularly, seismic and gravity data have revealed the presence of partial melts at the base of the crust in the central MVB [69, 70]. These magmas might be stored at the base of the crust transferring heat to shallower crustal levels. The partial melting of the upper continental crust (depth at the base $\sim 10 \mathrm{~km}$ [71]) generated dacitic magma (e.g., N3-type cluster in the SC northern sector with an $F_{\mathrm{SC}}$ 
TABLE 6: Statistical parameters of major (\%wt) and trace (ppm) element composition for the Sierra de las Cruces magmatic clusters.

(a)

\begin{tabular}{|c|c|c|c|c|c|c|c|c|c|c|c|c|}
\hline \multirow{3}{*}{ Element } & \multicolumn{12}{|c|}{ Northern SC sector $(n=22)$} \\
\hline & \multicolumn{4}{|c|}{$\mathrm{N} 1(n=3)$} & \multicolumn{4}{|c|}{$\mathrm{N} 2(n=12)$} & \multicolumn{4}{|c|}{$\mathrm{N} 3(n=7)$} \\
\hline & $\bar{x}$ & Min. & Max. & $s$ & $\bar{x}$ & Min. & Max. & $s$ & $\bar{x}$ & Min. & Max. & $s$ \\
\hline$\left[\mathrm{SiO}_{2}\right]_{\mathrm{adj}}$ & 57.6 & 52.77 & 60.38 & 4.2 & 65.1 & 63.25 & 67.19 & 1.5 & 69.0 & 67.94 & 69.98 & 0.8 \\
\hline$\left[\mathrm{TiO}_{2}\right]_{\mathrm{adj}}$ & 1.1 & 0.71 & 1.79 & 0.6 & 0.69 & 0.59 & 0.82 & 0.07 & 0.522 & 0.486 & 0.552 & 0.031 \\
\hline$\left[\mathrm{Al}_{2} \mathrm{O}_{3}\right]_{\mathrm{adj}}$ & 16.5 & 15.38 & 18.46 & 1.7 & 16.2 & 15.54 & 16.83 & 0.5 & 15.9 & 15.11 & 16.49 & 0.5 \\
\hline$\left[\mathrm{Fe}_{2} \mathrm{O}_{3}\right]_{\mathrm{adj}}$ & 1.68 & 1.42 & 2.17 & 0.42 & 1.23 & 1.08 & 1.50 & 0.13 & 0.89 & 0.83 & 0.96 & 0.05 \\
\hline$[\mathrm{FeO}]_{\mathrm{adj}}$ & 5.1 & 4.05 & 7.23 & 1.8 & 3.08 & 2.70 & 3.76 & 0.33 & 2.22 & 2.08 & 2.39 & 0.11 \\
\hline$[\mathrm{MnO}]_{\mathrm{adj}}$ & 0.103 & 0.095 & 0.115 & 0.011 & 0.070 & 0.059 & 0.082 & 0.008 & 0.0574 & 0.053 & 0.060 & 0.0026 \\
\hline$[\mathrm{MgO}]_{\mathrm{adj}}$ & 6.7 & 6.23 & 7.19 & 0.5 & 2.5 & 1.15 & 4.17 & 0.8 & 1.11 & 0.698 & 1.577 & 0.30 \\
\hline$[\mathrm{CaO}]_{\mathrm{adj}}$ & 6.34 & 6.07 & 6.59 & 0.26 & 4.4 & 3.41 & 5.18 & 0.5 & 3.31 & 3.08 & 3.79 & 0.30 \\
\hline$\left[\mathrm{Na}_{2} \mathrm{O}\right]_{\mathrm{adj}}$ & 3.3 & 2.58 & 3.66 & 0.6 & 4.28 & 4.09 & 4.53 & 0.13 & 4.37 & 4.20 & 4.48 & 0.11 \\
\hline$\left[\mathrm{K}_{2} \mathrm{O}\right]_{\mathrm{adj}}$ & 1.442 & 1.419 & 1.462 & 0.022 & 2.23 & 1.84 & 2.61 & 0.30 & 2.51 & 2.29 & 2.80 & 0.19 \\
\hline$\left[\mathrm{P}_{2} \mathrm{O}_{5}\right]_{\mathrm{adj}}$ & 0.164 & 0.143 & 0.207 & 0.037 & 0.193 & 0.151 & 0.292 & 0.036 & 0.1344 & 0.130 & 0.141 & 0.0043 \\
\hline $\mathrm{La}$ & 14.0 & 12.3 & 16.2 & 2.0 & 20 & 13.6 & 34.8 & 6 & 19.8 & 15.1 & 23.6 & 3.2 \\
\hline $\mathrm{Eu}$ & 1.26 & 1.03 & 1.65 & 0.34 & 1.32 & 1.04 & 2.15 & 0.32 & 1.07 & 0.91 & 1.25 & 0.12 \\
\hline $\mathrm{Yb}$ & 1.90 & 1.60 & 2.20 & 0.30 & 1.76 & 1.26 & 2.70 & 0.40 & 1.52 & 1.16 & 1.70 & 0.22 \\
\hline $\mathrm{Ba}$ & 344 & 329 & 358 & 15 & 500 & 414 & 571 & 60 & 530 & 472 & 578 & 50 \\
\hline Co & 28 & 22 & 40 & 10 & 12.3 & 9.0 & 16.0 & 2.2 & 6.4 & 6.0 & 7.0 & 0.5 \\
\hline $\mathrm{Cr}$ & 290 & 230 & 360 & 70 & 90 & 60 & 160 & 34 & 32 & 20 & 40 & 7 \\
\hline $\mathrm{Hf}$ & 3.5 & 2.9 & 4.7 & 1.0 & 3.96 & 3.20 & 4.60 & 0.40 & 4.13 & 3.8 & 4.7 & 0.39 \\
\hline $\mathrm{Sr}$ & 459 & 445 & 474 & 15 & 520 & 431 & 601 & 60 & 410 & 351 & 566 & 70 \\
\hline Th & 2.87 & 2.80 & 3.00 & 0.12 & 5.3 & 3.6 & 6.7 & 1.2 & 6.0 & 3.4 & 8.2 & 1.4 \\
\hline $\mathrm{U}$ & 1.03 & 0.90 & 1.10 & 0.12 & 2.10 & 1.40 & 2.60 & 0.44 & 2.4 & 1.10 & 3.00 & 0.6 \\
\hline V & 160 & 123 & 216 & 50 & 92 & 75 & 109 & 10 & 60 & 52 & 73 & 7 \\
\hline $\mathrm{Y}$ & 20.7 & 18 & 22 & 2.3 & 19 & 12 & 34 & 6 & 16.1 & 12.0 & 22.0 & 3.2 \\
\hline $\mathrm{Zr}$ & 122 & 100 & 162 & 35 & 146 & 109 & 162 & 15 & 151 & 133 & 184 & 18 \\
\hline
\end{tabular}

(b)

\begin{tabular}{|c|c|c|c|c|c|c|c|c|c|c|}
\hline \multirow{3}{*}{ Element } & \multicolumn{10}{|c|}{ Central SC sector $(n=12)$} \\
\hline & \multirow{2}{*}{$\mathrm{C} 1(n=1)$} & \multicolumn{3}{|c|}{$\mathrm{C} 2(n=3)$} & \multirow{2}{*}{\multicolumn{2}{|c|}{$\mathrm{C} 3(n=1)$}} & \multirow[b]{2}{*}{$\bar{x}$} & \multicolumn{3}{|c|}{$\mathrm{C} 4(n=7)$} \\
\hline & & $\bar{x}$ & Min. & Max. & & & & Min. & Max. & $s$ \\
\hline$\left[\mathrm{SiO}_{2}\right]_{\mathrm{adj}}$ & 58.329 & 65.1 & 63.76 & 67.30 & 1.9 & 61.338 & 64.2 & 63.61 & 65.16 & 0.5 \\
\hline$\left[\mathrm{TiO}_{2}\right]_{\mathrm{adj}}$ & 1.109 & 0.71 & 0.63 & 0.77 & 0.08 & 0.791 & 0.69 & 0.65 & 0.78 & 0.05 \\
\hline$\left[\mathrm{Al}_{2} \mathrm{O}_{3}\right]_{\mathrm{adj}}$ & 17.043 & 16.3 & 15.89 & 16.84 & 0.5 & 17.400 & 16.46 & 15.99 & 17.10 & 0.40 \\
\hline$\left[\mathrm{Fe}_{2} \mathrm{O}_{3}\right]_{\mathrm{adj}}$ & 1.778 & 1.24 & 1.08 & 1.35 & 0.15 & 1.424 & 1.29 & 1.16 & 1.57 & 0.13 \\
\hline$[\mathrm{FeO}]_{\mathrm{adj}}$ & 5.079 & 3.11 & 2.70 & 3.36 & 0.36 & 4.068 & 3.23 & 2.90 & 3.91 & 0.33 \\
\hline$[\mathrm{MnO}]_{\mathrm{adj}}$ & 0.118 & 0.0783 & 0.0760 & 0.0810 & 0.0025 & 0.071 & 0.078 & 0.070 & 0.088 & 0.007 \\
\hline$[\mathrm{MgO}]_{\mathrm{adj}}$ & 3.663 & 2.2 & 1.51 & 3.06 & 0.8 & 3.918 & 3.0 & 2.31 & 3.61 & 0.5 \\
\hline$[\mathrm{CaO}]_{\mathrm{adj}}$ & 6.764 & 4.5 & 3.79 & 5.23 & 0.7 & 4.962 & 4.78 & 3.97 & 5.37 & 0.42 \\
\hline$\left[\mathrm{Na}_{2} \mathrm{O}\right]_{\mathrm{adj}}$ & 4.290 & 4.35 & 4.27 & 4.49 & 0.12 & 4.270 & 4.36 & 4.16 & 4.62 & 0.17 \\
\hline$\left[\mathrm{K}_{2} \mathrm{O}\right]_{\mathrm{adj}}$ & 1.497 & 2.163 & 2.136 & 2.180 & 0.023 & 1.592 & 1.77 & 1.66 & 1.95 & 0.11 \\
\hline$\left[\mathrm{P}_{2} \mathrm{O}_{5}\right]_{\mathrm{adj}}$ & 0.329 & 0.21 & 0.16 & 0.24 & 0.05 & 0.165 & 0.157 & 0.141 & 0.165 & 0.009 \\
\hline $\mathrm{La}$ & 26.8 & 26.0 & 23.6 & 27.7 & 2.2 & 11.1 & 14.3 & 12.1 & 19.1 & 2.3 \\
\hline $\mathrm{Eu}$ & 2.09 & 1.68 & 1.45 & 2.12 & 0.38 & 1.10 & 1.07 & 0.99 & 1.34 & 0.12 \\
\hline $\mathrm{Yb}$ & 2.30 & 1.87 & 1.60 & 2.10 & 0.25 & 1.50 & 1.48 & 1.30 & 1.70 & 0.16 \\
\hline
\end{tabular}


(b) Continued.

\begin{tabular}{|c|c|c|c|c|c|c|c|c|c|c|}
\hline \multirow{3}{*}{ Element } & \multicolumn{10}{|c|}{ Central SC sector $(n=12)$} \\
\hline & \multirow{2}{*}{$\mathrm{C} 1(n=1)$} & \multicolumn{3}{|c|}{$\mathrm{C} 2(n=3)$} & & \multirow{2}{*}{$\mathrm{C} 3(n=1)$} & \multirow[b]{2}{*}{$\bar{x}$} & \multicolumn{3}{|c|}{$\mathrm{C} 4(n=7)$} \\
\hline & & $\bar{x}$ & Min. & Max. & $s$ & & & Min. & Max. & $s$ \\
\hline $\mathrm{Ba}$ & 507 & 550 & 485 & 602 & 60 & 309 & 400 & 364 & 447 & 29 \\
\hline Co & 26 & 13.0 & 10.0 & 15.0 & 2.6 & 17 & 13.9 & 12.0 & 17.0 & 2.0 \\
\hline $\mathrm{Hf}$ & 3.90 & 3.73 & 3.60 & 3.90 & 0.15 & 3.20 & 3.59 & 3.40 & 3.70 & 0.11 \\
\hline $\mathrm{Sr}$ & 813 & 600 & 434 & 683 & 140 & 453 & 469 & 451 & 507 & 21 \\
\hline $\mathrm{U}$ & 1.70 & 1.94 & 1.80 & 2.02 & 0.12 & 1.20 & 1.38 & 1.00 & 1.70 & 0.22 \\
\hline V & 150 & 89 & 71 & 103 & 16 & 100 & 88 & 81 & 99 & 7 \\
\hline $\mathrm{Y}$ & 24.0 & 19.7 & 17.0 & 21.0 & 2.3 & 14.0 & 15.6 & 13.0 & 20.0 & 2.2 \\
\hline $\mathrm{Zr}$ & 138 & 137.7 & 137 & 139 & 1.2 & 114 & 131 & 123 & 138 & 6 \\
\hline
\end{tabular}

(c)

\begin{tabular}{|c|c|c|c|c|c|c|c|c|c|c|c|c|}
\hline \multirow{3}{*}{ Element } & \multicolumn{12}{|c|}{ Southern and transition SC sectors $(n=22)$} \\
\hline & \multicolumn{4}{|c|}{$\operatorname{ST} 1(n=8)$} & \multicolumn{4}{|c|}{$\mathrm{ST} 2(n=9)$} & \multicolumn{4}{|c|}{ ST3 $(n=5)$} \\
\hline & $\bar{x}$ & Min. & Max. & $s$ & $\bar{x}$ & Min. & Max. & $s$ & $\bar{x}$ & Min. & Max. & $s$ \\
\hline$\left[\mathrm{SiO}_{2}\right]_{\mathrm{adj}}$ & 59.3 & 54.03 & 61.83 & 2.5 & 64.6 & 63.30 & 65.97 & 0.9 & 67.4 & 64.92 & 69.41 & 1.8 \\
\hline$\left[\mathrm{TiO}_{2}\right]_{\mathrm{adj}}$ & 1.09 & 0.84 & 1.56 & 0.23 & 0.72 & 0.63 & 0.92 & 0.09 & 0.61 & 0.54 & 0.66 & 0.05 \\
\hline$\left[\mathrm{Al}_{2} \mathrm{O}_{3}\right]_{\mathrm{adj}}$ & 18.1 & 15.68 & 22.04 & 2.1 & 16.7 & 15.76 & 17.75 & 0.6 & 16.26 & 15.95 & 17.04 & 0.44 \\
\hline$\left[\mathrm{Fe}_{2} \mathrm{O}_{3}\right]_{\mathrm{adj}}$ & 1.59 & 1.11 & 2.10 & 0.28 & 1.28 & 1.11 & 1.44 & 0.12 & 1.03 & 0.86 & 1.17 & 0.13 \\
\hline$[\mathrm{FeO}]_{\mathrm{adj}}$ & 4.5 & 3.18 & 5.99 & 0.8 & 3.21 & 2.78 & 3.61 & 0.30 & 2.58 & 2.14 & 2.92 & 0.33 \\
\hline$[\mathrm{MnO}]_{\mathrm{adj}}$ & 0.105 & 0.079 & 0.138 & 0.018 & 0.071 & 0.052 & 0.088 & 0.014 & 0.054 & 0.022 & 0.079 & 0.021 \\
\hline$[\mathrm{MgO}]_{\mathrm{adj}}$ & 4.0 & 2.48 & 6.78 & 1.7 & 2.3 & 1.41 & 3.51 & 0.7 & 1.6 & 0.49 & 2.81 & 1.0 \\
\hline$[\mathrm{CaO}]_{\mathrm{adj}}$ & 5.6 & 2.96 & 7.51 & 1.4 & 4.53 & 4.04 & 5.11 & 0.39 & 3.9 & 3.23 & 4.87 & 0.7 \\
\hline$\left[\mathrm{Na}_{2} \mathrm{O}\right]_{\mathrm{adj}}$ & 4.00 & 3.02 & 4.39 & 0.44 & 4.51 & 4.28 & 4.77 & 0.14 & 4.34 & 4.05 & 4.59 & 0.26 \\
\hline$\left[\mathrm{K}_{2} \mathrm{O}\right]_{\mathrm{adj}}$ & 1.33 & 0.78 & 2.01 & 0.43 & 1.84 & 1.63 & 2.09 & 0.15 & 2.19 & 1.94 & 2.35 & 0.15 \\
\hline$\left[\mathrm{P}_{2} \mathrm{O}_{5}\right]_{\mathrm{adj}}$ & 0.27 & 0.14 & 0.64 & 0.16 & 0.17 & 0.11 & 0.25 & 0.05 & 0.155 & 0.135 & 0.177 & 0.018 \\
\hline $\mathrm{La}$ & 18 & 11.5 & 34.8 & 7 & 14.5 & 11.1 & 18.2 & 2.2 & 19.0 & 16.9 & 25.2 & 3.5 \\
\hline $\mathrm{Eu}$ & 1.6 & 1.13 & 2.67 & 0.5 & 1.13 & 1.04 & 1.34 & 0.09 & 1.24 & 1.10 & 1.49 & 0.16 \\
\hline $\mathrm{Yb}$ & 2.0 & 1.3 & 2.7 & 0.5 & 1.52 & 1.01 & 2.30 & 0.34 & 1.74 & 1.40 & 2.10 & 0.30 \\
\hline $\mathrm{Ba}$ & 420 & 276 & 660 & 150 & 416 & 369 & 471 & 37 & 469 & 434 & 499 & 25 \\
\hline $\mathrm{Co}$ & 19 & 10 & 29 & 5 & 12.9 & 10.0 & 20.0 & 3.3 & 8.8 & 5.0 & 12.0 & 2.9 \\
\hline Hf & 4.2 & 3.4 & 5.4 & 0.7 & 3.68 & 3.30 & 4.10 & 0.24 & 3.90 & 3.60 & 4.20 & 0.28 \\
\hline Sr & 500 & 303 & 763 & 130 & 474 & 416 & 533 & 40 & 410 & 364 & 495 & 50 \\
\hline $\mathrm{U}$ & 1.04 & 0.60 & 1.32 & 0.28 & 1.50 & 0.80 & 2.00 & 0.34 & 2.0 & 1.5 & 3.1 & 0.6 \\
\hline $\mathrm{V}$ & 110 & 39 & 150 & 33 & 83 & 59 & 96 & 12 & 69 & 51 & 84 & 12 \\
\hline Y & 23 & 13.0 & 32.2 & 6 & 14.9 & 11.0 & 17.0 & 1.8 & 22 & 16 & 36 & 8 \\
\hline $\mathrm{Zr}$ & 162 & 129 & 237 & 38 & 136 & 125 & 149 & 8 & 148 & 126 & 164 & 14 \\
\hline
\end{tabular}

average composition; Figures 9(a), 11, and 12). This relatively low-temperature magma was stored in the shallow crust. Subsequently, a small volume of andesitic magma (e.g., N1type cluster with an $I_{\mathrm{SC}}$ average composition; Figures 11 and $12)$, probably generated at lower crust (depth $25-45 \mathrm{~km} \mathrm{[71]),}$ intruded in the dacitic magma chamber, losing heat to the surroundings and starting to vesiculate, prior to effusion.

This interaction process between dacitic-andesitic magmas occurred continuously in the SC during a period of $\sim 3 \mathrm{Ma}$. Mass-balance analysis (model A) for SC northern sector has showed that from $\sim 11$ to $58 \%$ of the andesitic end-member was partially mixed with the felsic magma, as observed in Q diagrams (Figure 13). Repeated injections of this andesitic magma into the dacitic magma caused mingling events in the central and the southern SC sectors.

Average value and their uncertainty for northern SC compositional poles $\left(I_{\mathrm{SC}}\right.$ and $\left.F_{\mathrm{SC}}\right)$ have been included in the major-element Harker diagrams (Figure 11). Also, for comparison, the end-member components modeled for the magma mixing process in Popocatepetl $\left(M_{\mathrm{PO}}\right.$, mafic and $F_{\mathrm{PO}}$, felsic [32]) and Iztaccihuatl $\left(M_{\mathrm{IZ}}\right.$, mafic and $F_{\mathrm{IZ}}$, felsic [31]), two stratovolcanoes located behind the SC volcanic range, have been incorporated in these diagrams.

Magma mixing evaluation in SC northern sector, using the alternative approach proposed by Zou [33] (model B), resulted in hyperbolic mixing models for several ratio-ratio 
TABLE 7: $A-D$ coefficients of hyperbolic Equations (10a)-(10d) for magma mixing between N1 and N3 end-members (northern Sierra de las Cruces sector), generated applying the mass-balance model by Zou [33].

\begin{tabular}{|c|c|c|c|c|c|c|}
\hline \multirow{2}{*}{ Ratio-ratio system } & \multirow{2}{*}{$y$-axis } & \multirow{2}{*}{$x$-axis } & \multicolumn{4}{|c|}{ Hyperbolic mixing equation coefficients } \\
\hline & & & $A$ & B & C & $D$ \\
\hline 1 & {$\left[\mathrm{Fe}_{2} \mathrm{O}_{3}\right]_{\mathrm{adj}} /\left[\mathrm{K}_{2} \mathrm{O}\right]_{\mathrm{adj}}$} & {$\left[\mathrm{SiO}_{2}\right]_{\mathrm{adj}} /[\mathrm{FeO}]_{\mathrm{adj}}$} & 0.81 & -9.60 & 45.1 & 64.7 \\
\hline 2 & {$\left[\mathrm{Fe}_{2} \mathrm{O}_{3}\right]_{\mathrm{adj}} /\left[\mathrm{Al}_{2} \mathrm{O}_{3}\right]_{\mathrm{adj}}$} & {$\left[\mathrm{SiO}_{2}\right]_{\mathrm{adj}} /[\mathrm{FeO}]_{\mathrm{adj}}$} & 0.81 & -44.5 & -223 & 64.7 \\
\hline 3 & $\mathrm{~V} / \mathrm{Ba}$ & {$\left[\mathrm{SiO}_{2}\right]_{\mathrm{adj}} /[\mathrm{FeO}]_{\mathrm{adj}}$} & -49.2 & -1939 & 6792 & 7584 \\
\hline 4 & $\mathrm{~V} / \mathrm{U}$ & {$\left[\mathrm{SiO}_{2}\right]_{\mathrm{adj}} /[\mathrm{FeO}]_{\mathrm{adj}}$} & -49.2 & -9.95 & 67.2 & 7584 \\
\hline 5 & $\mathrm{Cr} / \mathrm{Th}$ & {$\left[\mathrm{SiO}_{2}\right]_{\mathrm{adj}} /[\mathrm{FeO}]_{\mathrm{adj}}$} & -481 & -24.2 & 148 & 18168 \\
\hline 6 & $\mathrm{Cr} / \mathrm{Yb}$ & {$\left[\mathrm{SiO}_{2}\right]_{\mathrm{adj}} /[\mathrm{FeO}]_{\mathrm{adj}}$} & -481 & -3.53 & -43.5 & 18167 \\
\hline 7 & {$[\mathrm{MgO}]_{\mathrm{adj}} / \mathrm{Eu}$} & {$\left[\mathrm{SiO}_{2}\right]_{\mathrm{adj}} / \mathrm{V}$} & -224 & -96 & -25.3 & 398 \\
\hline 8 & {$[\mathrm{MgO}]_{\mathrm{adj}} / \mathrm{Hf}$} & {$\left[\mathrm{SiO}_{2}\right]_{\mathrm{adj}} / \mathrm{V}$} & -225 & -451 & -3.61 & 398 \\
\hline 9 & {$[\mathrm{CaO}]_{\mathrm{adj}} / \mathrm{Ta}$} & {$\left[\mathrm{SiO}_{2}\right]_{\mathrm{adj}} / \mathrm{V}$} & 149 & -66 & 12.7 & 247 \\
\hline 10 & {$[\mathrm{CaO}]_{\mathrm{adj}} / \mathrm{Zr}$} & {$\left[\mathrm{SiO}_{2}\right]_{\mathrm{adj}} / \mathrm{V}$} & 149 & -16840 & 280 & 247 \\
\hline 11 & $\mathrm{Ga} / \mathrm{Ni}$ & {$\left[\mathrm{SiO}_{2}\right]_{\mathrm{adj}} / \mathrm{V}$} & 2038 & 2600 & -5518 & 167 \\
\hline 12 & $\mathrm{Ga} / \mathrm{Rb}$ & {$\left[\mathrm{SiO}_{2}\right]_{\mathrm{adj}} / \mathrm{V}$} & 2037 & -8280 & 1685 & 167 \\
\hline
\end{tabular}

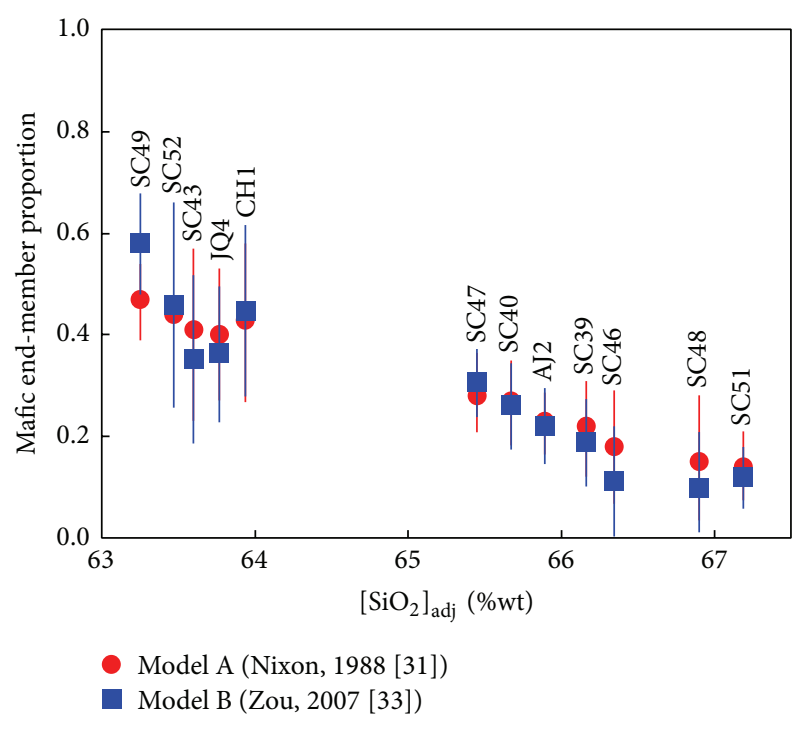

FIGURE 14: Mean \pm one standard deviation of intermediate endmember proportions (N1) in the comingled lavas (N2) from the Sierra de las Cruces northern sector versus $\left[\mathrm{SiO}_{2}\right]_{\text {adj }}$, produced by the incomplete mixing of $\mathrm{N} 1$ and $\mathrm{N} 3$ end-members: (a) red filled circle and line calculated $(n=11)$ from the mass-balance approach proposed by Nixon [31] and (b) blue filled square and line calculated $(n=12)$ from the mass-balance approach proposed by Zou [33].

systems involving major and trace elements (Table 7). Mixing models (Figures 15-16) have yielded end-member compositions that are close to the samples of N1 and N3 groups. According to $F$ test and $t$-test, no significant differences exist between the sample compositions and the modeled endmember compositions. Additionally, these models suggest that the comingled lava compositions can be explained by mixing N1: N3 end-members from $0.11: 0.89$ to $0.58: 0.42$ (Figure 14). Clearly, these results are comparable to those obtained applying the mass-balance model A (Figure 14).

\section{Conclusions}

(1) Statistical and mass-balance techniques have been successfully used as igneous petrological tools.

(2) From multidimensional discrimination diagrams, a transitional continental arc to within-plate setting can be tentatively considered as a consistent tectonic framework for the Sierra de las Cruces volcanic range. Felsic volcanism was derived from the upper continental crust, with a continental arc affinity, whereas the intermediate magmas (spheroidal enclaves) were generated in deeper levels of the crust in an extensional setting.

(3) Discordancy and significance tests have revealed that evidence does not exist of a geochemical contribution of several major and trace elements from the subducting Cocos plate to the SC magma genesis. The definitive validity of this hypothesis necessary requires, at least, a similar behavior for volatile components (water, $\mathrm{CO}_{2}, \mathrm{SO}_{2}$, etc.) and also fluid-linked isotopic species (e.g., Li, B). However, this information has not been available in this work.

(4) A cluster analysis confirms the existence of three lithological groups in the SC: (a) dacitic lavas without disequilibrium features, (b) intermediate magmatic enclaves, and (c) comingled lavas, produced by the incomplete mixing between the other lithological clusters.

(5) Mass-balance models have revealed that the chemical composition of the comingled lavas from the SC northern sector can be reproduced with $\sim 11$ to $58 \%$ of the andesitic end-member.

\section{Conflict of Interests}

The author declares that there is no conflict of interests regarding the publication of this paper. 


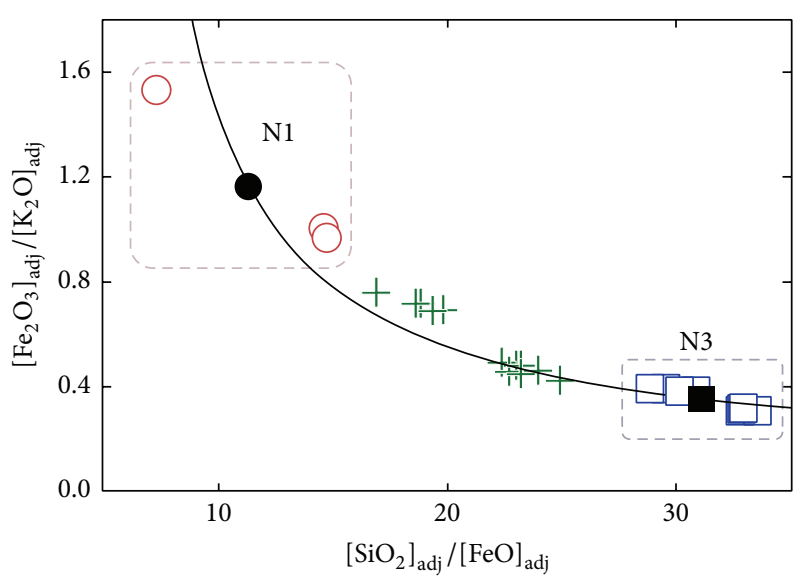

(a)

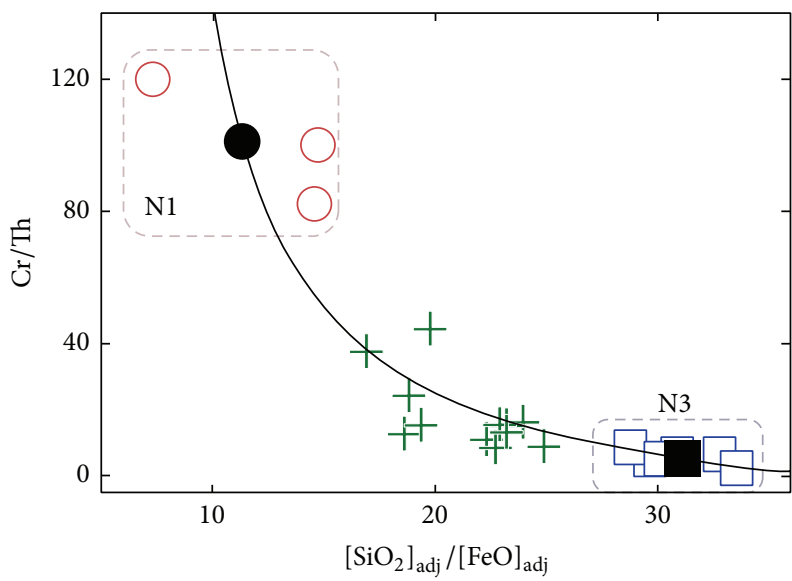

(c)

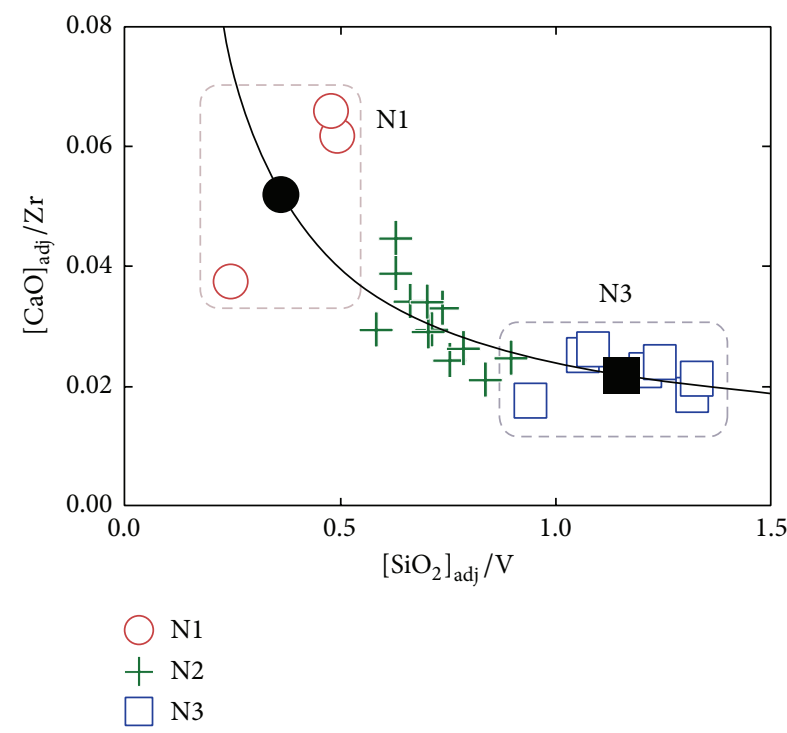

(e)

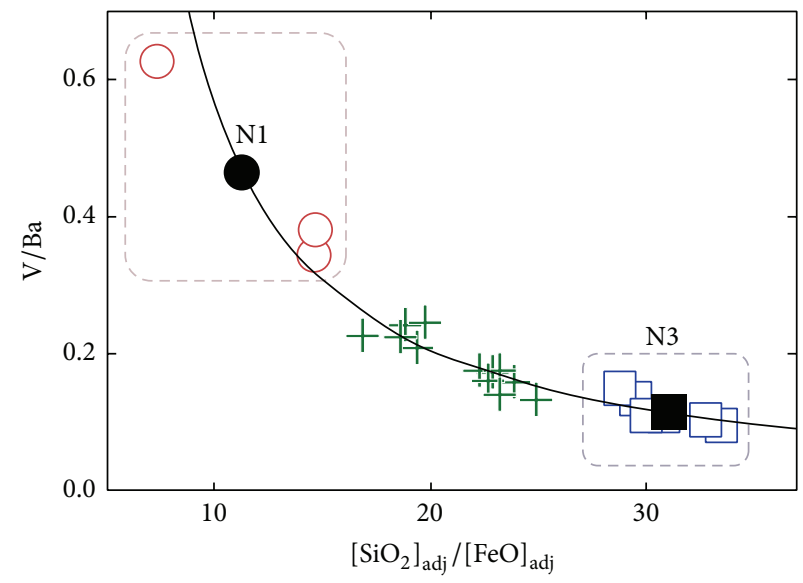

(b)

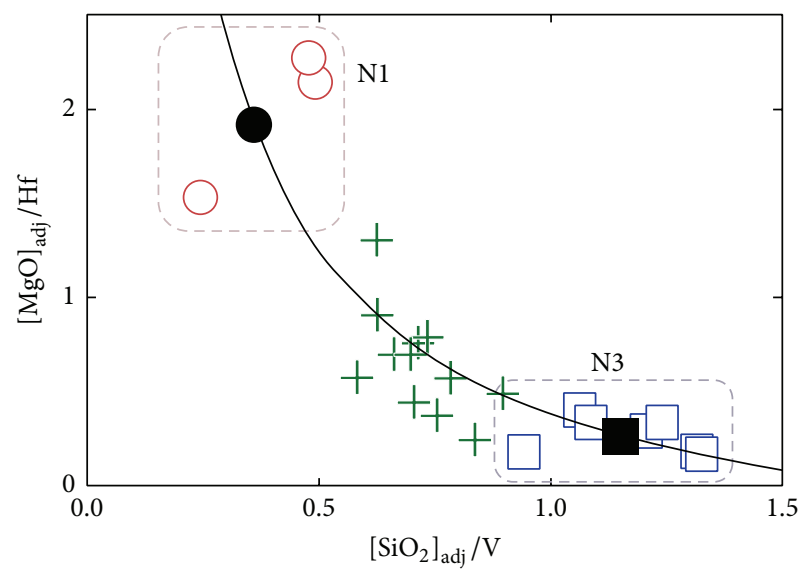

(d)

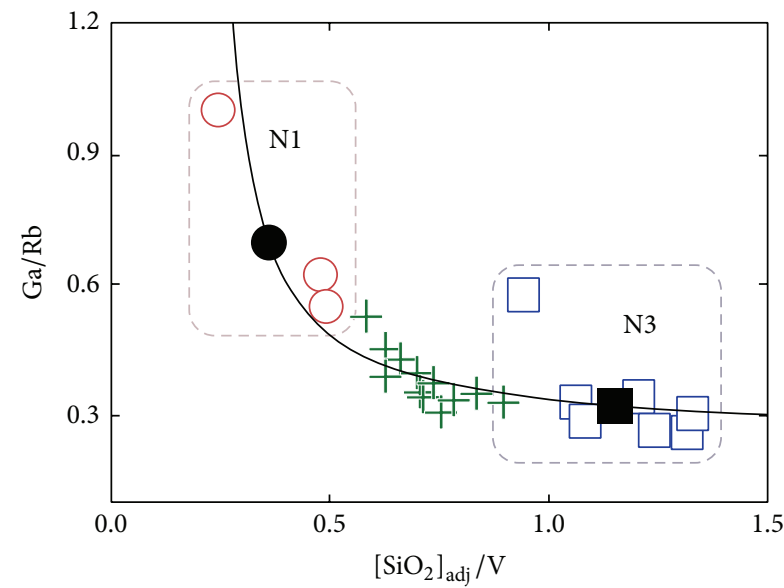

$\bigcirc \mathrm{N} 1$
$+\mathrm{N} 2$
$\square \mathrm{N} 3$

(f)

FiguRE 15: Geochemical ratio-ratio diagrams of the Sierra de las Cruces northern sector that include hyperbolic mixing models (black solid line) between average intermediate $\mathrm{N} 1$ lavas (black filled circle, $I_{\mathrm{SC}}$ ) and average felsic N3 lavas (black filled square, $F_{\mathrm{SC}}$ ): (a) $\left[\mathrm{Fe}_{2} \mathrm{O}_{3}\right]_{\mathrm{adj}} /\left[\mathrm{K}_{2} \mathrm{O}\right]_{\mathrm{adj}}-\left[\mathrm{SiO}_{2}\right]_{\mathrm{adj}} /[\mathrm{FeO}]_{\mathrm{adj}} ;(\mathrm{b}) \mathrm{V} / \mathrm{Ba}-\left[\mathrm{SiO}_{2}\right]_{\mathrm{adj}} /[\mathrm{FeO}]_{\mathrm{adj}} ;(\mathrm{c}) \mathrm{Cr} / \mathrm{Th}-\left[\mathrm{SiO}_{2}\right]_{\mathrm{adj}} /[\mathrm{FeO}]_{\mathrm{adj}} ;(\mathrm{d})[\mathrm{MgO}]_{\mathrm{adj}} / \mathrm{Hf}-[\mathrm{SiO}]_{\mathrm{adj}} / \mathrm{V} ;(\mathrm{e})$ $[\mathrm{CaO}]_{\mathrm{adj}} / \mathrm{Zr}-\left[\mathrm{SiO}_{2}\right]_{\mathrm{adj}} / \mathrm{V}$; (f) $\mathrm{Ga} / \mathrm{Rb}-\left[\mathrm{SiO}_{2}\right]_{\mathrm{adj}} / \mathrm{V}$. Hyperbolic mixing equations, generated following the mass-balance approach by Zou [33], are reported in Table 7. 


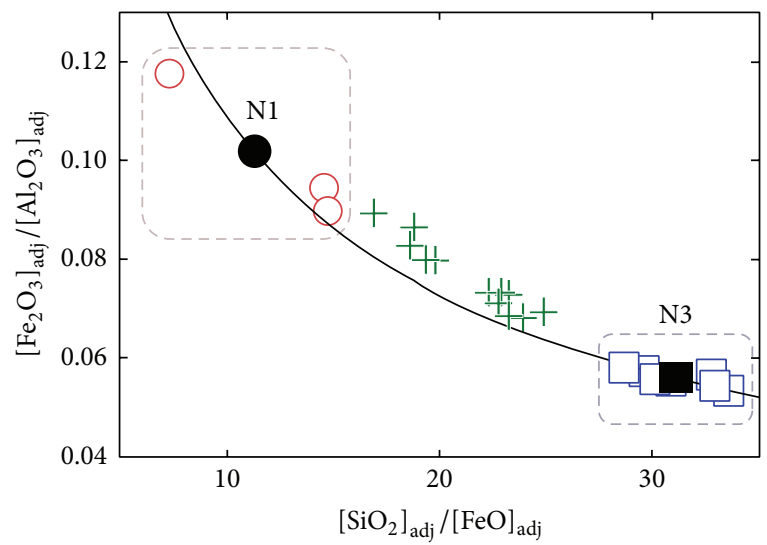

(a)

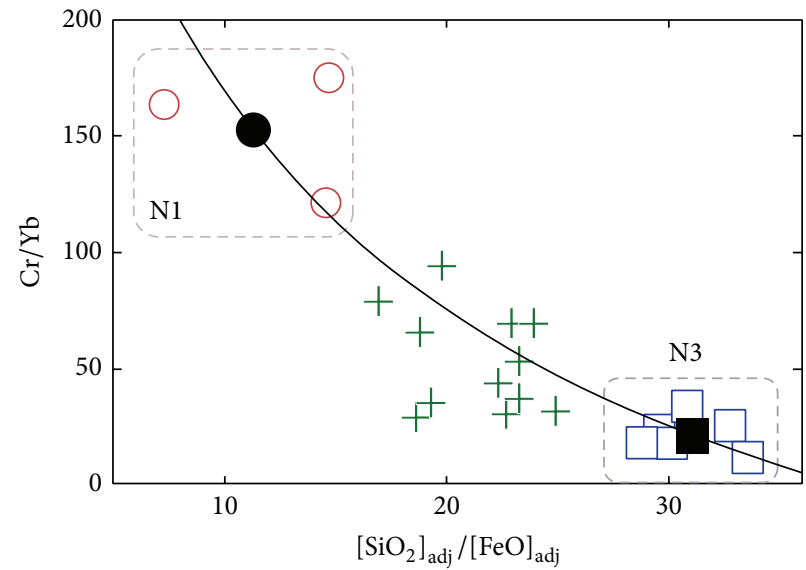

(c)

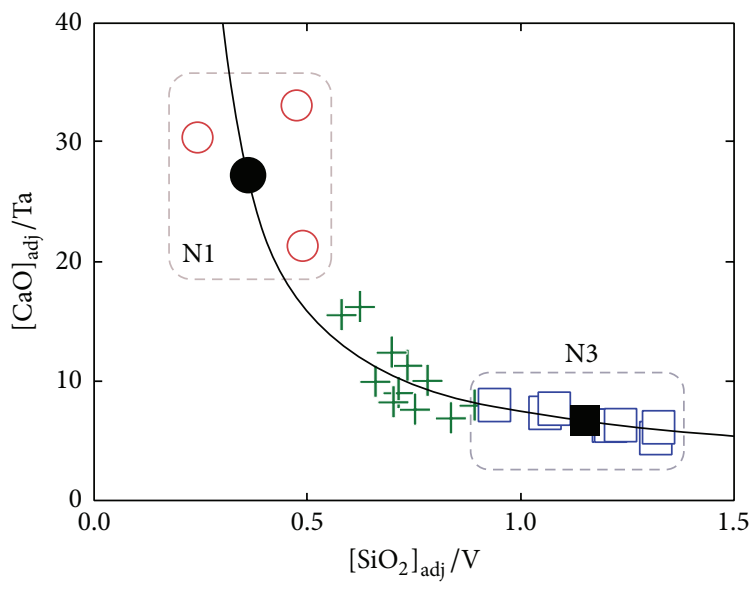

$\bigcirc \mathrm{N} 1$
$+\mathrm{N} 2$
$\square \mathrm{N} 3$

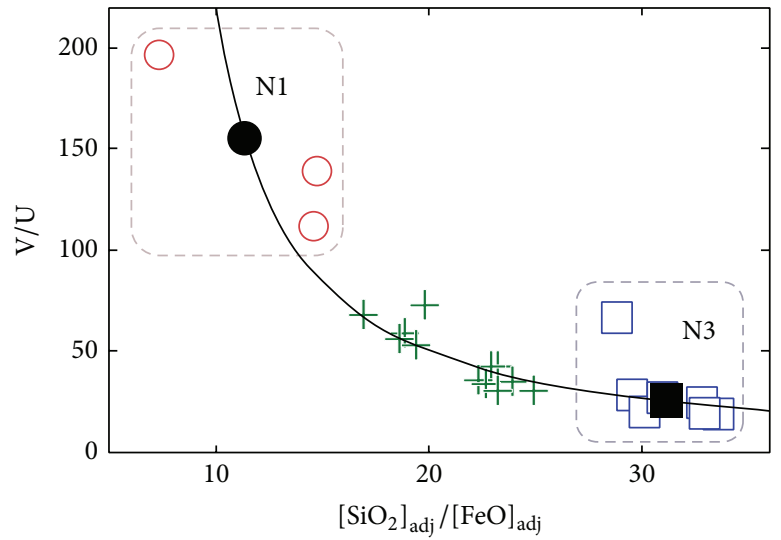

(b)

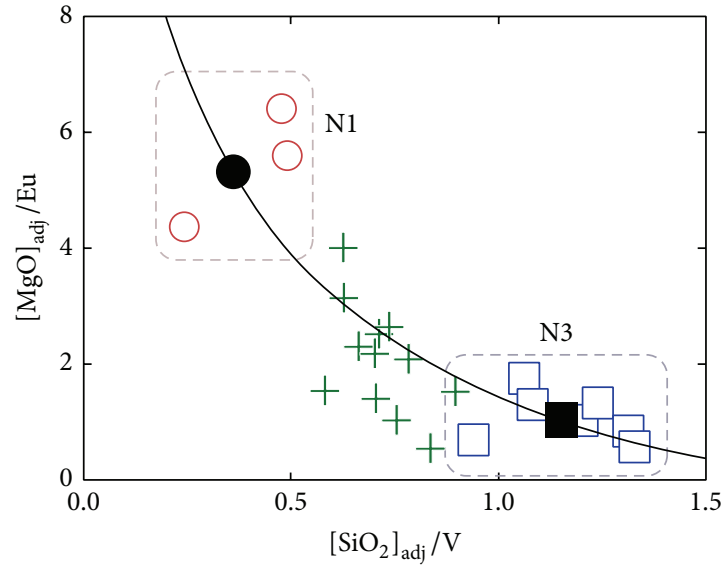

(d)

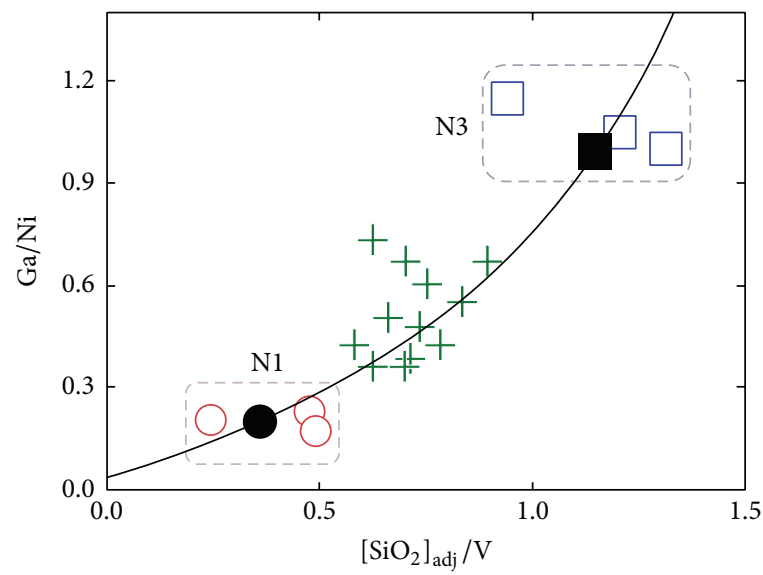

$\bigcirc \mathrm{N} 1$

$+\mathrm{N} 2$

N3

(e)

(f)

Figure 16: Geochemical ratio-ratio diagrams of the Sierra de las Cruces northern sector that include hyperbolic mixing models (black solid line) between average intermediate $\mathrm{N} 1$ lavas (black filled circle, $I_{\mathrm{SC}}$ ) and average felsic $\mathrm{N} 3$ lavas (black filled square, $F_{\mathrm{SC}}$ ): (a) $\left[\mathrm{Fe}_{2} \mathrm{O}_{3}\right]_{\mathrm{adj}} /\left[\mathrm{Al}_{2} \mathrm{O}_{3}\right]_{\mathrm{adj}}-\left[\mathrm{SiO}_{2}\right]_{\mathrm{adj}} /[\mathrm{FeO}]_{\mathrm{adj}} ;$ (b) $\mathrm{V} / \mathrm{U}-\left[\mathrm{SiO}_{2}\right]_{\mathrm{adj}} /[\mathrm{FeO}]_{\mathrm{adj}} ;(\mathrm{c}) \mathrm{Cr} / \mathrm{Yb}-\left[\mathrm{SiO}_{2}\right]_{\mathrm{adj}} /[\mathrm{FeO}]_{\mathrm{adj}} ;(\mathrm{d})[\mathrm{MgO}]_{\mathrm{adj}} / \mathrm{Eu}-[\mathrm{SiO}]_{\mathrm{adj}} / \mathrm{V} ;(\mathrm{e})$ $[\mathrm{CaO}]_{\mathrm{adj}} / \mathrm{Ta}-\left[\mathrm{SiO}_{2}\right]_{\mathrm{adj}} / \mathrm{V}$; (f) $\mathrm{Ga} / \mathrm{Ni}-\left[\mathrm{SiO}_{2}\right]_{\mathrm{adj}} / \mathrm{V}$. Hyperbolic mixing equations, generated following the mass-balance approach by Zou [33], are reported in Table 7 . 
TABLE 8: Results of the application of significance tests of Fisher $F$ and Student $t$ to the acid rock data from the Sierra de las Cruces at the strict 99\% confidence level (CL) prepared from Excel output of UDASYS [37].

\begin{tabular}{|c|c|c|c|c|c|c|c|c|c|c|c|c|c|}
\hline Element & Group A & Group B & $n_{\mathrm{A}}$ & $n_{\mathrm{B}}$ & Df & Sign & $t_{-}$calc & $\begin{array}{c}t \text { _criteria } \\
\text { One- } \\
\text { sided } \\
\end{array}$ & $\begin{array}{l}\mathrm{H}_{0} \\
\text { One- } \\
\text { sided }\end{array}$ & $\begin{array}{l}\text { CL_t } \\
\text { One- } \\
\text { sided }\end{array}$ & $\begin{array}{c}t_{\text {_criteria }} \\
\text { Two- } \\
\text { sided } \\
\end{array}$ & $\begin{array}{l}\mathrm{H}_{0} \\
\text { Two- } \\
\text { sided } \\
\end{array}$ & $\begin{array}{l}\text { CL_t } t \\
\text { Two- } \\
\text { sided }\end{array}$ \\
\hline \multicolumn{14}{|l|}{$\begin{array}{l}\text { (a) Major } \\
\text { elements }\end{array}$} \\
\hline$\left[\mathrm{SiO}_{2}\right]_{\mathrm{adj}}$ & Gr 2 & Gr 1 & 32 & 11 & 41.0 & - & 0.471 & 2.421 & True & $<50$ & 2.701 & True & $<50$ \\
\hline$\left[\mathrm{TiO}_{2}\right]_{\text {adj }}$ & Gr 2 & Gr 1 & 32 & 11 & 41.0 & - & 0.509 & 2.421 & True & $<50$ & 2.701 & True & $<50$ \\
\hline$\left[\mathrm{Al}_{2} \mathrm{O}_{3}\right]_{\mathrm{adj}}$ & Gr 2 & Gr 1 & 32 & 11 & 41.0 & - & 0.687 & 2.421 & True & 72.5 & 2.701 & True & 44.9 \\
\hline$\left[\mathrm{Fe}_{2} \mathrm{O}_{3}\right]_{\text {adj }}$ & Gr 2 & Gr 1 & 32 & 11 & 41.0 & + & 0.571 & 2.421 & True & $<50$ & 2.701 & True & $<50$ \\
\hline$[\mathrm{FeO}]_{\mathrm{adj}}$ & Gr 2 & Gr 1 & 32 & 11 & 41.0 & + & 0.575 & 2.421 & True & $<50$ & 2.701 & True & $<50$ \\
\hline$[\mathrm{MnO}]_{\mathrm{adj}}$ & Gr 2 & Gr 1 & 32 & 11 & 12.0 & + & 1.599 & 2.680 & True & 93.2 & 3.053 & True & 86.4 \\
\hline$[\mathrm{MgO}]_{\mathrm{adj}}$ & Gr 2 & Gr 1 & 32 & 11 & 41.0 & + & 0.612 & 2.421 & True & $<50$ & 2.701 & True & $<50$ \\
\hline$[\mathrm{CaO}]_{\mathrm{adj}}$ & Gr 2 & Gr 1 & 32 & 11 & 41.0 & + & 0.602 & 2.421 & True & $<50$ & 2.701 & True & $<50$ \\
\hline$\left[\mathrm{Na}_{2} \mathrm{O}\right]_{\mathrm{adj}}$ & Gr 2 & Gr 1 & 32 & 11 & 41.0 & - & 1.877 & 2.421 & True & 96.6 & 2.701 & True & 93.2 \\
\hline$\left[\mathrm{K}_{2} \mathrm{O}\right]_{\mathrm{adj}}$ & Gr 2 & Gr 1 & 32 & 11 & 41.0 & + & 0.917 & 2.421 & True & 81.7 & 2.701 & True & 63.3 \\
\hline$\left[\mathrm{P}_{2} \mathrm{O}_{5}\right]_{\mathrm{adj}}$ & Gr 2 & Gr 1 & 31 & 11 & 40.0 & + & 0.431 & 2.423 & True & $<50$ & 2.705 & True & $<50$ \\
\hline \multicolumn{14}{|l|}{$\begin{array}{l}\text { (b) Trace } \\
\text { elements }\end{array}$} \\
\hline $\mathrm{La}$ & Gr 2 & Gr 1 & 32 & 10 & 39.1 & + & 2.661 & 2.425 & False & 99.4 & 2.707 & True & 98.9 \\
\hline $\mathrm{Ce}$ & Gr 2 & Gr 1 & 32 & 11 & 41.0 & + & 1.915 & 2.421 & True & 96.9 & 2.701 & True & 93.8 \\
\hline $\operatorname{Pr}$ & Gr 2 & Gr 1 & 32 & 10 & 40.0 & + & 2.507 & 2.423 & False & 99.2 & 2.705 & True & 98.4 \\
\hline $\mathrm{Nd}$ & Gr 2 & Gr 1 & 31 & 10 & 38.9 & + & 2.117 & 2.426 & True & 98.0 & 2.708 & True & 95.9 \\
\hline $\mathrm{Sm}$ & Gr 2 & Gr 1 & 31 & 10 & 37.9 & + & 1.454 & 2.429 & True & 92.3 & 2.713 & True & 84.6 \\
\hline $\mathrm{Eu}$ & Gr 2 & Gr 1 & 30 & 10 & 37.6 & + & 0.909 & 2.430 & True & 81.4 & 2.713 & True & 62.8 \\
\hline $\mathrm{Gd}$ & Gr 2 & Gr 1 & 31 & 11 & 40.0 & + & 0.096 & 2.423 & True & $<50$ & 2.704 & True & $<50$ \\
\hline $\mathrm{Tb}$ & Gr 2 & Gr 1 & 31 & 11 & 40.0 & + & 0.144 & 2.423 & True & $<50$ & 2.704 & True & $<50$ \\
\hline Dy & Gr 2 & Gr 1 & 31 & 11 & 40.0 & + & 0.331 & 2.423 & True & $<50$ & 2.704 & True & $<50$ \\
\hline Но & Gr 2 & Gr 1 & 31 & 11 & 40.0 & + & 0.503 & 2.423 & True & $<50$ & 2.704 & True & $<50$ \\
\hline Er & Gr 2 & Gr 1 & 31 & 11 & 40.0 & + & 0.147 & 2.423 & True & $<50$ & 2.704 & True & $<50$ \\
\hline $\mathrm{Tm}$ & Gr 2 & Gr 1 & 31 & 11 & 40.0 & + & 0.243 & 2.423 & True & $<50$ & 2.704 & True & $<50$ \\
\hline $\mathrm{Yb}$ & Gr 2 & Gr 1 & 31 & 11 & 40.0 & + & 0.590 & 2.423 & True & $<50$ & 2.704 & True & $<50$ \\
\hline $\mathrm{Lu}$ & Gr 2 & Gr 1 & 32 & 11 & 41.0 & + & 0.996 & 2.421 & True & 83.7 & 2.701 & True & 67.5 \\
\hline $\mathrm{Ba}$ & Gr 2 & Gr 1 & 32 & 11 & 41.0 & + & 1.433 & 2.421 & True & 92.0 & 2.701 & True & 84.0 \\
\hline $\mathrm{Be}$ & Gr 2 & Gr 1 & 31 & 9 & 38.0 & + & 1.070 & 2.429 & True & 85.5 & 2.712 & True & 70.9 \\
\hline Co & Gr 2 & Gr 1 & 32 & 10 & 40.0 & + & 1.330 & 2.423 & True & 90.5 & 2.705 & True & 80.9 \\
\hline $\mathrm{Cr}$ & Gr 2 & Gr 1 & 30 & 11 & 39.0 & + & 0.511 & 2.423 & True & $<50$ & 2.708 & True & $<50$ \\
\hline Cs & Gr 2 & Gr 1 & 32 & 11 & 41.0 & + & 1.297 & 2.421 & True & 89.9 & 2.701 & True & 79.8 \\
\hline $\mathrm{Cu}$ & Gr 2 & Gr 1 & 27 & 11 & 36.0 & - & 0.180 & 2.434 & True & $<50$ & 2.720 & True & $<50$ \\
\hline $\mathrm{Ga}$ & Gr 2 & Gr 1 & 32 & 11 & 41.0 & + & 0.817 & 2.421 & True & 78.5 & 2.701 & True & 57.0 \\
\hline $\mathrm{Hf}$ & Gr 2 & Gr 1 & 32 & 11 & 41.0 & + & 1.305 & 2.421 & True & 90.0 & 2.701 & True & 80.1 \\
\hline $\mathrm{Nb}$ & Gr 2 & Gr 1 & 30 & 11 & 39.0 & + & 1.425 & 2.426 & True & 91.9 & 2.708 & True & 83.8 \\
\hline $\mathrm{Ni}$ & Gr 2 & Gr 1 & 27 & 9 & 34.0 & + & 0.583 & 2.441 & True & $<50$ & 2.728 & True & $<50$ \\
\hline $\mathrm{Pb}$ & Gr 2 & Gr 1 & 31 & 11 & 40.0 & + & 1.226 & 2.423 & True & 88.6 & 2.704 & True & 77.3 \\
\hline $\mathrm{Rb}$ & Gr 2 & Gr 1 & 32 & 11 & 41.0 & + & 0.735 & 2.421 & True & 75.2 & 2.701 & True & 50.5 \\
\hline $\mathrm{Sb}$ & Gr 2 & Gr 1 & 32 & 11 & 41.0 & + & 0.809 & 2.421 & True & 78.2 & 2.701 & True & 56.5 \\
\hline $\mathrm{Sc}$ & Gr 2 & Gr 1 & 32 & 11 & 41.0 & + & 1.282 & 2.421 & True & 89.7 & 2.701 & True & 79.3 \\
\hline
\end{tabular}


TABLE 8: Continued.

\begin{tabular}{|c|c|c|c|c|c|c|c|c|c|c|c|c|c|}
\hline Element & Group A & Group B & $n_{\mathrm{A}}$ & $n_{\mathrm{B}}$ & Df & Sign & $t_{-} \mathrm{calc}$ & $\begin{array}{c}t \_c r i t e r i a \\
\text { One- } \\
\text { sided }\end{array}$ & $\begin{array}{l}\mathrm{H}_{0} \\
\text { One- } \\
\text { sided }\end{array}$ & $\begin{array}{l}\text { CL_t } \\
\text { One- } \\
\text { sided }\end{array}$ & $\begin{array}{c}t \_c r i t e r i a \\
\text { Two- } \\
\text { sided } \\
\end{array}$ & $\begin{array}{l}\mathrm{H}_{0} \\
\text { Two- } \\
\text { sided }\end{array}$ & $\begin{array}{l}\text { CL_t } \\
\text { Two- } \\
\text { sided }\end{array}$ \\
\hline $\mathrm{Sr}$ & Gr 2 & Gr 1 & 32 & 10 & 40.0 & + & 1.528 & 2.423 & True & 93.3 & 2.705 & True & 86.6 \\
\hline $\mathrm{Ta}$ & Gr 2 & Gr 1 & 32 & 10 & 40.0 & + & 1.528 & 2.423 & True & 93.3 & 2.705 & True & 86.6 \\
\hline Th & Gr 2 & Gr 1 & 32 & 10 & 40.0 & + & 2.216 & 2.423 & True & 98.4 & 2.705 & True & 96.8 \\
\hline $\mathrm{Tl}$ & Gr 2 & Gr 1 & 32 & 11 & 41.0 & - & 0.509 & 2.421 & True & $<50$ & 2.701 & True & $<50$ \\
\hline $\mathrm{U}$ & Gr 2 & Gr 1 & 32 & 10 & 40.0 & + & 1.954 & 2.423 & True & 97.1 & 2.705 & True & 94.2 \\
\hline V & Gr 2 & Gr 1 & 32 & 11 & 41.0 & + & 0.533 & 2.421 & True & $<50$ & 2.701 & True & $<50$ \\
\hline $\mathrm{Y}$ & Gr 2 & Gr 1 & 31 & 10 & 39.0 & - & 0.018 & 2.426 & True & $<50$ & 2.708 & True & $<50$ \\
\hline $\begin{array}{l}\mathrm{Zr} \\
\text { (c) } \\
\text { Geochemical } \\
\text { ratios }^{\mathrm{a}}\end{array}$ & Gr 2 & Gr 1 & 32 & 11 & 41.0 & + & 0.478 & 2.421 & True & $<50$ & 2.701 & True & $<50$ \\
\hline LILE4_LREE3 & Gr 2 & Gr 1 & 32 & 11 & 41.0 & - & 0.787 & 2.421 & True & 77.4 & 2.701 & True & 54.8 \\
\hline LILE4_HFSE4 & Gr 2 & Gr 1 & 32 & 11 & 41.0 & + & 0.091 & 2.421 & True & $<50$ & 2.701 & True & $<50$ \\
\hline Nb_anomaly & Gr 2 & Gr 1 & 31 & 11 & 40.0 & + & 0.421 & 2.423 & True & $<50$ & 2.705 & True & $<50$ \\
\hline
\end{tabular}

${ }^{a}$ LILE4_LREE3 $=[(\mathrm{K}+\mathrm{Rb}+\mathrm{Ba}+\mathrm{Sr}) / 4] /[(\mathrm{La}+\mathrm{Ce}+\mathrm{Nd}) / 3] ;$ LILE4_HFSE4 $=[(\mathrm{K}+\mathrm{Rb}+\mathrm{Ba}+\mathrm{Sr}) / 4] /[(\mathrm{Ti}+\mathrm{P}+\mathrm{Nb}+\mathrm{Zr}) / 4] . \mathrm{Nb} \_$anomaly $=\{\mathrm{Nb} / \mathrm{Nb}\}_{\mathrm{pm}}$ $=\left[2 \times\left(\mathrm{Nb}_{\mathrm{sa}} / \mathrm{Nb}_{\mathrm{pm}}\right)\right] /\left[\left(\mathrm{Ba}_{\mathrm{sa}} / \mathrm{Ba}_{\mathrm{pm}}\right)+\left(\mathrm{La}_{\mathrm{sa}} / \mathrm{La}_{\mathrm{pm}}\right)\right]$; the subscript sa stands for the sample and pm for the primitive mantle; the superscript $*$ refers to the $\mathrm{Nb}$ concentration that would result from a smooth pattern for Ba to La on a primitive mantle-normalized multielement diagram [38].

\section{Acknowledgments}

This study was funded by PAICYT-UANL program (Project no. CT786-02). Thanks are due to P. Rodríguez-Saavedra, R. Soto-Villalobos, R. Sosa-Flores, and I. Muñoz-Muñoz for valuable assistance in the petrographic analysis, data management, and the editing of some figures. The author is also grateful to S. P. Verma for the revision of an earlier version of this paper. Finally, thanks are also due to the three anonymous reviewers. They, while highly appreciating this work, provided useful suggestions for improvement.

\section{References}

[1] H. R. Rollinson, Using of Geochemical Data: Evaluation, Presentation, Interpretation, Longman, Oxford, UK, 1993.

[2] M. G. Best, Igneous and Metamorphic Petrology, WileyBlackwell, London, UK, 2013.

[3] D. Perugini and G. Poli, "The mixing of magmas in plutonic and volcanic environments: analogies and differences," Lithos, vol. 153, pp. 261-277, 2012.

[4] J. K. Russell, "Magma mixing processes: insights and constraints from thermodynamic calculations," in Reviews in Mineralogy. Modern Methods of Igneous Petrology: Understanding Magmatic Processes, J. Nicholls and J. K. Russell, Eds., vol. 24, pp. 153-190, 1990.

[5] J. D. Winter, Principles of Igneous and Metamorphic Petrology, Prentice Hall, Upper Saddle River, NJ, USA, 2009.

[6] G. G. Kuşcu and P. A. Floyd, "Mineral compositional and textural evidence for magma mingling in the Saraykent volcanics," Lithos, vol. 56, no. 2-3, pp. 207-230, 2001.

[7] J. A. Cortés, J. L. Palma, and M. Wilson, "Deciphering magma mixing: the application of cluster analysis to the mineral chemistry of crystal populations," Journal of Volcanology and Geothermal Research, vol. 165, no. 3-4, pp. 163-188, 2007.
[8] E. Savazzi and R. A. Reyment, Aspects of Multivariate Statistical Analysis in Geology, Elsevier Science, New York, NY, USA, 1999.

[9] R. W. Le Maitre, "A new approach to the classification of igneous rocks using the basalt-andesite-dacite-rhyolite suite as an example," Contributions to Mineralogy and Petrology, vol. 56, no. 2, pp. 191-203, 1976.

[10] P. C. Ragland, J. F. Conley, W. C. Parker, and J. A. Van Orman, "Use of principal components analysis in petrology: an example from the Martinsville igneous complex, Virginia, U.S.A," Mineralogy and Petrology, vol. 60, no. 3-4, pp. 165-184, 1997.

[11] R. De Rosa, P. Donato, and G. Ventura, "Fractal analysis of mingled/mixed magmas: an example from the Upper Pollara eruption (Salina Island, southern TyrrhenianSea, Italy)," Lithos, vol. 65, no. 3-4, pp. 299-311, 2002.

[12] G. S. Wallace and G. W. Bergantz, "Constraints on mingling of crystal populations from off-center zoning profiles: a statistical approach," American Mineralogist, vol. 89, no. 1, pp. 64-73, 2004.

[13] K. S. Tefend, T. A. Vogel, T. P. Flood, and R. Ehrlich, "Identifying relationships among silicic magma batches by polytopic vector analysis: a study of the Topopah Spring and Pah Canyon ashflow sheets of the southwest Nevada volcanic field," Journal of Volcanology and Geothermal Research, vol. 167, no. 1-4, pp. 198211, 2007.

[14] S. P. Verma, I. S. Torres-Alvarado, and Z. T. Sotelo-Rodríguez, "SINCLAS: standard igneous norm and volcanic rock classification system," Computers and Geosciences, vol. 28, no. 5, pp. 711-715, 2002.

[15] S. P. Verma, I. S. Torres-Alvarado, and F. Velasco-Tapia, "A revised CIPW norm," Schweizerische Mineralogische und Petrographische Mitteilungen, vol. 83, no. 2, pp. 197-216, 2003.

[16] J. C. Bailey, "Geochemical criteria for a refined tectonic discrimination of orogenic andesites," Chemical Geology, vol. 32, no. 14, pp. 139-154, 1981. 
[17] M. P. Gorton and E. S. Shandl, "From continents to island arcs: a geochemical index of tectonic setting for arc-related and within-plate felsic to intermediate volcanic rocks," The Canadian Mineralogist, vol. 38, no. 5, pp. 1065-1073, 2000.

[18] J. A. Pearce, N. B. W. Harris, and A. G. Tindle, "Trace element discrimination diagrams for the tectonic interpretation of granitic rocks," Journal of Petrology, vol. 25, no. 4, pp. 956-983, 1984.

[19] J. Aitchinson, The Statistical Analysis of Compositional Data, Chapman and Hall, London, UK, 1986.

[20] S. Agrawal, "Discrimination between late-orogenic, postorogenic, and anorogenic granites by major element compositions," Journal of Geology, vol. 103, no. 5, pp. 529-537, 1995.

[21] S. P. Verma and S. K. Verma, "First fifteen probabilitybased multi-dimensional tectonic discrimination diagrams for intermediate magmas and their robustness against postemplacement compositional changes and petrogenetic processes," Turkish Journal of Earth Sciences, 2013.

[22] S. P. Verma, K. Pandarinath, S. K. Verma, and S. Agrawal, "Fifteen new discriminant-function-based multi-dimensional robust diagrams for acid rocks and their application to Precambrian rocks," Lithos, vol. 168-169, pp. 113-123, 2013.

[23] F. Velasco-Tapia, P. Rodríguez-Saavedra, A. Márquez et al., "Mineralogical and geochemical evidence of magma mingling/mixing in the Sierra de Las Cruces volcanic range, Mexican Volcanic Belt," Journal of Iberian Geology, vol. 39, pp. 147-166, 2013.

[24] A. García-Palomo, J. J. Zamorano, C. López-Miguel et al., "El arreglo morfoestructural de la Sierra de Las Cruces, México central," Revista Mexicana de Ciencias Geológicas, vol. 25, pp. 158-178, 2008.

[25] P. Rodríguez-Saavedra, Caracterización geoquímica de procesos magmaticos en la parte central del Cinturón Volcánico Mexicano: Sierra de Las Cruces [M.S. thesis], Universidad Autónoma de Nuevo León, Linares, Nuevo León, Mexico, 2007.

[26] M. L. Osete, V.-C. Ruiz-Martínez, C. Caballero, C. Galindo, J. Urrutia-Fucugauchi, and D. H. Tarling, "Southward migration of continental volcanic activity in the Sierra de Las Cruces, Mexico: palaeomagnetic and radiometric evidence," Tectonophysics, vol. 318, no. 1-4, pp. 201-215, 2000.

[27] F. Velasco-Tapia and S. P. Verma, "Estudios geológicos y geoquímicos en la Sierra de Chichinautzin, Cinturón Volcánico Mexicano," Revista Mexicana de Ciencias Geológicas, vol. 18, pp. 1-36, 2001.

[28] F. Velasco-Tapia and S. P. Verma, "First partial melting inversion model for a rift-related origin of the Sierra de Chichinautzin volcanic field, Central Mexican Volcanic Belt," International Geology Review, vol. 43, no. 9, pp. 788-817, 2001.

[29] F. Velasco-Tapia and S. P. Verma, "Magmatic processes at the volcanic front of Central Mexican Volcanic Belt: sierra de Chichinautzin Volcanic Field (Mexico)," Turkish Journal of Earth Sciences, vol. 22, pp. 32-60, 2013.

[30] S. P. Verma, "Absence of Cocos plate subduction-related mafic volcanism in southern Mexico: a unique case on Earth?" Geology, vol. 30, pp. 1095-1098, 2002.

[31] G. T. Nixon, "Petrology of the younger andesites and dacites of iztaccíhuatl volcano, Mexico: II. chemical stratigraphy, magma mixing, and the composition of basaltic magma influx," Journal of Petrology, vol. 29, no. 2, pp. 265-303, 1988.
[32] J. B. Witter, V. C. Kress, and C. G. Newhall, "Volcán Popocatépetl, Mexico. Petrology, magma mixing, and immediate sources of volatiles for the 1994-present eruption," Journal of Petrology, vol. 46, no. 11, pp. 2337-2366, 2005.

[33] H. Zou, Quantitative Geochemistry, Imperial College Press, London, UK, 2007.

[34] E. A. K. Middlemost, "Iron oxidation ratios, norms and the classification of volcanic rocks," Chemical Geology, vol. 77, no. 1, pp. 19-26, 1989.

[35] M. J. Le Bas, "Nephelinitic and basanitic rocks," Journal of Petrology, vol. 30, no. 5, pp. 1299-1312, 1989.

[36] M. J. Le Bas, R. W. Le Maitre, A. Streckeisen, and B. Zanettin, "A chemical classification of volcanic rocks based on the total alkali-silica diagram," Journal of Petrology, vol. 27, no. 3, pp. 745750, 1986.

[37] S. P. Verma, R. Cruz-Huicochea, and L. Díaz-González, "Univariate data analysis system: deciphering mean compositions of island and continental arc magmas, and influence of the underlying crust," International Geology Review, 2013.

[38] S. P. Verma, "Continental rift setting for the central part of the Mexican Volcanic Belt: a statistical approach," Open Geology Journal, vol. 3, pp. 8-29, 2009.

[39] S. P. Verma and S. Agrawal, "New tectonic discrimination diagrams for basic and ultrabasic volcanic rocks through logtransformed ratios of high field strength elements and implications for petrogenetic processes," Revista Mexicana de Ciencias Geologicas, vol. 28, no. 1, pp. 24-44, 2011.

[40] S. P. Verma, "Application of multi-dimensional discrimination diagrams and probability calculations to acid rocks from Portugal and Spain," Comunicações Geológicas, vol. 99, pp. 79-93, 2012.

[41] S. P. Verma and L. Díaz-González, "Application of the discordant outlier detection and separation system in the geosciences," International Geology Review, vol. 54, pp. 593-614, 2012.

[42] N. Bratchell, "Cluster analysis," Chemometrics and Intelligent Laboratory Systems, vol. 6, no. 2, pp. 105-125, 1989.

[43] J. H. Ward Jr., "Hierarchical grouping to optimize an objective function," Journal of the American Statistical Association, vol. 58, pp. 236-244, 1963.

[44] J. C. Davis, Statistics and Data Analysis, John Wiley \& Sons, New York, NY, USA, 1986.

[45] P. R. Bevington and D. K. Robinson, Data Reduction and Error Analysis for the Physical Sciences, McGraw-Hill, Boston, Mass, USA, 2003.

[46] D. H. Shurbet and S. E. Cebull, "Tectonic interpretation of the Trans-Mexicano Volcanic Belt,” Tectonophysics, vol. 101, no. 1-2, pp. 159-165, 1984.

[47] A. Márquez, R. Oyarzun, M. Doblas, and S. P. Verma, "Alkalic (ocean-island basalt type) and calc-alkalic volcanism in the Mexican volcanic belt: a case for plume-related magmatism and propagating rifting at an active margin?" Geology, vol. 27, no. 1, pp. 51-54, 1999.

[48] S. P. Verma, "Solely extension-related origin of the eastern to west-central Mexican Volcanic Belt (Mexico) from partial melting inversion model," Current Science, vol. 86, no. 5, pp. 713-719, 2004.

[49] H. C. Sheth, I. S. Torres-Alvarado, and S. P. Verma, "Beyond subduction and plumes: a unified tectonic-petrogenetic model for the Mexican volcanic belt," International Geology Review, vol. 42, no. 12, pp. 1116-1132, 2000. 
[50] L. Ferrari, "Slab detachment control on mafic volcanic pulse and mantle heterogeneity in central Mexico," Geology, vol. 32, no. 1, pp. 77-80, 2004.

[51] L. Ferrari, C. M. Petrone, and L. Francalanci, "Generation of oceanic-island basalt-type volcanism in the western TransMexican volcanic belt by slab rollback, asthenosphere infiltration, and variable flux melting," Geology, vol. 29, no. 6, pp. 507510, 2001.

[52] D. L. Blatter, G. Lang Farmer, and I. S. E. Carmichael, "A North-South transect across the central mexican volcanic belt at $\sim 100^{\circ} \mathrm{W}$ : spatial distribution, petrological, geochemical, and isotopic characteristics of quaternary volcanism," Journal of Petrology, vol. 48, no. 5, pp. 901-950, 2007.

[53] L. Mori, A. Gómez-Tuena, P. Schaaf, S. L. Goldstein, O. PérezArvizu, and G. Solís-Pichardo, "Lithospheric removal as a trigger for flood basalt magmatism in the Trans-Mexican Volcanic Belt," Journal of Petrology, vol. 50, no. 11, pp. 2157-2186, 2009.

[54] X. Pérez-Campos, Y. Kim, A. Husker et al., "Horizontal subduction and truncation of the Cocos Plate beneath central Mexico," Geophysical Research Letters, vol. 35, no. 18, Article ID L18303, 2008.

[55] J. R. Peláez Gaviria, C. A. Mortera Gutiérrez, W. L. Bandy, and F. Michaud, "Morphology and magnetic survey of the Rivera-Cocos plate boundary of Colima, Mexico," Geofísica Internacional, vol. 52, pp. 73-85, 2013.

[56] A. Husker and P. M. Davis, "Tomography and thermal state of the cocos plate subduction beneath mexico city," Journal of Geophysical Research B, vol. 114, no. 4, Article ID B04306, 2009.

[57] J. F. Pacheco and S. K. Singh, "Seismicity and state of stress in Guerrero segment of the Mexican subduction zone," Journal of Geophysical Research B, vol. 115, no. 1, Article ID B01303, 2010.

[58] Y. Tatsumi and S. Eggins, Subduction Zone Magmatism, John Wiley \& Sons, Ann Arbor, Mich, USA, 1995.

[59] J. Martinod, L. Husson, P. Roperch, B. Guillaume, and N. Espurt, "Horizontal subduction zones, convergence velocity and the building of the Andes," Earth and Planetary Science Letters, vol. 299, no. 3-4, pp. 299-309, 2010.

[60] P. J. Wallace and I. S. E. Carmichael, "Petrology of Volcán Tequila, Jalisco, Mexico: disequilibrium phenocryst assemblages and evolution of the subvolcanic magma system," Contributions to Mineralogy and Petrology, vol. 117, no. 4, pp. 345-361, 1994.

[61] H. M. Frey and R. A. Lange, "Phenocryst complexity in andesites and dacites from the Tequila volcanic field, Mexico: resolving the effects of degassing vs. magma mixing," Contributions to Mineralogy and Petrology, vol. 162, no. 2, pp. 415-445, 2011.

[62] S. E. Ownby, R. A. Lange, C. M. Hall, and H. Delgado-Granados, "Origin of andesite in the deep crust and eruption rates in the Tancítaro-Nueva Italia region of the Central Mexican Arc," Bulletin of the Geological Society of America, vol. 123, no. 1-2, pp. 274-294, 2011.

[63] P. Schaaf, J. Stimac, C. Siebe, and J. L. Macías, "Geochemical evidence for mantle origin and crustal processes in volcanic rocks from Popocatépetl and surrounding monogenetic volcanoes, central Mexico," Journal of Petrology, vol. 46, no. 6, pp. 1243-1282, 2005.

[64] G. Sosa-Ceballos, J. E. Gardner, C. Siebe, and J. L. Macías, "A caldera-forming eruption $\sim 14,10014 \mathrm{Cyr}$ BP at Popocatépetl volcano, México: insights from eruption dynamics and magma mixing," Journal of Volcanology and Geothermal Research, vol. 213-214, pp. 27-40, 2012.
[65] G. P. García-Tovar and R. G. Martínez-Serrano, "Geología y geoquímica de las lavas pleistocénicas del estratovolcán Talepón, Sierra Nevada, México," Revista Mexicana de Ciencias Geológicas, vol. 28, pp. 301-322, 2011.

[66] S. A. Nelson and I. S. E. Carmichael, "Pleistocene to recent alkalic volcanism in the region of Sanganguey volcano, Nayarit, Mexico," Contributions to Mineralogy and Petrology, vol. 85, no. 4, pp. 321-335, 1984.

[67] G. Carrasco-Núñez, M. McCurry, M. J. Branney, M. Norry, and C. Wilcox, "Complex magma mixing, mingling, and withdrawal associated with an intra-Plinian ignimbrite eruption at a large silicic caldera volcano: Los Humeros of central Mexico," Geological Society of America Bulletin, vol. 124, pp. 1793-1809, 2012.

[68] S. P. Verma, U. C. Arredondo-Parra, J. Andaverde, E. GómezArias, and F. J. Guerrero-Martínez, "Three-dimensional temperature field simulation of a cooling of a magma chamber, La Primavera caldera, Jalisco, Mexico," International Geology Review, vol. 54, no. 7, pp. 833-843, 2012.

[69] J. E. Fix, "The crust and the upper mantle of central Mexico," Geophysical Journal of the Royal Astronomical Society, vol. 43, pp. 453-499, 1975.

[70] J. O. Campos-Enríquez and O. Sánchez-Zamora, "Crustal structure across southern Mexico inferred from gravity data," Journal of South American Earth Sciences, vol. 13, no. 6, pp. 479-489, 2000.

[71] F. Ortega-Gutiérrez, M. Elías-Herrera, and M. G. DávalosElizondo, "On the nature and role of the lower crust in the volcanic front of the Trans-Mexican Volcanic Belt and its forearc region, southern and central Mexico," Revista Mexicana de Ciencias Geologicas, vol. 25, no. 2, pp. 346-364, 2008. 

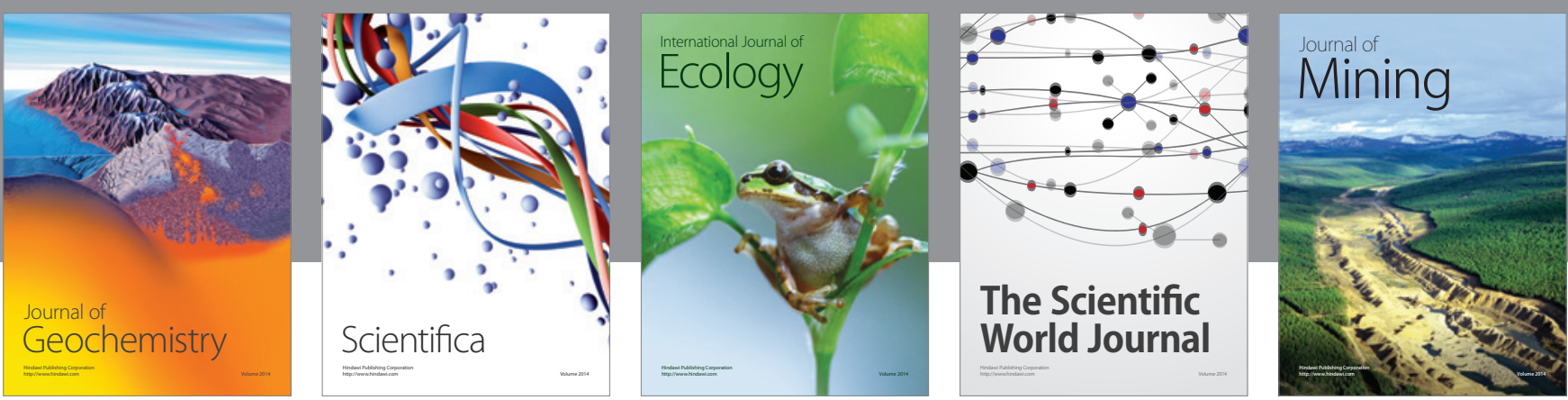

The Scientific World Journal
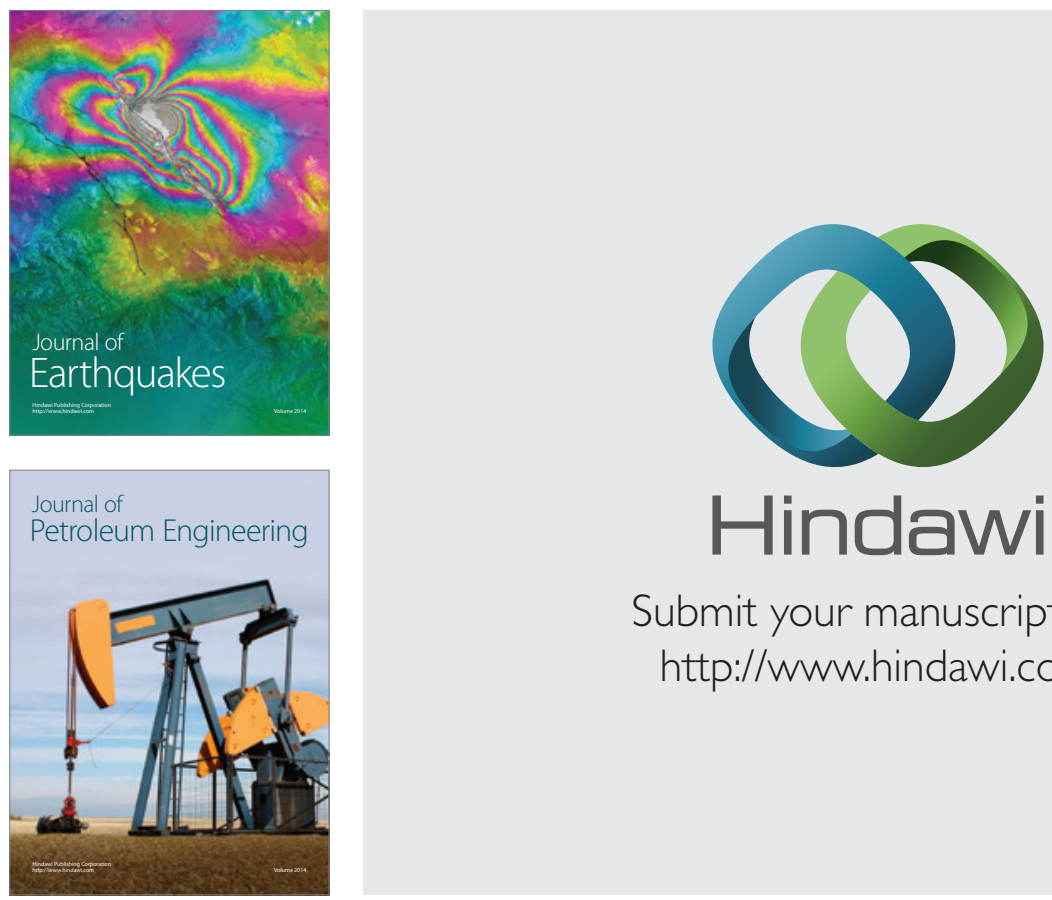

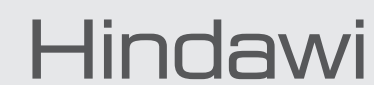

Submit your manuscripts at

http://www.hindawi.com
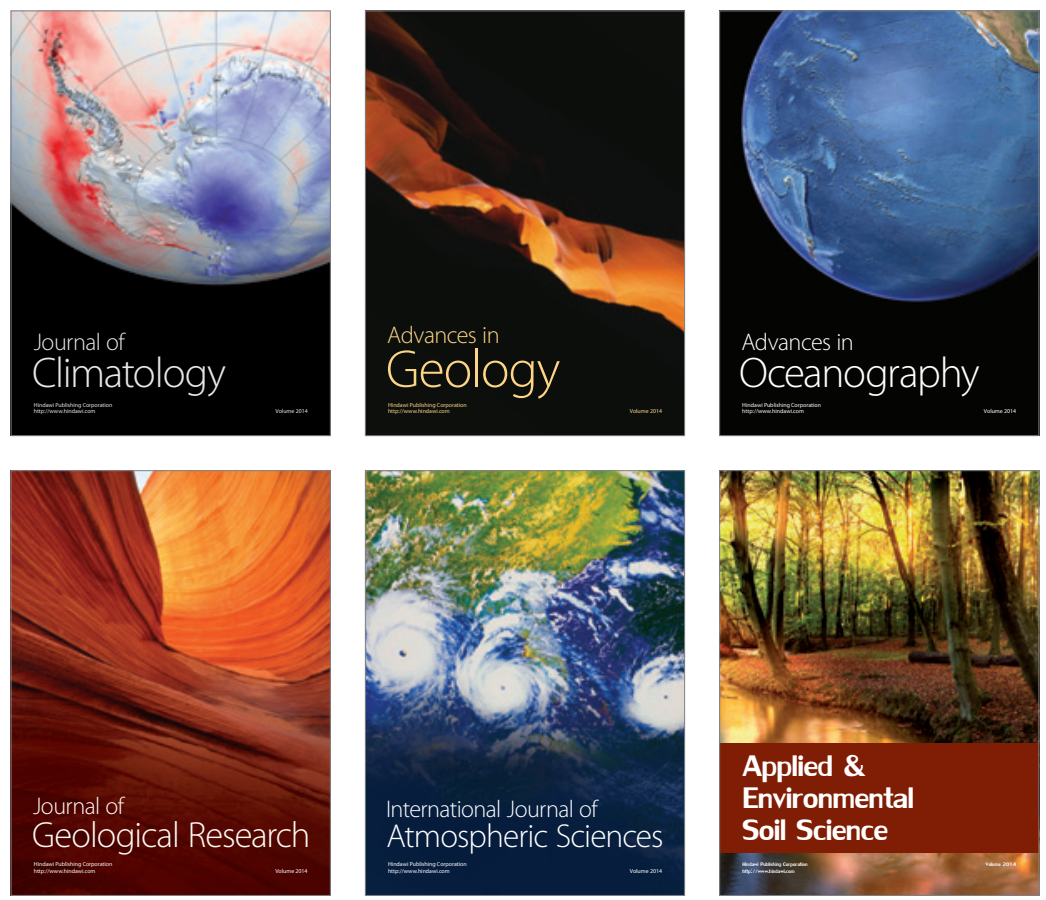
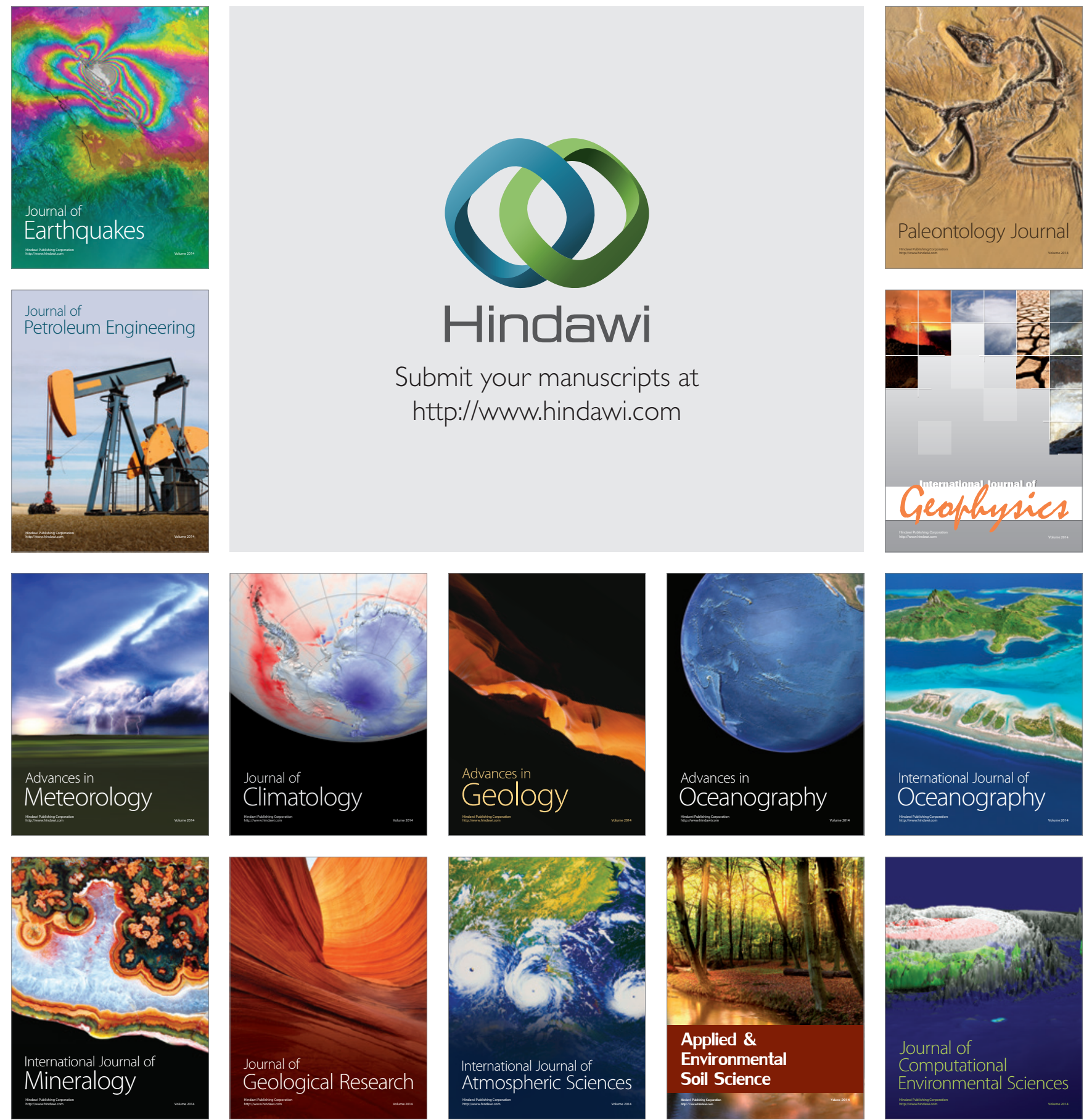